\title{
Marcos Borges Machado
}

Padrão autonômico cardiovascular e tratamento cirúrgico da obesidade: influência da gastroplastia com derivação gastrojejunal em Y de Roux

Tese apresentada à Faculdade de Medicina da Universidade de São Paulo para obtenção do título de Doutor em Ciências

Área da concentração: Emergências Clínicas Orientador: Prof. Dr. Augusto Scalabrini Neto 


\section{DEDICATÓRIA}

À minha esposa, Maria Emilia, que sempre me estimulou e ofereceu-me condições para dedicar-me ao estudo, muitas vezes confortando-me nos momentos difíceis. Um exemplo de capacidade de conciliação da competência profissional com a dedicação à família.

Aos meus filhos Letícia, Rafael e Pedro, que privei de momentos preciosos de convívio. Agora posso responder "sim" à pergunta que freqüentemente ouvi: "Papai, você vai terminar logo este trabalho?"

Aos meus pais, Marcelino e Valdete, meus exemplos de vida. 


\section{AGRADECIMENTO ESPECIAL}

Ao Prof. Dr. Augusto Scalabrini Neto, pela sua confiança e competência

demonstradas nestes anos de convívio. Ofereceu-me a segurança de professor e a compreensão de amigo. 


\section{AGRADECIMENTOS}

Ao Prof. Dr. Irineu Tadeu Velasco, professor titular da Disciplina de Emergências Clínicas da Faculdade de Medicina da Universidade de São Paulo, pela oportunidade concedida.

Ao Dr. Daoud Nasser, Dra. Adriana Sales Finizala e enfermeira Hélia Nasser, do Centro de Cirurgia da Obesidade Mórbida de Maringá, pela gentileza, presteza e paciência no encaminhamento dos pacientes para esta pesquisa.

Aos Drs. Sandro Scolari, Marino Mardegam e Gilberto Polo, pela colaboração no encaminhamento de pacientes para a pesquisa.

À psicóloga Adriana Cláudia Bavelloni, pela colaboração na avaliação de qualidade de vida dos pacientes.

Aos médicos e funcionários da Clínica Cardiolab, de Maringá, que sempre receberam os pacientes da pesquisa com gentileza e atenção e que me ofereceram importante apoio para a concretização deste estudo.

À Louize Figueira Marinho, pela sua dedicação e competência, auxiliandome no convite aos pacientes e no preparo e realização das avaliações. 
Às funcionárias do meu consultório, Lucilene e Luiza, pela ajuda e paciência.

Às funcionárias da Disciplina de Emergências Clínicas, Angélica, Rose e Lúcia, pela atenção, compreensão e auxílio durante todo o período da pósgraduação.

Ao Dr. Anis Rassi Junior e Dr. Jorge Akira Honda, pela gentileza da permissão para o uso de ilustrações de suas autorias neste trabalho.

À estatista Valéria Troncoso Baltar, pela análise estatística desta pesquisa, sempre muito atenciosa e competente.

À todos os pacientes participantes desta pesquisa, que gentilmente submeteram-se às avaliações com a intenção única de colaborar com o conhecimento científico. 


\section{NORMATIZAÇÃO ADOTADA}

Esta tese está de acordo com:

Referências: adaptado do International commmittee of Medical Journal Editors (Vancouver)

Universidade de São Paulo: Faculdade de Medicina. Serviço de Biblioteca e Documentação. Guia de apresentação de dissertações, teses e monografias. Elaborado por Anneliese Carneiro Cunha, Maria Julia de A. L. Freddi, Maria F. Crestana, Marinalva de Souza Aragão, Suely Campos Cardoso, Valéria Vilhena. São Paulo: Serviço de Biblioteca e Documentação; 2004.

Abreviaturas dos títulos dos periódicos de acordo com List of Journals Index Medicus. 


\section{SUMÁRIO}

Lista de símbolos

Lista de siglas

Lista de figuras

Lista de tabelas

Resumo

Summary

1 INTRODUÇÃO.

1.1 Análise da variabilidade da freqüência cardíaca.

1.2 Teste de inclinação ortostática.................................................... 09

1.3 Dosagem de noradrenalina.................................................... 13

1.4 Tratamento cirúrgico da obesidade........................................... 14

1.5 Padrão autonômico e tratamento cirúrgico da obesidade.................. 16

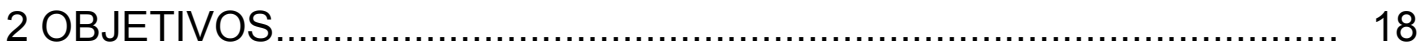

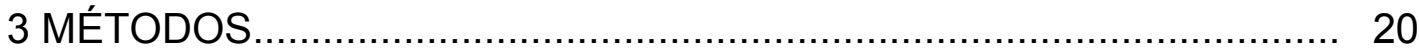

3.1 Desenho do estudo............................................................ 20

3.2 Casuística.............................................................................. 21

3.3 Avaliações realizadas................................................................ 25

3.3.1 Medidas antropométricas................................................. 25

3.3.2 Análise da variabilidade da freqüência cardíaca........................... 25

3.3.3 Teste de inclinação ortostática......................................... 28

3.3.4 Noradrenalina urinária......................................................... 30

3.3.5 Outros exames.................................................................. 31 
3.4 Análise estatística.............................................................. 32

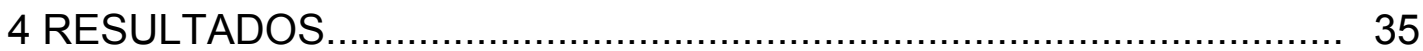

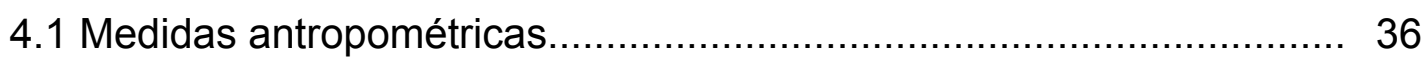

4.2 Variabilidade da freqüência cardíaca......................................... 38

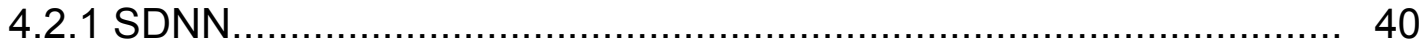

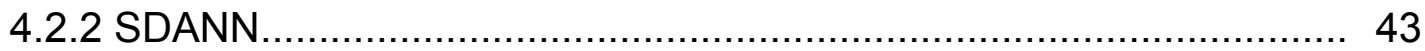

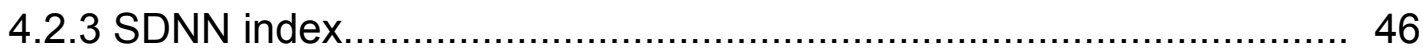

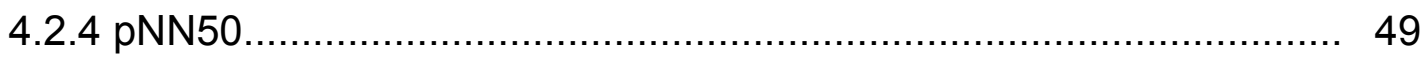

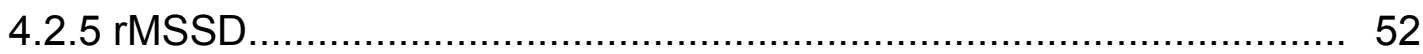

4.3 Teste de inclinação ortostática................................................. 55

4.4 Noradrenalina urinária............................................................ 59

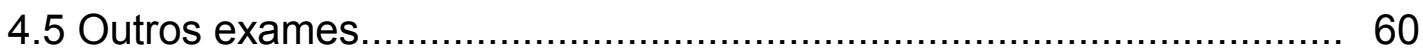

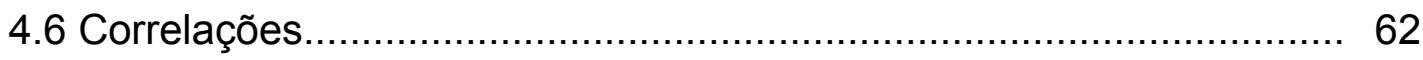

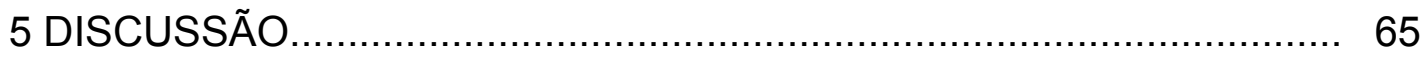

5.1 Caracterização da casuística................................................. 65

5.1.1 Variabilidade da freqüência cardíaca........................................ 66

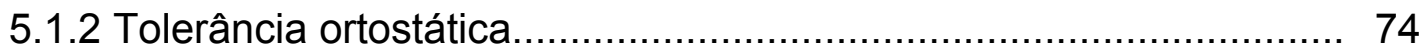

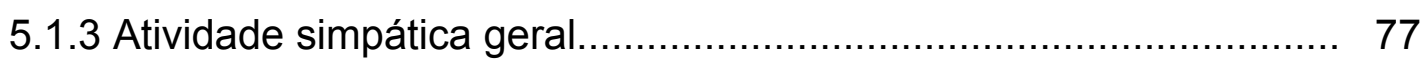

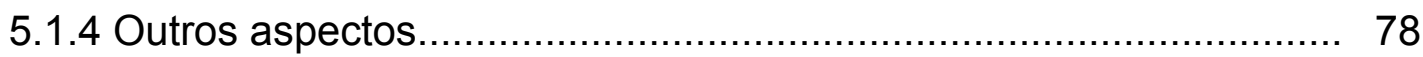

5.2 Considerações finais......................................................... 80

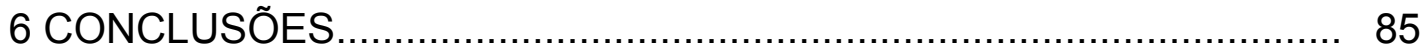

7 ANEXO

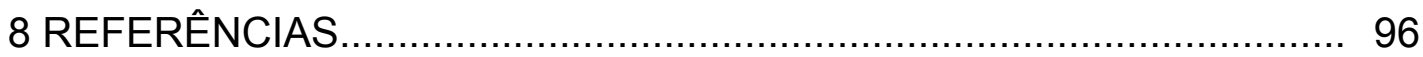

Apêndice 


\section{LISTA DE SÍMBOLOS}

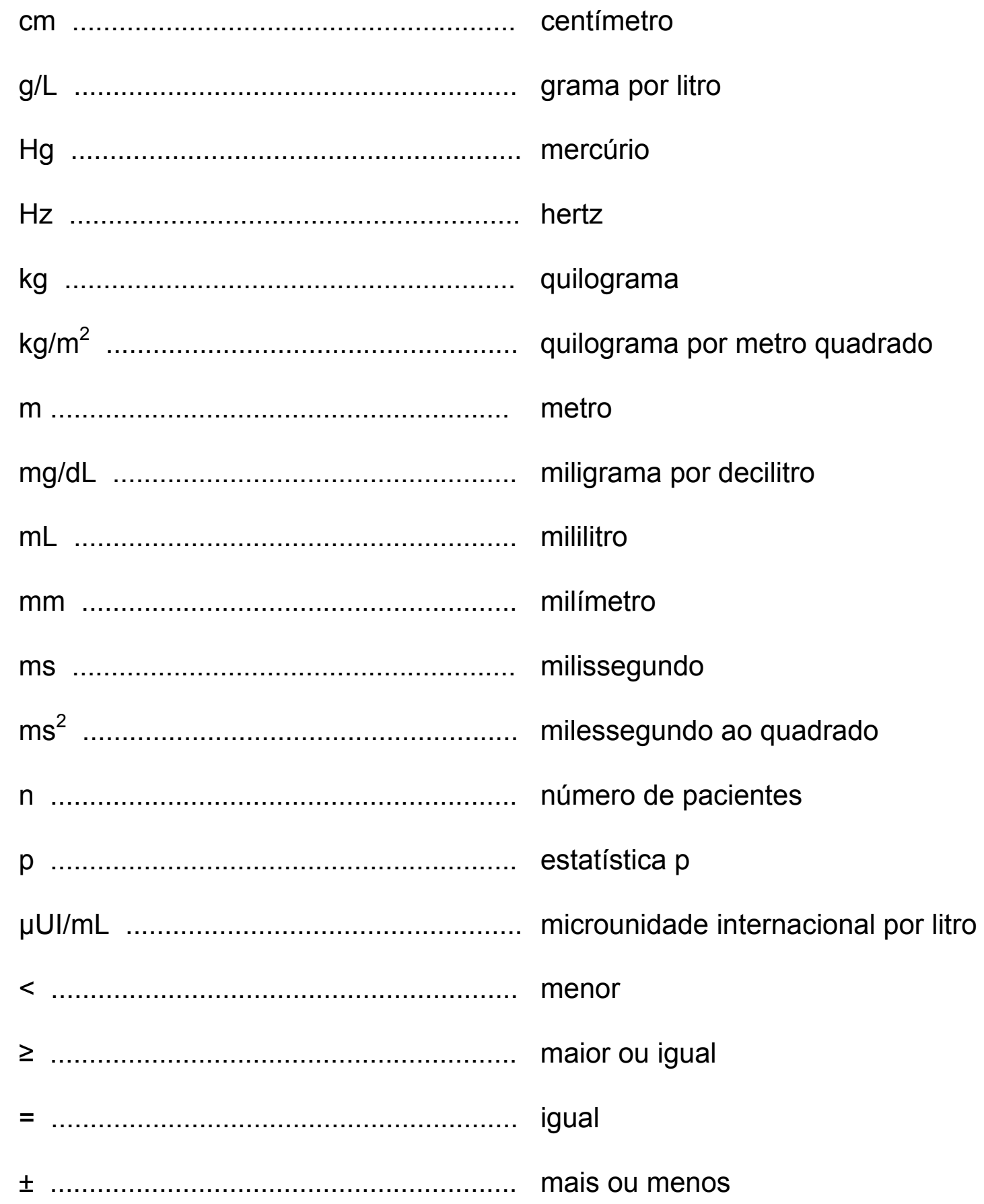




\section{LISTA DE SIGLAS}

AT1

ECA

EEG

HDL

HF

IC

IMC

LDL

LF

NN

PA

pNN50

QRS

$\mathrm{RR}$

rMSSD

SDANN

SDNN receptor tipo 1 da angiotensina II

enzima de conversão da angiotensina

equação de estimação generalizada

"high-density lipoprotein"

"high frequency"

intervalo de confiança

índice de massa corpórea

"low-density lipoprotein"

"low frequency"

período de tempo entre batimentos cardíacos normais

pressão arterial

porcentagem de intervalos entre batimentos cardíacos normais adjacentes com diferença de duração maior que 50 milissegundos

seqüência de ondas eletrocardiográficas relacionadas à despolarização ventricular

intervalo entre duas ondas $\mathrm{R}$ do eletrocardiograma

raiz quadrada da média do quadrado das diferenças entre batimentos cardíacos normais adjacentes

desvio-padrão das médias dos intervalos $R R$ normais (NN) obtidas a cada cinco minutos

desvio-padrão da média dos intervalos $\mathrm{RR}$ normais (NN) 
SDNN index

média dos desvios-padrão dos intervalos RR normais (NN) obtidos a cada cinco minutos

SF-36

"Medical Outcomes Study 36-Item ShortForm Health Survey"

TSH

hormônio estimulante da tireóide

ULF

"ultra low frequency"

VFC

variabilidade da freqüência cardíaca

VLF

"very low frequency" 


\section{LISTA DE FIGURAS}

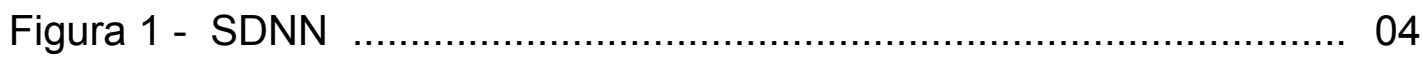

Figura 2 - SDANN e SDNN index …..................................................... 05

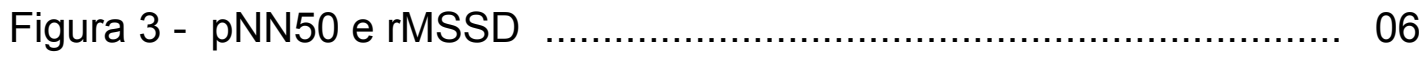

Figura 4 - Teste de inclinação ortostática ............................................ 09

Figura 5 - Resposta vasovagal ao teste de inclinação ortostática .......... 11

Figura 6 - Resposta disautonômica ao teste de inclinação ortostática ... 12

Figura 7 - Taquicardia postural ortostática ……….............................. 13

Figura 8 - Gastroplastia com derivação gastrojejunal em Y de Roux ..... 16

Figura 9 - Sistema de gravação do eletrocardiograma de 24 horas ....... 25

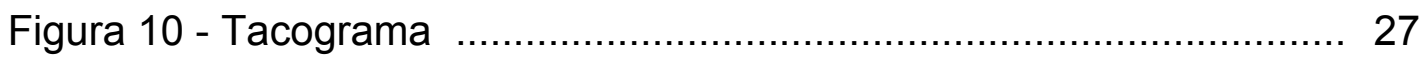

Figura 11 - Resultados da variabilidade da freqüência cardíaca ............. 28

Figura 12 - Metodologia do teste de inclinação ortostática ..................... 29

Figura 13 - Gráfico da evolução do índice SDNN conforme os sexos ..... 43

Figura 14 - Gráfico da evolução do índice SDANN conforme os sexos ... 46

Figura 15 - Gráfico da evolução do SDNN index conforme as faixas de idade

Figura 16 - Gráfico da evolução da variável pNN50 conforme as faixas etárias

Figura 17 - Gráfico de evolução do índice rMSSD conforme as faixas de idade 


\section{LISTA DE TABELAS}

Tabela 1 - Número mínimo de pacientes para os índices de variabilidade da freqüência cardíaca, considerando-se um nível de significância de $5 \%$ e poder estatístico de $80 \%$

Tabela 2 - Características da casuística

Tabela 3 - Número de pacientes conforme as categorias de pressão arterial e medicação anti-hipertensiva, nas fases pré e pósoperatória

Tabela 4 - Comparação do peso entre as fases pré e pós-operatória de forma geral e de acordo com os fatores sexo e idade

Tabela 5 - Comparação do índice de massa corpórea entre as fases pré e pós operatória de forma geral e de acordo com as faixas etárias

Tabela 6 - Comparação da circunferência abdominal entre as fases pré e pós-operatória de forma geral e de acordo com as faixas etárias

Tabela 7 - Estatísticas descritivas para o intervalo NN médio 40

Tabela 8 - Estatísticas descritivas para o índice SDNN 41

Tabela 9 - Comparação do SDNN entre as fases pré e pós-operatória de forma geral e de acordo com o fator sexo

Tabela 10 - Estatísticas descritivas para o índice SDANN

Tabela 11 - Comparação do SDANN entre o pré e o pós-operatório de forma geral e de acordo com o fator sexo

Tabela 12 - Estatísticas descritivas para o SDNN index

Tabela 13 - Comparação do SDNN index entre as fases pré e pósoperatória de forma geral e em relação ao fator idade

Tabela 14 - Estatísticas descritivas para o índice pNN50

Tabela 15 - Estatísticas descritivas para o índice rMSSD 
Tabela 16 - Comparação do índice rMSSD entre as fases pré e pósoperatória de forma geral e conforme o fator idade

Tabela 17 - Descrição dos resultados do teste de inclinação ortostática 56

Tabela 18 - Análise das respostas ao teste de inclinação ortostática após a cirurgia, em comparação com o pré-operatório

Tabela 19 - Características clínicas dos pacientes com hipotensão ortostática assintomática

Tabela 20 - Razão de chance de hipotensão ortostática após a cirurgia e influência dos fatores idade maior ou igual a 50 anos, uso de medicação anti-hipertensiva e sexo feminino

Tabela 21 - Estatísticas descritivas para a noradrenalina urinária

Tabela 22 - Comparação dos resultados das análises bioquímicas no sangue entre as fases pré e pós-operatória

Tabela 23 - "Raw Scale" dos oito domínios avaliados pelo questionário de qualidade de vida SF-36

Tabela 24 - Coeficientes de correlação de Pearson entre a variação das medidas de variabilidade da freqüência cardíaca e as variações de peso, circunferência abdominal e insulinemia de jejum 
Machado MB. Padrão autonômico cardiovascular e tratamento cirúrgico da obesidade: influência da gastroplastia com derivação gastrojejunal em Y de Roux [tese]. São Paulo: Faculdade de Medicina, Universidade de São Paulo; 2007. 113p.

INTRODUÇÃO: Informações da literatura associam a obesidade a maior atividade simpática. A gastroplastia com derivação gastrojejunal em $Y$ de Roux, que leva a redução rápida e intensa do peso, pode influenciar o padrão autonômico cardiovascular. O objetivo deste estudo é avaliar os efeitos dessa cirurgia sobre a modulação autonômica do coração, tolerância ortostática e excreção urinária de noradrenalina. METODOS: Trata-se de um estudo observacional longitudinal, realizado na cidade de Maringá - PR, com 71 pacientes, incluídos no período de julho de 2004 a dezembro de 2005, avaliados antes e seis meses após a cirurgia. Foram estudados 42 mulheres e 29 homens, com idade variando de 18 a 66 anos (mediana de 36 anos) e índice de massa corpórea (IMC) variando de 37,1 a $56,2 \mathrm{~kg} / \mathrm{m}^{2}$ (mediana de $41,9 \mathrm{~kg} / \mathrm{m}^{2}$ ). Do total, 28 eram hipertensos. Não foram incluídos pacientes com diagnóstico de diabetes melito. Análise da variabilidade da freqüência cardíaca no domínio do tempo através de gravações de Holter 24 horas, teste de inclinação ortostática e dosagem de noradrenalina em urina de 24 horas foram realizadas nas duas fases do estudo. Também foram avaliados glicemia e insulina de jejum, perfil lipídico, proteína C-reativa de alta sensibilidade, fibrinogênio e qualidade de vida através do questionário SF36. RESULTADOS: A redução média do peso, seis meses após a cirurgia, foi de $25,46 \%$ e da circunferência abdominal, de 20,4\%. A freqüência sinusal se reduziu significativamente, expressa pelo aumento do intervalo NN médio $(p<0,001)$. Os índices da variabilidade da freqüência cardíaca SDNN, SDANN, SDNN index, pNN50 e rMSSD apresentaram aumento significativo ( $p<0,001, p<0,001, p=0,002, p=0,001$ e $p=0,002$, respectivamente). Os homens apresentaram maior elevação do SDNN e SDANN do que as mulheres $(p=0,006$ e $p=0,007$, respectivamente). A idade foi fator significativo para a evolução do SDNN index $(p=0,015)$ e rMSSD $(p=0,002)$, reduzindo-se $o$ aumento com 0 avanço da idade. A redução da circunferência abdominal apresentou melhor correlação com o aumento da variabilidade da freqüência cardíaca que as reduções do peso e IMC. Nenhum paciente apresentou sintoma novo de intolerância ortostática após a cirurgia. A resposta vasovagal ao teste de inclinação não apresentou diferença significativa entre as duas fases do estudo. A resposta disautonômica foi encontrada em apenas dois casos, após a cirurgia, fato que não permitiu a avaliação deste tipo de resposta. Não houve nenhum caso de hipotensão ortostática sintomática. Houve redução do número de casos de hipotensão ortostática assintomática, com razão de chance para a ocorrência após a cirurgia, em relação ao pré-operatório, de 0,10 $(p=0,030)$. Não houve diferença nos níveis de noradrenalina urinária entre o pré e o pós-operatório. Houve redução da glicemia e insulina de jejum, melhora do perfil lipídico e redução da proteína C-reativa de alta sensibilidade, sem modificação do fibrinogênio. A qualidade de vida apresentou melhora. CONCLUSÃO: A gastroplastia com derivação gastrojejunal modificou o 
padrão autonômico, aumentando a ação parassimpática sobre o nó sinusal, evidenciada pelo aumento da variabilidade da freqüência cardíaca. A mudança ocorreu sem piora clínica da tolerância ortostática e sem aumento da suscetibilidade à síncope vasovagal.

Descritores: 1.Obesidade/cirurgia 2.Derivação gástrica 3.Perda de peso 4.Sistema nervoso autônomo 5.Freqüência cardíaca 6 .Hipotensão ortostática 7.Síncope vasovagal 8.Norepinefrina 
Machado MB. Autonomic cardiovascular activity and surgical treatment of obesity: effect of Roux-en-Y gastric bypass [thesis]. São Paulo: "Faculdade de Medicina, Universidade de São Paulo"; 2007. 113p.

INTRODUCTION: Findings from literature associate obesity with increased sympathetic activity. Roux-en-Y gastric bypass, which promotes large and rapid weigh loss, can influence the autonomic cardiovascular activity. The aim of the present study was to evaluate the influence of surgery on the heart autonomic modulation, orthostatic tolerance and 24-hour urinary norepinephrine. METHODS: The study was a longitudinal observation carried out in Maringá - PR, embracing 71 patients, recruited from July, 2004 to December, 2005, evaluated before surgery and six months post-operatively. Forty two (42) women and 29 men were investigated, with age varying from 18 to 66 years old (median $=36$ years old) and body mass index (BMI) varying from 37.1 to $56.2 \mathrm{~kg} / \mathrm{m}^{2}$ (median $=41.9 \mathrm{~kg} / \mathrm{m}^{2}$ ). Out of the total, 28 presented arterial hypertension. Patients diagnosed as diabetics were not included. The analysis of the time domain measures of heart rate variability, by using 24-hour Holter recordings, head-up tilt testing (HUT) and urinary 24hour norepinephrine assay was performed during both phases of the study. Fasting plasma glucose and insulin, lipid profile, high sensitivity C-reactive protein, fibrinogen and quality of life were also evaluated by applying the SF36 questionnaire, all before surgery and post-operatively. RESULTS: Six months after surgery, the average of weight loss was $25.46 \%$ and the waist circumference reduction was $20.4 \%$. The mean of NN interval showed a significant increase $(p<0,001)$, thus denoting a significant reduction of sinusal rate. The measures of heart rate variability, that is, SDNN, SDANN, SDNN index, pNN50 and rMSSD, showed significant increase $(p<0.001, p<0.001$, $p=0.002$ and $p=0.002$, respectively). Men presented greater increase of SDNN and SDANN than women ( $p=0,006$ and $p=0,007$, respectively). Age was a significant factor for the evolution of SDNN index $(p=0.015)$ and rMSSD $(p=0.002)$ with a lower increase according to the aging process. The waist circumference reduction presented better correlation with heart rate variability increase than weight loss and BMI reduction. After surgery, no patient showed new symptom of orthostatic intolerance. The vasovagal response to HUT did not present a significant difference between both phases of the study. Dysautonomic response occurred just in two cases, after surgery, not allowing the evaluation of that kind of response. There was no case of symptomatic orthostatic hypotension. There was a significant reduction of asymptomatic orthostatic hypotension cases, with odds ratio of $0.10(p=0.030)$ after surgery, in relation to the pre-operative phase. There was not a difference of urinary 24-hour norepinephrine in the period investigated. Fasting plasma glucose and insulin reduced while lipid profile improved and high sensitivity C-reactive protein reduced, without changing the fibrinogen. Quality of life improved. CONCLUSION: Gastric bypass changed the autonomic modulation, increasing the parasympathetic activity on sinus node, which was denoted by an increase in the heart rate variability. The change occurred without clinical worse in orthostatic tolerance and without increase in the susceptibility to vasovagal syncope. 
Keywords: 1 .Obesity/surgery 2.Gastric bypass 3.Weight loss 4.Autonomic nervous system 5.Heart rate 6.Hypotension, orthostatic 7.Syncope, vasovagal 8.Norepinephrine 


\section{INTRODUÇÃO}

A obesidade leva a aumento do risco de morte por todas as causas, principalmente por doenças cardiovasculares ${ }^{1}$. $O$ aumento da sua prevalência nos países desenvolvidos e em desenvolvimento tem representado um problema importante de saúde pública, com elevados custos relacionados a doenças associadas ${ }^{1-7}$. Esta situação tem motivado estudos voltados para um melhor entendimento de suas causas e conseqüências, bem como ao desenvolvimento e avaliação dos resultados de novos tratamentos.

A Organização Mundial de Saúde utiliza o índice de massa corpórea (IMC), que é calculado dividindo-se o peso, em quilogramas, pelo quadrado da altura em metros, para definir obesidade ${ }^{8}$. Para a população adulta, caracterizam obesidade índices superiores ou iguais a 30 quilogramas por metro quadrado $\left(\mathrm{kg} / \mathrm{m}^{2}\right)^{8}$. Apesar de apresentar limitações, não considerando questões relacionadas à idade e variações raciais ${ }^{3,9}$, este índice é referência para muitos estudos epidemiológicos e orientações sobre avaliação e tratamento da obesidade $e^{6,7,10}$.

Estratégias para estimar a gordura visceral, que é um fator independente de risco cardiovascular e morte ${ }^{3}$, também são empregadas. Entre elas, a medida da circunferência abdominal, pela sua simplicidade, é mais utilizada na prática clínica ${ }^{3,6,7,11 .}$ 
O papel do sistema nervoso autônomo na obesidade tem sido tema de publicações nos últimos anos, abordando questões etiológicas e terapêuticas. Apesar de não haver um entendimento claro, muitos trabalhos mostram que o excesso de peso está associado a um desequilíbrio autonômico, resultando em uma maior atividade simpática ${ }^{12-15}$. Esta relação poderia contribuir para o desenvolvimento de doenças cardiovasculares ${ }^{16,17}$.

Vários métodos podem ser usados para a avaliação do sistema nervoso autônomo na obesidade ${ }^{18,19}$, dentre os quais a análise da variabilidade da freqüência cardíaca, o teste de inclinação ortostática e a dosagem direta de noradrenalina são recursos mais acessíveis. Outros métodos, como a estimativa da liberação de noradrenalina pelo método de diluição da noradrenalina marcada com um isótopo radioativo, a avaliação da atividade nervosa simpática periférica por microneurografia e a análise da sensibilidade barorreflexa, apesar de relevantes, são mais complexos e exigem maior estrutura laboratorial ${ }^{13,15,20-28}$.

\subsection{Análise da variabilidade da freqüência cardíaca}

A análise da variabilidade da freqüência cardíaca (VFC) é um instrumento não invasivo de avaliação da modulação autonômica cardíaca. Tem como base a observação de que as variações do ritmo sinusal são influenciadas pela interação entre o sistema nervoso simpático e o parassimpático ${ }^{29,30}$.

A ação parassimpática é mediada pela acetilcolina, através do nervo vago, e leva a aumento da variabilidade da freqüência cardíaca, enquanto a 
atividade simpática, mediada pela adrenalina e noradrenalina, aumenta a freqüência cardíaca e reduz sua variabilidade ${ }^{25,} \quad 29, \quad 30$. A atividade parassimpática sobre o nó sinusal é a mais claramente reconhecida, produzindo efeito rápido e curto sobre a freqüência cardíaca. As flutuações da freqüência relacionadas ao ciclo respiratório refletem esta ação ${ }^{25,30}$. Já o efeito da atividade simpática leva a flutuações mais lentas da freqüência cardíaca, não bem reconhecidas ${ }^{25,30}$.

Existem diversos métodos descritos para a análise da variabilidade da freqüência cardíaca. O método de análise no domínio do tempo e a análise espectral (domínio da freqüência) são os mais conhecidos. Utilizam períodos contínuos de eletrocardiograma para o estudo da variabilidade, em que cada complexo QRS decorrente da despolarização ventricular de origem sinusal é detectado, sendo o intervalo entre eles reconhecido como intervalo RR ou intervalo NN. Daí a razão de a variabilidade da freqüência cardíaca também ser conhecida como variabilidade de $R R^{30}$

A análise no domínio do tempo pode ser realizada por meio de índices estatísticos, calculados por fórmulas matemáticas baseadas na medida direta dos intervalos RR ou na diferença entre os intervalos adjacentes ${ }^{30}$.

Os índices baseados apenas na medida direta dos intervalos RR refletem a interação entre as ações simpática e parassimpática. Nesta categoria estão incluídos três índices, conhecidos pelas siglas: SDNN, SDANN e SDNN index. O primeiro, SDNN, é o desvio-padrão da média de todos os intervalos RR normais, expresso em milissegundos (ms) (Figura 1). Indica a variabilidade ocorrida durante todo o período analisado. O segundo 
índice, SDANN, é o desvio-padrão das médias dos intervalos RR normais obtidas a cada cinco minutos, expresso também em milissegundos (Figura 2-A). Indica as alterações da freqüência cardíaca que ocorrem em ciclos maiores que cinco minutos. O terceiro índice, SDNN index, é a média dos desvios-padrão dos intervalos RR normais obtidos a cada cinco minutos, expresso também em milissegundos (Figura 2-B). Indica as alterações da freqüência cardíaca que ocorrem em ciclos menores que 5 minutos. ${ }^{30,31}$

Figura 1 - SDNN

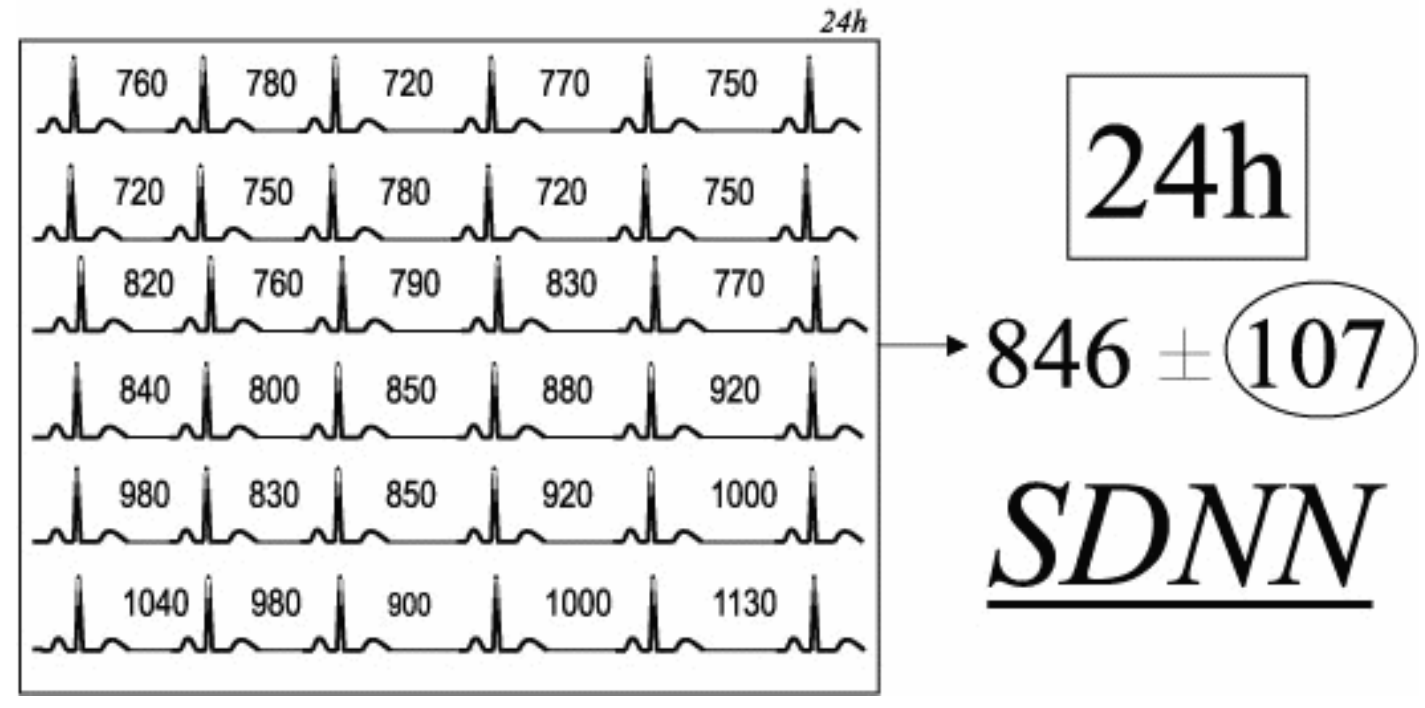

FONTE: Rassi Junior A. Compeendendo melhor as medidas de análise da variabilidade da freqüência cardíaca. Diagnósticos em cardiologia [periódico online]. 2003;20: [26 telas]. Disponível em:

http://www.cardios.com.br/Jornais/jornal-20/metodos\%20diagnosticos.htm llustração reproduzida com permissão do autor.

Exemplo onde a média dos intervalos RR normais foi $846 \mathrm{~ms}$ e o desviopadrão, que corresponde ao SDNN, foi $107 \mathrm{~ms}$. 
Figura 2 - SDANN e SDNN index

A

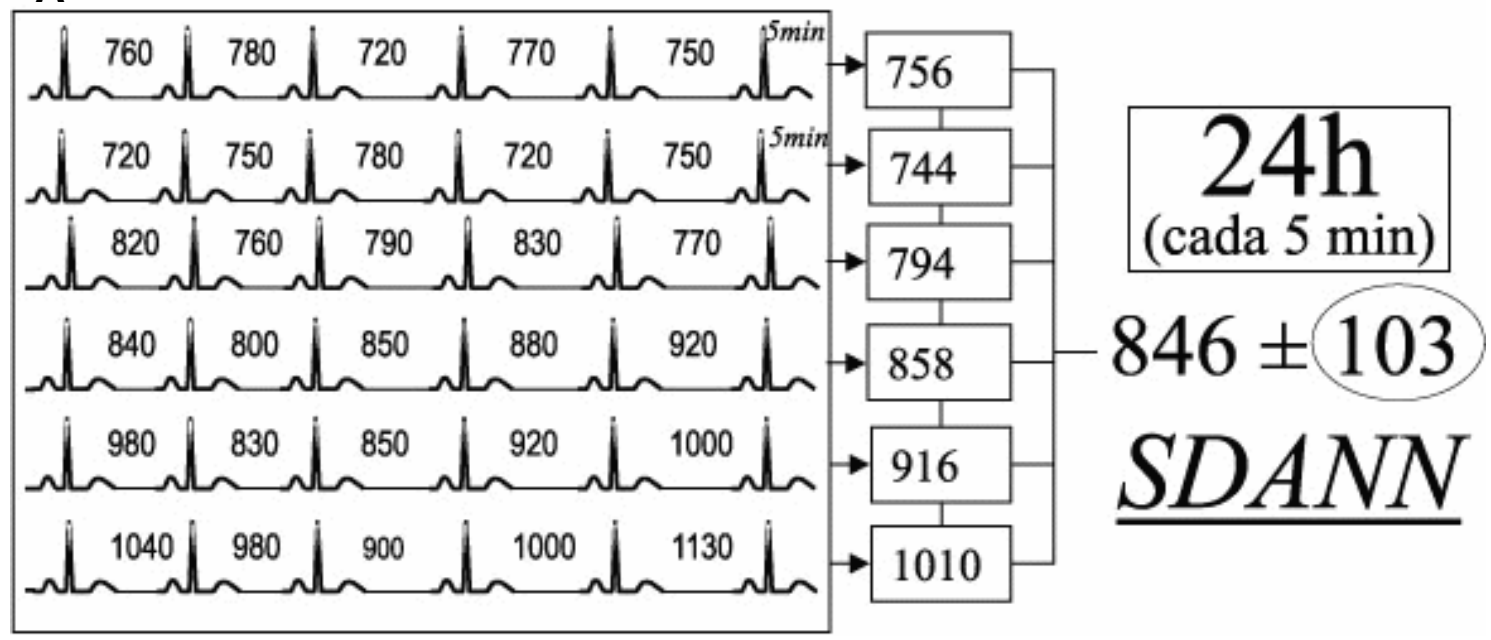

B

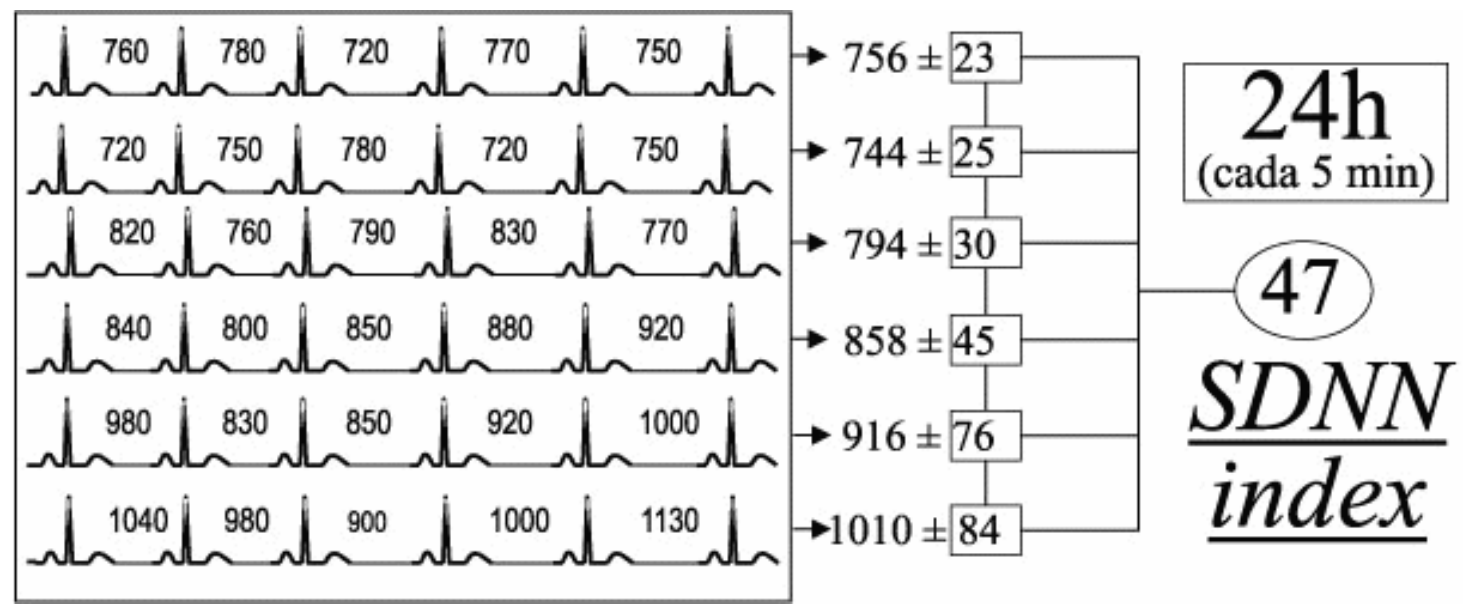

FONTE: Rassi Junior A. Compeendendo melhor as medidas de análise da variabilidade da freqüência cardíaca. Diagnósticos em cardiologia [periódico online]. 2003;20: [26 telas]. Disponível em:

http://www.cardios.com.br/Jornais/jornal-20/metodos\%20diagnosticos.htm llustração reproduzida com permissão do autor.

A: Exemplo onde estão colocadas as médias dos intervalos $R R$ de seis segmentos de cinco minutos; a média destes valores foi de $846 \mathrm{~ms}$ e o desvio-padrão, correspondendo ao SDANN, foi 103 ms.

B: Exemplo onde estão colocados os desvios-padrão das médias dos intervalos RR de seis segmentos de cinco minutos; a média dos desviospadrão, que corresponde ao SDNN index, foi $47 \mathrm{~ms}$.

Os índices do domínio do tempo baseados nas diferenças entre intervalos $\mathrm{RR}$ adjacentes refletem as alterações curtas e rápidas do ciclo 
cardíaco, que são produzidas pela ação parassimpática. Um dos índices desta categoria é a porcentagem de intervalos RR adjacentes com diferença de duração maior que 50 milissegundos, conhecido pela sigla pNN50 (Figura 3-A). O outro é a raiz quadrada da média do quadrado das diferenças entre os intervalos RR normais adjacentes, conhecido pela sigla rMSSD, expressa em milissegundos (Figura 3-B). ${ }^{30,31}$

Figura 3 - pNN50 e rMSSD

\section{$A-p N N 50$}

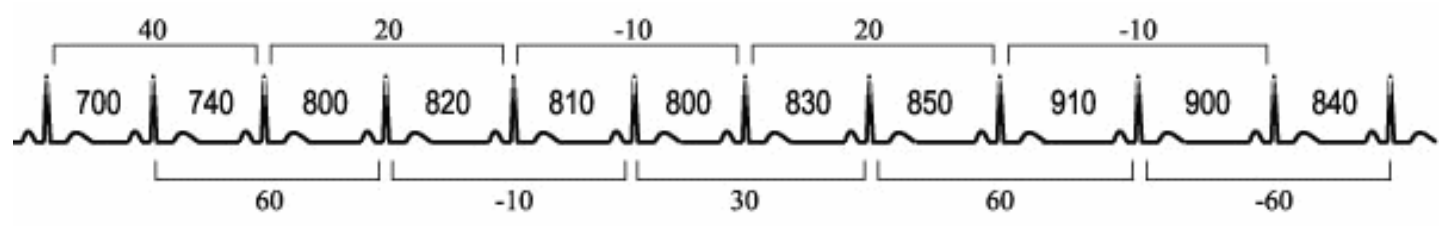

B - rMSSD

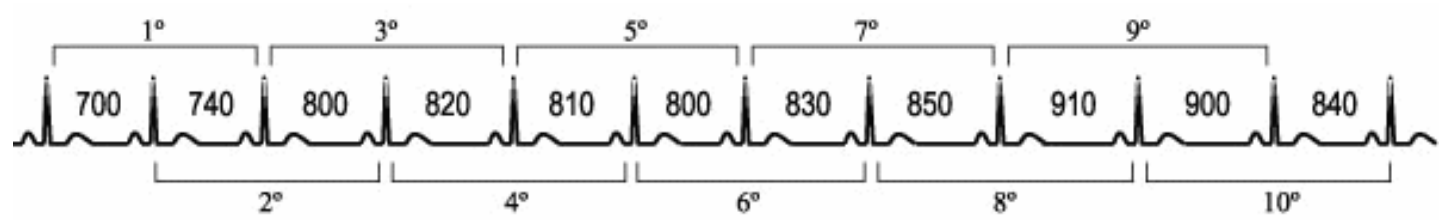

$$
\frac{\left(40^{2}\right)+\left(60^{2}\right)+\left(20^{2}\right)+\left(-10^{2}\right)+\left(-10^{2}\right)+\left(30^{2}\right)+\left(20^{2}\right)+\left(60^{2}\right)+\left(-10^{2}\right)+\left(-60^{2}\right)}{10}=\sqrt{1440}=37,94
$$

FONTE: Rassi Junior A. Compeendendo melhor as medidas de análise da variabilidade da freqüência cardíaca. Diagnósticos em cardiologia [periódico online]. 2003;20: [26 telas]. Disponível em:

http://www.cardios.com.br/Jornais/jornal-20/metodos\%20diagnosticos.htm llustração reproduzida com permissão do autor.

A: Exemplo onde, dos 10 intervalos RR adjacentes, apenas três (o segundo, o oitavo e o décimo) apresentaram diferença de duração superior a $50 \mathrm{~ms}$; 0 pNN50, portanto, foi $30 \%$.

B: Exemplo com os intervalos RR de um trecho de eletrocardiograma e o cálculo da rMSSD, cujo resultado foi 37,94 ms. 
A variabilidade da freqüência cardíaca no domínio do tempo é mais freqüentemente calculada em registros eletrocardiográficos longos, com até 24 horas de duração, obtidos a partir de gravadores de eletrocardiografia ambulatorial (sistema Holter) ${ }^{30}$. Embora também possa ser calculada em registros de curta duração, a comparação entre resultados somente pode ser realizada quando obtidos de eletrocardiogramas com a mesma duração ${ }^{30}$.

A análise espectral (domínio da frequência) baseia-se na identificação, através de métodos matemáticos (transformação rápida de Fourier ou modelo auto-regressivo), de diferentes faixas de freqüências de oscilação dos ciclos $\operatorname{cardíacos}^{30}$. As mais estudadas são a de freqüência alta, conhecida pela sigla HF ("high frequency"), e a de freqüência baixa, conhecida pela sigla LF ("low frequency"). A faixa HF está entre 0,15 e 0,40 $\mathrm{Hz}$ e reflete as variações da freqüência cardíaca relacionadas ao ciclo respiratório, influenciadas pela atividade parassimpática. A faixa $L F$, entre 0,04 e $0,15 \mathrm{~Hz}$, é reconhecida como modulada pelo simpático e parassimpático e, em algumas situações, tem sido associada ao sistema barorreceptor. Outras faixas com freqüências mais baixas também podem ser identificadas, porém suas correlações fisiológicas são menos conhecidas $^{25,30}$. Este método é melhor explorado em eletrocardiogramas de curta duração, com controle da freqüência respiratória ${ }^{29,30}$.

Os índices do domínio do tempo e da análise espectral se correlacionam ${ }^{30}$. Apesar de fornecerem informações sobre a modulação do sistema nervoso autônomo sobre o nó sinusal, exploram melhor a atividade 
parassimpática. Não conseguem exprimir de modo mais específico a atividade simpática ${ }^{25,30}$.

O estudo da variabilidade da freqüência cardíaca é um método muito útil em pesquisa, porém com aplicabilidade clínica limitada. Apesar da falta de uma melhor compreensão do significado fisiológico de alguns índices, muitos estudos mostram que a redução da variabilidade da freqüência cardíaca é fator de risco de morte por causa cardíaca em pacientes que sofreram infarto do miocárdio, com insuficiência cardíaca, e em idosos ${ }^{29,32-}$ 34.

O controle autonômico cardíaco parece ser um fator importante na fisiopatologia de arritmias malignas e morte súbita. A obesidade representa um fator de risco para morte súbita ${ }^{35-38}$, embora a participação do sistema nervoso autônomo não esteja clara. Neste contexto, o estudo da relação entre obesidade e o controle autonômico cardíaco, através da variabilidade da freqüência cardíaca, merece destaque.

Alguns estudos avaliaram o efeito da redução do peso sobre a variabilidade da freqüência cardíaca, por meio de dietas hipocalóricas, como estratégia isolada ou associada a atividades físicas ou ao uso da medicação orlistat, que é um inibidor de lipases no trato gastrointestinal. Foram avaliadas reduções médias de peso de $4,5 \%$ a $14,4 \%$, após períodos de acompanhamento que variaram de 3 semanas a um ano. De maneira geral, demonstraram aumento da variabilidade após a perda de peso, sugerindo mudança da modulação autonômica, no sentido de maior atividade parassimpática ${ }^{27,39-45}$. Foi levantada a possibilidade de os níveis séricos de 
insulina elevados, nos obesos, estarem relacionados à redução da atividade parassimpática ${ }^{41}$.

As estratégias para o tratamento da obesidade empregadas nestes estudos não permitiram a avaliação de perdas mais intensas de peso.

\subsection{Teste de inclinação ortostática}

O teste de inclinação ortostática, mais conhecido pelo termo em inglês "tilt test", é baseado na avaliação do comportamento da freqüência cardíaca e da pressão arterial frente ao estresse ortostático imposto pela inclinação passiva $^{46}$. A partir do decúbito horizontal, o paciente é inclinado para a frente até atingir um ângulo que, na maior parte dos estudos, varia de 60 a 70 graus, através de mesa apropriada para o exame, com apoio para os pés $^{31}$ (Figura 4). Permanece nesta posição por 30 a 45 minutos. Caso ocorra alteração hemodinâmica acompanhada de síncope ou pré-síncope, a mesa é reposicionada na posição horizontal antes de completar o tempo total programado para a inclinação. ${ }^{18-20,46}$.

Figura 4 - Teste de inclinação ortostática

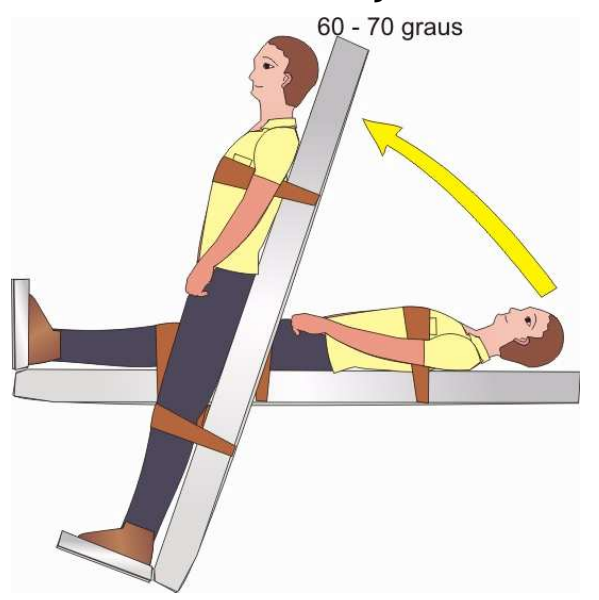

Desenho esquemático da inclinação da mesa de exame. 
As repostas do sistema nervoso autônomo, a partir da ativação de barorreceptores, são os principais fatores responsáveis pela manutenção de um padrão circulatório adequando na posição ortostática ${ }^{47}$. O efeito da gravidade aumenta o volume sangüíneo nos membros inferiores e no abdome, levando à redução do enchimento cardíaco e queda da pressão arterial, o que estimula barorreceptores arteriais e cardiopulmonares, desencadeando mecanismos reguladores mediados pelo sistema nervoso simpático $^{47,48}$.

Ao contrário da situação em que o paciente adota ativamente a posição em pé, na qual a contração muscular esquelética ajuda o retorno venoso, no teste de inclinação ortostática este fator é inibido, levando a um maior estímulo do sistema nervoso autônomo ${ }^{47}$.

O teste é indicado para o estudo dos mecanismos fisiológicos envolvidos na regulação da pressão arterial e freqüência cardíaca ante a mudança postural $^{49}$ e na pesquisa de alterações autonômicas associadas à intolerância ortostática ${ }^{46-48,50}$.

As respostas anormais ao exame podem ser classificadas basicamente em três tipos: resposta vasovagal, resposta disautonômica e taquicardia postural ortostática ${ }^{46-48,50}$.

$\mathrm{Na}$ resposta vasovagal, o período inicial da inclinação mostra um padrão hemodinâmico normal. Após alguns minutos ocorre abrupta e acentuada redução da pressão arterial, associada ou não a bradicardia, levando à perda de consciência, rapidamente revertida com o retorno da mesa à posição horizontal (Figura 5). A redução do retorno venoso durante a 
inclinação precipita aumento significativo do inotropismo ventricular, ativando mecanorreceptores cujo efeito final é uma rápida redução do tônus simpático, produzindo hipotensão, com ou sem bradicardia, e levando à perda da consciência. Este comportamento é interpretado como uma hipersensibilidade do sistema autonômico ao estresse ortostático $46,47,50$.

Figura 5 - Resposta vasovagal ao teste de inclinação ortostática

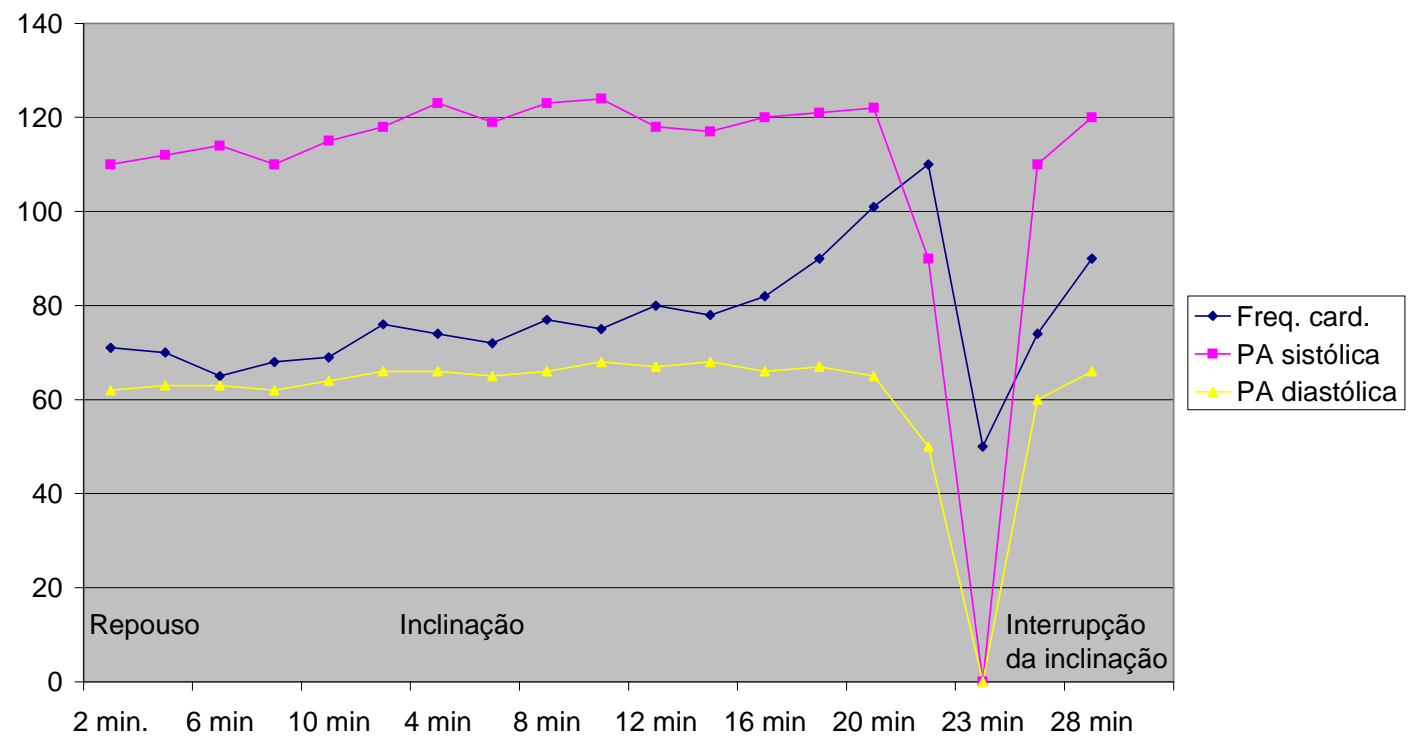

Exemplo de resposta vasovagal desencadeada após 22 minutos de inclinação. Na legenda, Freq. card. indica freqüência cardíaca e PA indica pressão arterial.

Na resposta disautonômica o paciente apresenta queda progressiva da pressão arterial, iniciada desde o princípio da inclinação, habitualmente sem alteração significativa da freqüência cardíaca (Figura 6). Tal resposta reflete incapacidade do sistema nervoso autônomo para promover a adaptação hemodinâmica à mudança postural. Quando esta disfunção torna-se intensa, 
os pacientes podem apresentar franca hipotensão, sintomática, imediatamente à inclinação ou à adoção ativa da posição em pé ${ }^{46,47,50}$.

Figura 6 - Resposta disautonômica ao teste de inclinação ortostática

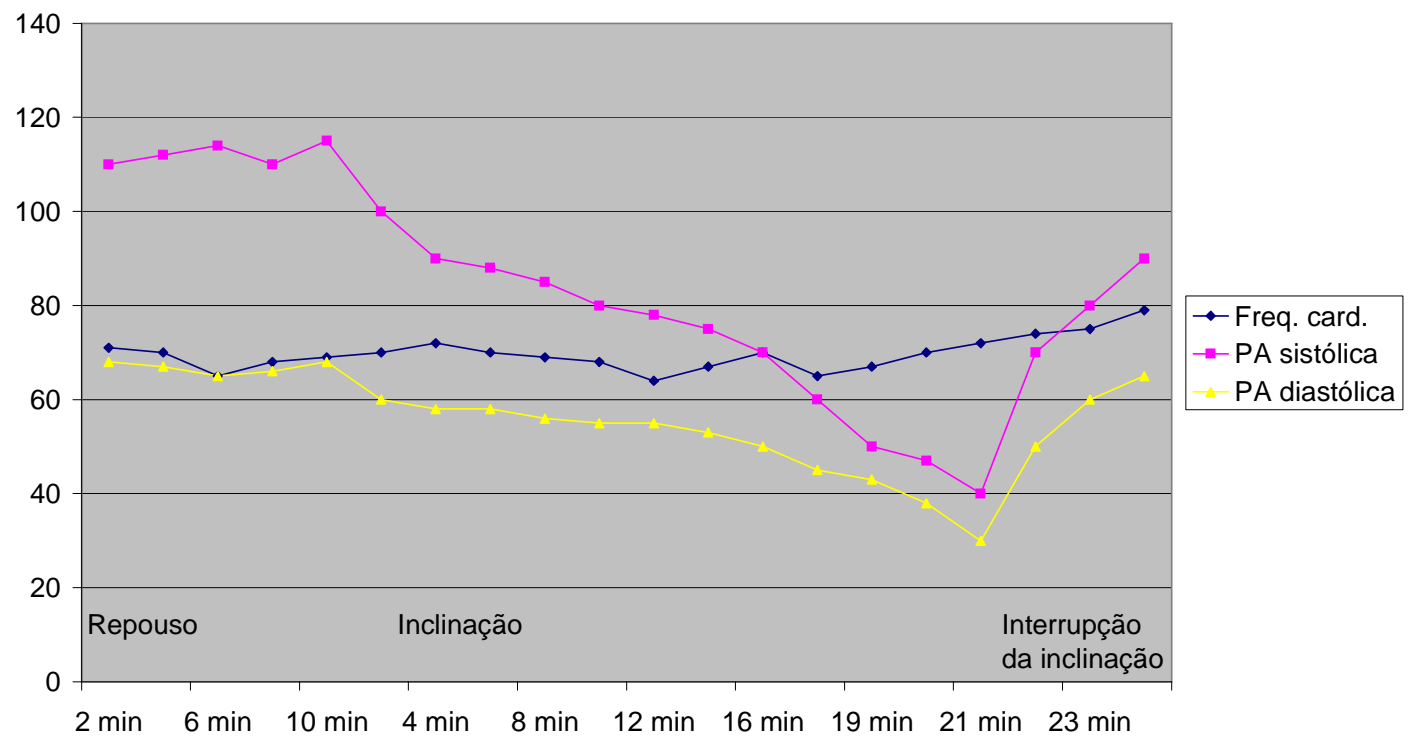

Exemplo de resposta disautonômica, evidenciada pela queda progressiva da pressão arterial. Na legenda, Freq. card. indica freqüência cardíaca e PA indica pressão arterial.

A taquicardia postural ortostática é definida como um aumento da freqüência cardíaca que ultrapasse 30 batimentos por minuto ou atinja valores superiores a 120 batimentos por minuto, nos primeiros minutos da inclinação, freqüentemente associado a redução discreta da pressão arterial (Figura 7). Aceita-se que possa ser produzida por mais de um mecanismo. Um deles poderia ser decorrente de hipersensibilidade dos receptores adrenérgicos beta. Outro poderia estar relacionado a uma forma menos intensa de insuficiência autonômica. ${ }^{46,47,50,51}$ 
Figura 7 - Taquicardia postural ortostática

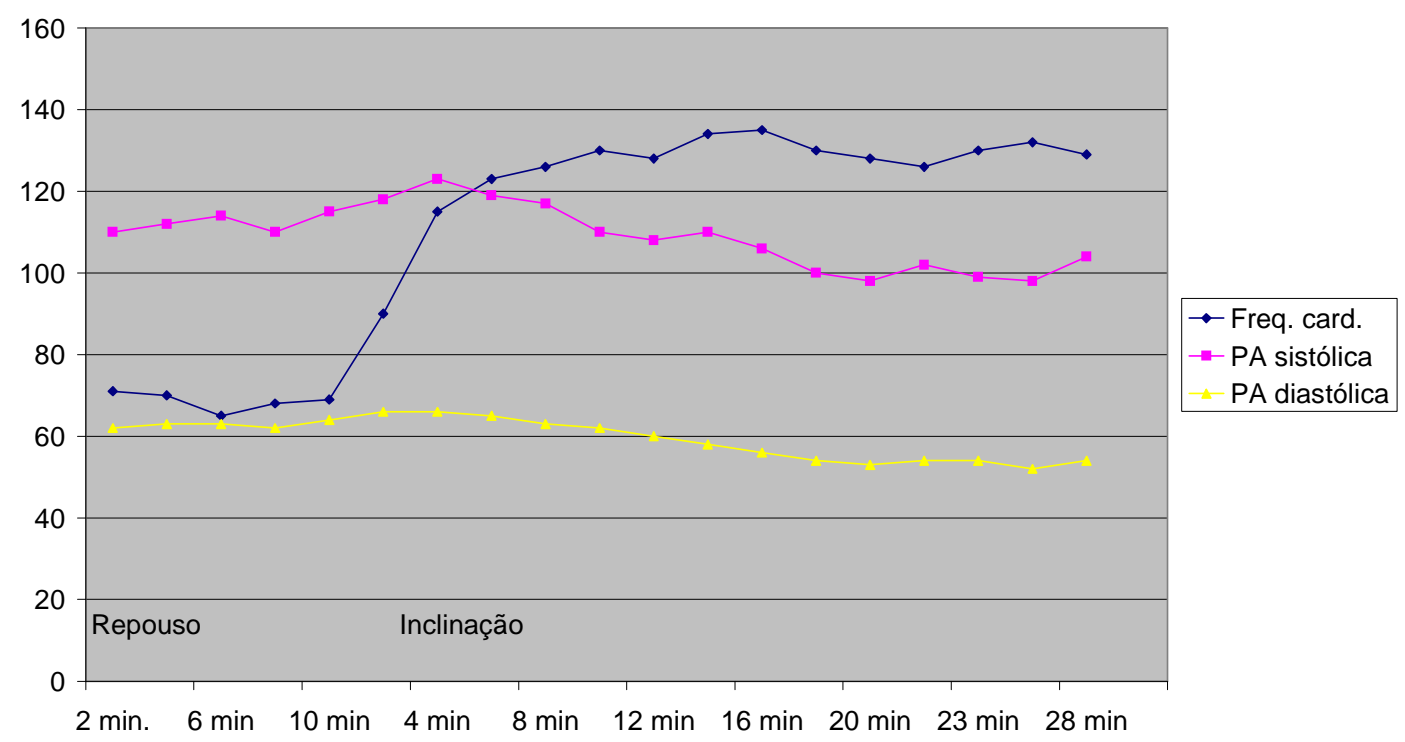

Exemplo taquicardia postural ortostática, evidenciada pelo aumento rápido e importante da freqüência cardíaca após a inclinação. Na legenda Freq. card. indica freqüência cardíaca e PA indica pressão arterial.

O efeito da obesidade sobre a tolerância ortostática tem sido pouco estudado. Alguns estudos colocam que a modificação da modulação autonômica imposta pelo estresse ortostático seria menor nos obesos, sugerindo uma menor habilidade para se adaptarem às mudanças posturais 28, 52, 53. Quanto ao efeito da redução do peso sobre a tolerância ortostática, as informações são ainda mais escassas e inconclusivas ${ }^{53}$.

\subsection{Dosagem de noradrenalina}

A dosagem direta de noradrenalina é uma ferramenta utilizada para a avaliação da atividade nervosa simpática geral. Tanto a dosagem no sangue quanto em urina de 24 horas apresentam limitações ${ }^{12,} 20$. Embora alguns autores tenham utilizado mais a dosagem plasmática, que representa uma 
amostra específica de determinada situação e horário, outros utilizam a dosagem urinária no sentido de tentar refletir a atividade simpática diária total $^{13,15,41,54-56}$.

Os estudos que avaliaram a atividade simpática geral na obesidade através da dosagem direta da noradrenalina não são uniformes nos seus $\operatorname{achados}^{57}$. Quanto à dosagem plasmática, há estudos em que não foi encontrada diferença entre obesos e não obesos ${ }^{13,23,41}$ e estudos indicando maiores níveis em obesos ${ }^{58,59}$. Grassi et al. ${ }^{15}$ mostraram redução dos níveis de noradrenalina plasmática com a redução de peso por meio de dieta. $\bigcirc$ uso da dosagem em urina de 24 horas também tem mostrado resultados diferentes, com achados indicando relação entre maior índice de massa corpórea e maior excreção de noradrenalina ${ }^{54,56}$ e achados não mostrando diferença entre obesos e não obesos ${ }^{41}$. Emdin et al. ${ }^{41}$ encontraram resultados sugestivos de redução da excreção urinária de noradrenalina com a redução de peso por meio de dieta, em poucos pacientes, porém sem atingir diferença estatística.

\subsection{Tratamento cirúrgico da obesidade}

As estratégias convencionais de tratamento da obesidade - baseadas em orientações dietéticas, exercícios físicos e uso de medicação - têm produzido apenas resultados modestos no que se refere à perda e manutenção da redução do peso $^{60}$. Na maioria dos casos, o peso é recuperado e os potenciais benefícios do tratamento não são mantidos ${ }^{61}$, o que evidencia a necessidade de medidas mais efetivas. 
O tratamento cirúrgico da obesidade, conhecido como cirurgia bariátrica, é um recurso atualmente reservado para pacientes com índice de massa corpórea maior ou igual a $40 \mathrm{~kg} / \mathrm{m}^{2}$, ou acima de $35 \mathrm{~kg} / \mathrm{m}^{2}$ quando associado a comorbidades relacionadas à obesidade. As estratégias clínicas para redução de peso devem ter falhado e os pacientes devem estar bem informados, motivados e com risco cirúrgico aceitável ${ }^{6,7,61,62}$.

Apesar da indicação restrita para o tratamento cirúrgico, o número de procedimentos tem aumentado de forma muito importante nos últimos anos. As razões para este aumento envolvem vários fatores, entre eles a falta de maior efetividade do tratamento clínico, aumento do número de pacientes com obesidade importante e maior aprimoramento técnico dos cirurgiões ${ }^{62}$.

As técnicas cirúrgicas mais utilizadas e citadas na literatura são a gastroplastia vertical com bandagem, a banda gástrica ajustável e a gastroplastia com derivação gastrojejunal em Y de Roux ("Roux-en-Y gastric bypass"). As duas primeiras criam uma pequena câmara gástrica que se esvazia no restante do estômago através de uma via de saída estreita, e a última cria uma pequena bolsa gástrica, isolada do restante do estômago, que se esvazia em uma alça do intestino delgado ${ }^{60,62,63}$. Levam a grande e rápida perda de peso, com melhor manutenção em comparação com o tratamento não cirúrgico ${ }^{60,62}$. Entre as técnicas citadas, a gastroplastia com derivação gastrojejunal em $Y$ de Roux (Figura 8) é a que leva a maior e mais sustentada perda de peso, motivo pelo qual tem sido muito empregada atualmente ${ }^{60,63-65}$. 
Figura 8 - Gastroplastia com derivação gastrojejunal em Y de Roux

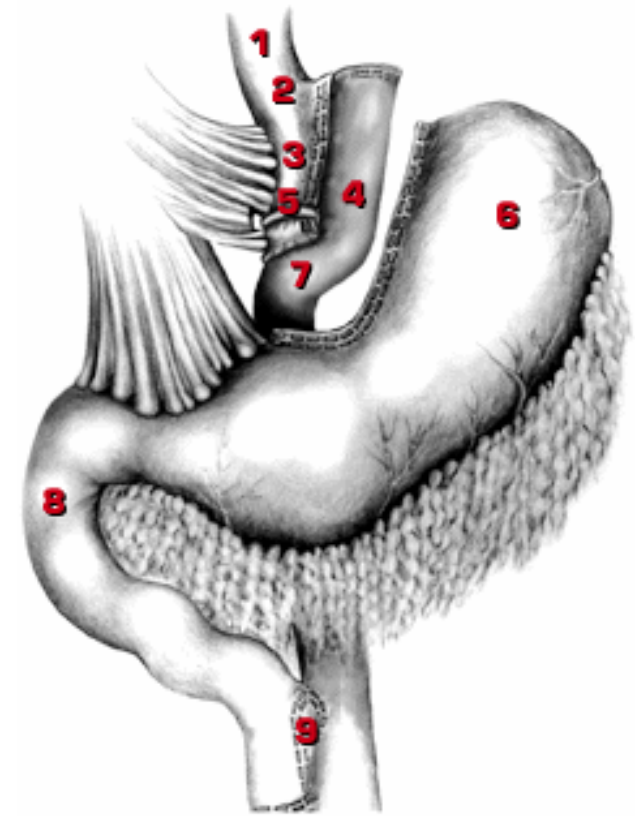

1. Esôfago

2. Junção do esôfago com o estômago

3. Nova bolsa de estômago

4. Intestino

5. Anel

6. Estômago excluído

7. Anastomose da bolsa do estômago com o intestino

8. Duodeno

9. Anastomose do intestino

FONTE: http://www.gastroweb.com.br. Reproduzida com permissão do Dr. Jorge Akira Honda.

O tratamento cirúrgico da obesidade é mais efetivo que o tratamento convencional para o controle de condições associadas à obesidade, como diabetes melito, hipertensão e dislipidemia, em pacientes com índice de massa corpórea maior ou igual a $40 \mathrm{~kg} / \mathrm{m}^{2}{ }^{65-73}$. O tipo de cirurgia pode influenciar o resultado a longo prazo, com um benefício mais sustentado com a gastroplastia com derivação gastrojejunal em $Y$ de $\operatorname{Roux}{ }^{65,67,74}$. Em relação à redução de mortalidade, a questão ainda não está clara ${ }^{65,69,73,75}$.

\subsection{Padrão autonômico e tratamento cirúrgico da obesidade}

A variabilidade da freqüência cardíaca e a excreção urinária de noradrenalina foram estudadas por Karason et al. ${ }^{54}$. Foi avaliado um grupo de 27 pacientes obesos submetidos a cirurgia bariátrica. Um ano após o procedimento houve aumento da variabilidade da freqüência cardíaca e 
redução da excreção urinária de noradrenalina. Esta é a única publicação conhecida, até o momento, que aborda o efeito do tratamento cirúrgico da obesidade sobre a variabilidade da freqüência cardíaca.

A redução da excreção urinária de noradrenalina também foi mostrada por Van de Borne et al. ${ }^{55}$, quando avaliaram 28 pacientes submetidos a gastroplastia vertical com bandagem.

O estudo da relação entre o tratamento cirúrgico da obesidade e o padrão autonômico cardiovascular se torna mais atrativo quando constatamos que existem relatos de casos de hipotensão ortostática sintomática e síncope colocados como possivelmente relacionados a procedimentos cirúrgicos gástricos para tratamento de obesidade ${ }^{76-78}$. A redução da atividade simpática com perda do controle adequado da pressão arterial decorrente da rápida perda de peso poderia estar relacionada à hipotensão ortostática ${ }^{77}$.

Estes relatos nos induzem a questionar se a perda de peso ou algum fator relacionado à cirurgia poderiam influenciar a tolerância ortostática. Não há investigação conhecida avaliando esta questão.

A cirurgia bariátrica leva a grande perda de peso, modificando rapidamente um estado cujos mecanismos envolvidos na sua origem ainda não são bem entendidos. Assim, consideramos que a avaliação das conseqüências desta intervenção é oportuna. O seu efeito sobre o sistema nervoso autônomo cardiovascular merece mais estudos. 


\section{OBJETIVOS}

Investigamos, na presente pesquisa, modificações autonômicas decorrentes da perda rápida de peso provocada pela gastroplastia com derivação gastrojejunal em $Y$ de Roux, com enfoque na variabilidade da freqüência cardíaca, na tolerância ortostática e na excreção urinária de noradrenalina, em uma população com obesidade importante.

Utilizamos testes autonômicos não invasivos, com técnica e aplicabilidades clínicas e científicas conhecidas, que podem fornecer informações relacionadas à modulação autonômica cardíaca durante as atividades habituais, controle hemodinâmico postural e atividade simpática geral em 24 horas.

O estudo tem como objetivos primários investigar:

- o efeito do tratamento cirúrgico da obesidade pela gastroplastia com derivação gastrojejunal em $\mathrm{Y}$ de Roux sobre a modulação autonômica cardíaca, através da análise da variabilidade da freqüência cardíaca no domínio do tempo;

- a influência do tratamento cirúrgico da obesidade sobre a tolerância ortostática.

Trabalhamos com a hipótese de que a grande e rápida perda de peso decorrente da gastroplastia com derivação gastrojejunal modifica o padrão autonômico cardíaco e a tolerância ortostática. 
Como objetivo secundário, a pesquisa se propõe avaliar o efeito da cirurgia sobre a atividade simpática geral, através da excreção urinária de noradrenalina em 24 horas. A perda importante de peso poderia reduzir a atividade simpática a ponto de ser detectada pela redução na dosagem urinária de noradrenalina. 


\section{MÉTODOS}

\subsection{Desenho do estudo}

A pesquisa é um estudo observacional longitudinal, em que 71 pacientes submetidos a gastroplastia com derivação gastrojejunal em $Y$ de Roux foram estudados em duas fases: antes e seis meses após a cirurgia (mediana de 183 dias, variando de 176 a 205 dias).

Avaliação de medidas antropométricas, análise da variabilidade da freqüência cardíaca, estudo da resposta ao teste de inclinação ortostática e dosagem de noradrenalina em urina de 24 horas foram realizados nas duas fases do estudo. A título de fornecer informações complementares, outras avaliações também foram realizadas: monitorização ambulatorial da pressão arterial sistêmica, dosagens bioquímicas no sangue e avaliação de qualidade de vida.

Os exames de todos os pacientes foram realizados procurando-se obedecer à mesma seqüência, tanto na fase pré-operatória como seis meses após a cirurgia. Seguindo-se à realização do teste de inclinação ortostática, foi instalado gravador de Holter e realizada coleta de sangue. No mesmo dia foram avaliados o peso, altura e circunferência abdominal, sendo também iniciado o preparo para a coleta de urina de 24 horas, que foi realizada sete dias depois. Nesse período foi realizado o exame de monitorização ambulatorial da pressão arterial. 
Os resultados das duas fases do estudo foram comparados, com foco nas modificações da variabilidade da freqüência cardíaca, do teste de inclinação ortostática e da dosagem de noradrenalina em urina de 24 horas.

O projeto da pesquisa e o termo de consentimento livre e esclarecido foram aprovados pela Comissão de Ética para Análise de Projetos de Pesquisa do Hospital das Clínicas da Faculdade de Medicina da Universidade de São Paulo e pelo Comitê Permanente de Ética em Pesquisa Envolvendo Seres Humanos da Universidade Estadual de Maringá.

\subsection{Casuística}

A casuística foi composta a partir de pacientes com o tratamento cirúrgico da obesidade já indicado, provenientes do serviço de cirurgia do Hospital Regional da Universidade Estadual de Maringá e de serviços privados da cidade de Maringá, Estado do Paraná, no período contínuo de julho de 2004 a dezembro de 2005. Os autores não participaram da indicação do tratamento.

Os critérios de inclusão foram:

- índice de massa corpórea igual ou superior a $40 \mathrm{~kg} / \mathrm{m}^{2}$;

- índice de massa corpórea entre 35 e $39,9 \mathrm{~kg} / \mathrm{m}^{2}$ associado a comorbidades relacionadas à obesidade $e^{6,7,10}$.

Os critérios de exclusão foram:

- presença de cardiopatia e/ou eletrocardiograma anormal;

- diagnóstico de diabetes melito ou disfunção de tireóide;

- uso de medicação hipoglicemiante; 
- glicemia de jejum igual ou superior a $126 \mathrm{mg} / \mathrm{dL}$;

- dosagem anormal do hormônio estimulante da tireóide;

- uso de reposição de hormônio tireoideano;

- dosagem anormal de uréia ou creatinina.

A caracterização das comorbidades e dos critérios de inclusão e exclusão foi feita a partir da avaliação pré-operatória de rotina. Todos os pacientes apresentavam medidas de peso e altura, avaliação de cardiologista e endocrinologista e exames complementares constituídos por eletrocardiograma, radiografia de tórax e exames laboratoriais de glicemia de jejum, uréia, creatinina, colesterol total e frações, triglicérides e dosagem do hormônio estimulante da tireóide (TSH).

Entre os pacientes que não apresentavam critério de exclusão, foram caracterizadas as seguintes comorbidades relacionadas à obesidade: hipertensão arterial sistêmica, dislipidemia e doenças articulares degenerativas.

A avaliação médica pré-operatória, a afirmação do paciente ou o uso de medicação anti-hipertensiva foram os parâmetros utilizados para caracterizar o diagnóstico de hipertensão arterial sistêmica.

Foram considerados como portadores de dislipidemia os pacientes em uso de medicação hipolipemiante ou com pelo menos uma das seguintes condições: LDL-colesterol maior ou igual a $160 \mathrm{mg} / \mathrm{dL}$, HDL-colesterol menor que $40 \mathrm{mg} / \mathrm{dL}$ e triglicérides igual ou superior a $200 \mathrm{mg} / \mathrm{dL}^{11}$. 
Os pacientes considerados como portadores de doenças articulares degenerativas relacionadas à obesidade foram aqueles que apresentavam este diagnóstico na avaliação pré-operatória.

O tamanho da casuística foi estimado, para efeito de planejamento da pesquisa, em um mínimo de 50 pacientes, com base nos resultados de outros estudos que avaliaram o efeito da perda de peso, por meio de dieta, sobre a variabilidade da freqüência cardíaca. Após a avaliação de 34 pacientes nas duas fases da pesquisa, o cálculo do tamanho da casuística foi obtido com base nos resultados desta casuística piloto, considerando-se um nível de significância de $5 \%$ e poder estatístico mínimo de $80 \%$. Para preencher estes critérios para os índices estatísticos da variabilidade da freqüência cardíaca, obteve-se um número mínimo de 49 pacientes (Tabela 1). Quanto ao teste de inclinação ortostática, para detectar diferenças a partir de 2,5\%, chegou-se a um número mínimo de 65 pacientes. Para estes cálculos foi utilizado o programa "The SAS system for windows" versão 8.02 (SAS Institute, Cary, Carolina do Norte, Estados Unidos).

Tabela 1 - Número mínimo de pacientes para os índices da variabilidade da freqüência cardíaca, considerando-se um nível de significância de $5 \%$ e poder estatístico de $80 \%$

\begin{tabular}{lc}
\hline \multicolumn{1}{c}{ ÍNDICES } & Número de pacientes \\
\hline SDNN & 10 \\
SDANN & 10 \\
SDNN index & 17 \\
PNN50 & 23 \\
RMSSD & 49 \\
\hline
\end{tabular}


Noventa e um pacientes, que preenchiam os critérios de inclusão e não apresentavam nenhum critério de exclusão, foram convidados a participar da pesquisa. Setenta e cinco foram incluídos e quatro não realizaram a avaliação pós-operatória, totalizando 71 pacientes avaliados antes da cirurgia e seis meses após. Todos leram e assinaram o termo de consentimento livre e esclarecido. As características da casuística estão descritas na Tabela 2.

Tabela 2 - Características da casuística

Número total................................................. 71

Sexo feminino ........................................... 42

Sexo masculino............................................ 29

Mediana da idade....................................... 36 anos (18-66 anos) $)^{(1)}$

Menos de 30 anos.............................. 21

Entre 30 e 39 anos.............................. 25

Entre 40 e 49 anos............................. 15

50 anos ou mais.................................. 10

Mediana do peso...................................... $114 \mathrm{~kg}(90,2-176 \mathrm{~kg})^{(1)}$

Mediana do índice de massa corpórea......... $41,9 \mathrm{~kg} / \mathrm{m}^{2}\left(37,1-56,2 \mathrm{~kg} / \mathrm{m}^{2}\right)^{(1)}$

Número pessoas com comorbidades ${ }^{(2)}$.......... 55

Dislipidemia.......................................... 37

Hipertensão arterial sistêmica............... 28

Artropatia........................................... 11

Pessoas com medicação anti-hipertensiva ${ }^{(2)} .25$

Diurético.......................................... 16

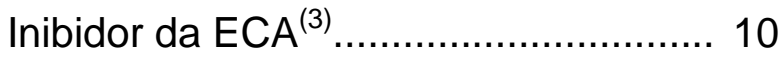

Betabloqueador.................................. 9

Bloqueador de canal de cálcio............. 5

Bloqueador de receptor $\mathrm{AT}_{1}{ }^{(4)} \ldots \ldots \ldots \ldots . .3$

Agonista alfa central........................ 3

(1)Dados indicados como mediana (valor mais baixo - valor mais alto). ${ }^{(2)}$ Medicações isoladas ou associadas. ${ }^{(3)} \mathrm{ECA}$ indica enzima de conversão da angiotensina. ${ }^{(4)} A T_{1}$ indica receptores tipo 1 da angiotensina II. 


\subsection{Avaliações realizadas}

\subsubsection{Medidas antropométricas}

O peso e a altura dos pacientes foram avaliados através de balança eletrônica equipada com régua própria para mensuração da altura (Balança Eletrônica Personal Filizola, São Paulo, Brasil), com precisão de 0,1 kg para o peso e de 0,01 m para a altura. O índice de massa corpórea foi calculado dividindo-se o peso, em quilogramas, pelo quadrado da altura, em metros. A circunferência abdominal foi medida com fita métrica com precisão de 0,1 $\mathrm{cm}$, entre a crista ilíaca e a última costela ${ }^{6,10}$.

\subsubsection{Análise da variabilidade da freqüência cardíaca}

A análise da variabilidade da freqüência cardíaca foi realizada através de eletrocardiograma com 24 horas de duração, a partir de gravações ambulatoriais obtidas por gravador digital (gravador de Holter CardioFlash, Cardios, São Paulo, Brasil)(Figura 9) e processadas por sistema computadorizado de análise com freqüência de amostragem de 200 Hertz (analisador de Holter DMI Burdick, Deerfil, Wisconsin, EUA).

Figura 9 - Sistema de gravação do eletrocardiograma de 24 horas

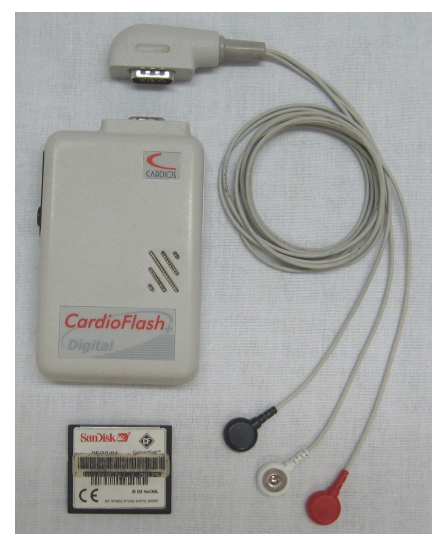

Gravador, cabo e cartão de armazenamento da gravação 
Foram calculados os índices estatísticos da variabilidade da freqüência cardíaca no domínio do tempo ${ }^{30}$ : SDNN, SDANN, SDNN index, pNN50 e rMSSD.

A pNN50 e a rMSSD foram utilizadas como índices relacionados à variabilidade produzida pela atividade parassimpática. Os demais índices foram utilizados como relacionados à variabilidade tota $\left.\right|^{30}$.

A média dos intervalos RR normais (intervalo NN médio), que indica a duração média de tempo entre dois batimentos normais, também foi avaliada. Quanto maior o intervalo NN médio, menor a média da freqüência sinusal.

Todas as gravações do eletrocardiograma de 24 horas foram analisadas pelo autor, com grande atenção à qualidade da gravação e à identificação correta dos batimentos. Aquelas com quantidade de artefato maior do que $1 \%$ foram repetidas. Após o processamento automático de análise, o autor revisou todas as gravações no sentido de proceder às correções necessárias. Foram revistas as categorias diferentes de batimentos, separadas pelo sistema automático em normais, ventriculares e de origem indefinida. Em seguida foram revisadas as categorias de arritmias, separadas em: ventriculares, supraventriculares, pausas, taquicardias e bradicardias. Para maior sensibilidade, com vista a uma revisão mais detalhada da gravação, o sistema foi configurado para exibir as pausas iguais ou superiores a 1,0 segundo, freqüências cardíacas menores que 79 batimentos por minuto e maiores que 80 batimentos por minuto, e batimentos com precocidade maior que $20 \%$. Após a conferência e as 
correções necessárias, foi analisado o tacograma, gráfico onde o eixo horizontal representa o horário e o vertical a duração do intervalo RR (Figura 10). Todos os intervalos entre os batimentos cardíacos são representados neste gráfico por um ponto, podendo ser revisados e corrigidos, se necessário. Os pontos que estavam fora do agrupamento dos demais foram revistos e, se necessário, corrigidos. Somente após cumpridas todas estas etapas foi calculada a variabilidade da freqüência cardíaca, utilizando-se a função específica do programa de análise de Holter, que considera apenas os batimentos normais, descartando os intervalos anteriores e posteriores aos batimentos ectópicos (Figura 11).

Figura 10 - Tacograma

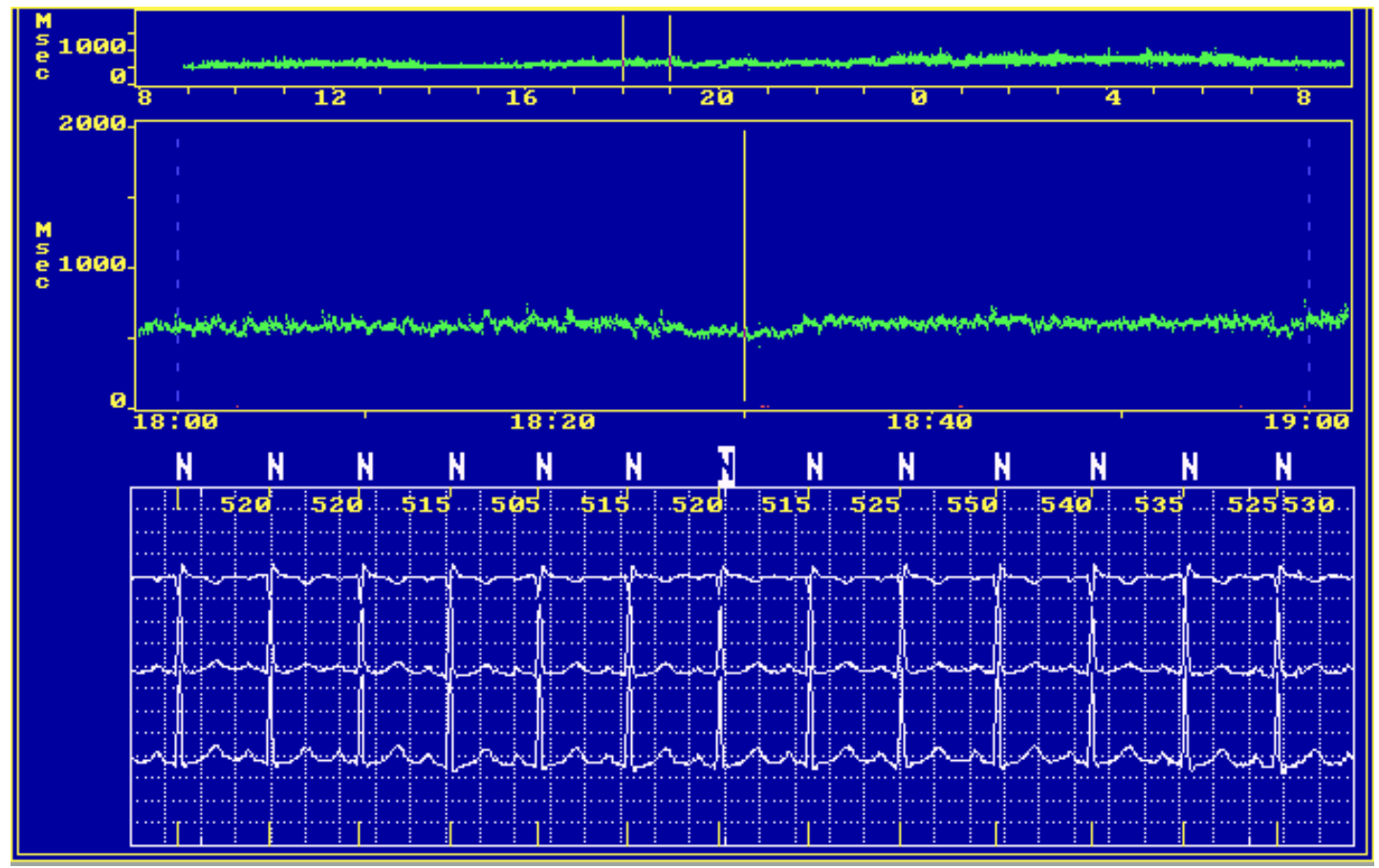

Tela do tacograma do programa de análise de Holter. O primeiro gráfico (mais superior na figura) representa a distribuição dos intervalos RR (pontos verdes) nas 24 horas. O segundo é a representação do período de uma hora indicado pelas linhas verticais paralelas do primeiro gráfico. A parte inferior mostra, no eletrocardiograma, cada intervalo $R R$ individualmente, selecionado pela linha vertical sobre os pontos verdes no segundo gráfico. 
Figura 11 - Resultados da variabilidade da freqüência cardíaca

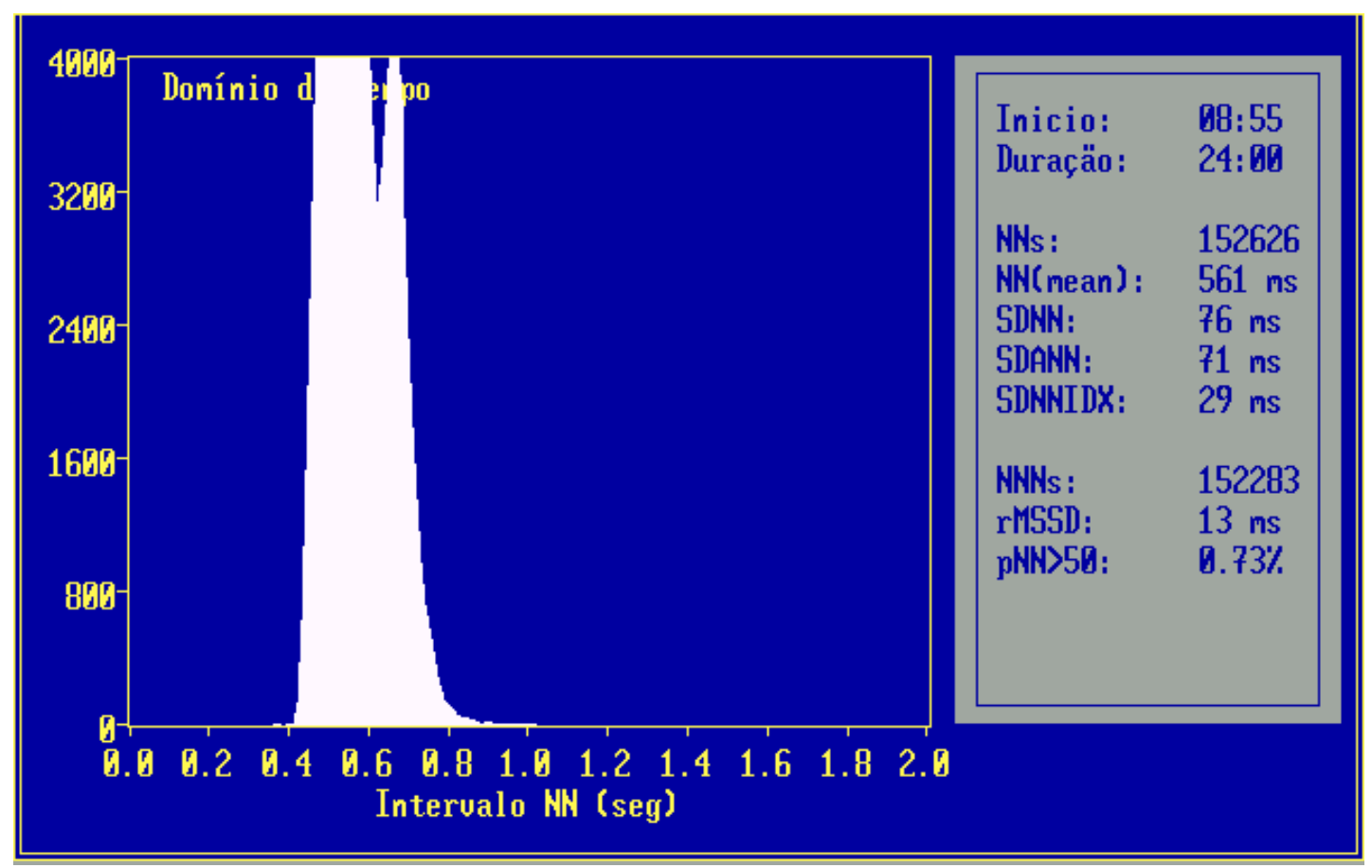

Tela do programa de análise da variabilidade da freqüência cardíaca, no domínio do tempo, mostrando gráfico com a distribuição de todos os intervalos RR normais (NN) de acordo com suas durações e freqüências de ocorrência. O quadro ao lado do gráfico mostra o resultado dos cálculos dos índices de variabilidade.

Foram excluídos os pacientes em que não se conseguiu uma gravação com boa qualidade e aqueles que apresentaram número de batimentos ectópicos igual ou superior a 10 por hora.

\subsubsection{Teste de inclinação ortostática}

O teste de inclinação ortostática foi realizado com mesa basculante manual, com apoio para os pés e cintos de segurança (Carci, São Paulo, Brasil) (Figura 12). A monitorização da freqüência cardíaca durante o exame foi feita de forma contínua, através de monitor e aparelho de eletrocardiograma (Cardiofax V, ECAPS12, Nihon Kodhen, Tókio, Japão). As 
aferições da pressão arterial sistêmica foram realizadas no braço esquerdo posicionado na altura aproximada do coração, de forma intermitente, com esfigmomanômetro de coluna de mercúrio. O tamanho do manguito foi escolhido obedecendo-se a orientação de largura mínima de $40 \%$ e comprimento de $80 \%$ da circunferência do braço ${ }^{79}$.

Figura 12 - Metodologia do teste de inclinação ortostática

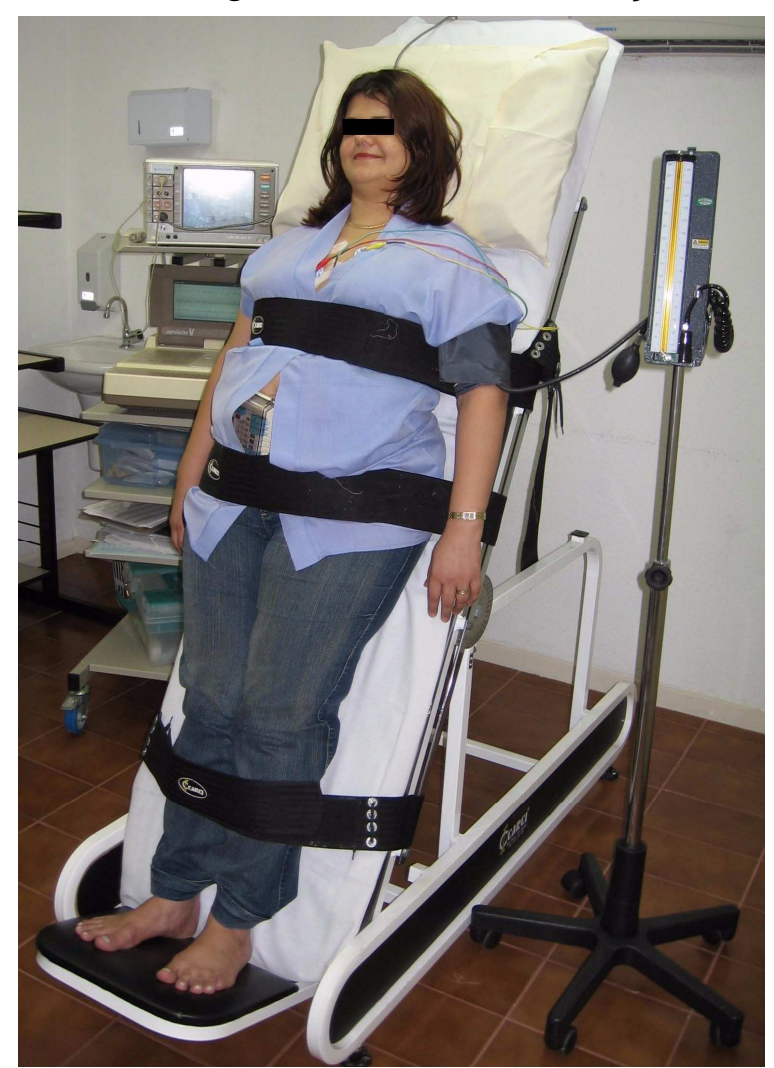

Paciente na mesa de exame, com inclinação de 60 graus

Os pacientes permaneceram em repouso em decúbito dorsal horizontal por 20 minutos, com registro da pressão arterial e freqüência cardíaca a cada dois minutos. Após este período, foi realizada a inclinação da mesa, em 10 a 15 segundos, até 60 graus. A aferição da pressão arterial e o registro da freqüência cardíaca foram realizados no primeiro e terceiro 
minutos após a inclinação e subseqüentemente a cada 2 minutos ${ }^{80}$. A mesa retornou à posição horizontal após completados 45 minutos, ou antes, na ocorrência de síncope ou pré-síncope associadas a queda da pressão arterial sistólica para níveis menores que $90 \mathrm{~mm} \mathrm{Hg}$ e/ou freqüência cardíaca abaixo de 45 batimentos por minuto ${ }^{53}$.

Foram pesquisadas as respostas clássicas ao teste: vasovagal, disautonômica e taquicardia ortostática postural. A presença de hipotensão ortostática também foi pesquisada, definida como redução igual ou superior a $20 \mathrm{~mm} \mathrm{Hg}$ da pressão arterial sistólica ou redução da pressão arterial diastólica igual ou superior a $10 \mathrm{~mm} \mathrm{Hg}$, dentro dos primeiros 3 minutos da fase de inclinação, acompanhada ou não de sintoma ${ }^{81}$.

Os testes de inclinação foram realizados após período de jejum de pelo menos 6 horas, no período da manhã, entre as sete e as nove horas.

\subsubsection{Noradrenalina urinária}

A dosagem urinária de noradrenalina foi realizada em urina de 24 horas, pelo método de cromatografia líquida de alta performance ${ }^{82}$. A coleta foi realizada após preparo prévio por 7 dias, com a orientação de evitar exercícios físicos, café, chás, chocolate, frutas em geral, sorvetes e refrigerantes. O material foi mantido refrigerado e, em laboratório privado da cidade de Maringá (Laboratório São Camilo), foi acidificado, com a adição de ácido clorídrico a 50\%, na proporção de $20 \mathrm{~mL}$ para cada litro de urina. Uma amostra de $10 \mathrm{~mL}$ foi colhida, acondicionada em caixa térmica, com gelo, para manter temperatura entre dois e oito graus Celsius, e enviada, por via 
aérea, para a cidade de Belo Horizonte, onde a análise foi realizada, no Laboratório Hermes Pardini, em cromatógrafo marca Varian, modelo SpectrAA.

\subsubsection{Outros exames}

Exames de monitorização ambulatorial da pressão arterial em 24 horas foram realizados por monitor não invasivo, oscilométrico, validado segundo os critérios da "British Hypertension Society" (Monitor Ambulatorial de Pressão Arterial Mobil-O-Graph, no Brasil DynaMAPA Cardios - São Paulo $)^{83}$. Aferições da pressão arterial foram realizadas a cada vinte minutos durante a vigília e a cada trinta minutos no sono. O período do sono foi estabelecido entre 23 horas e 07 horas na preparação do equipamento, antes do exame, e posteriormente corrigido conforme a informação fornecida pelo paciente, através de anotação em diário. O tamanho do manguito foi escolhido de acordo com a circunferência do braço ${ }^{84}$.

Exames de sangue foram realizados com a coleta do material após jejum de 12 horas. Colesterol total, HDL-colesterol, triglicérides e glicose foram dosados através do método enzimático automatizado ${ }^{82}$ (Architect $\mathrm{Cl}$ 8200, Abbott Diagnóstics). A dosagem de insulina e a proteína C-reativa de alta sensibilidade foram realizadas através do método de quimioluninescência automatizada $^{82}$ (Immulite 2000, DPC - Siemens). Fibrinogênio foi dosado pelo método coagulométrico funcional automatizado $^{82}$ (Quick Timer, Drake). Todos os exames de sangue foram executados em laboratório privado (Laboratório São Camilo, Maringá, 
Paraná). O resultado do LDL-colesterol foi obtido indiretamente, através da fórmula de Friedwald ${ }^{11,85}$.

Avaliação de qualidade de vida foi realizada através do questionário genérico "Medical Outcomes Study 36-Item Short-Form Health Survey (SF$36)$," na versão traduzida e validada para a língua portuguesa $\left(\right.$ Anexo ${ }^{86}$. Este instrumento avalia oito domínios: capacidade funcional, aspectos físicos, dor, estado geral de saúde, vitalidade, aspectos sociais, aspecto emocional e saúde mental. São 11 questões que investigam 36 itens. A partir de pontuações atribuídas a cada resposta, é calculado um valor para cada um dos oito domínios, o qual varia de zero a 100, sendo zero o pior e 100 o melhor (Anexo). Este valor é chamado "Raw Scale". Todos os questionários foram aplicados por psicólogo.

\subsection{Análise estatística}

Considerando-se que as variáveis respostas foram medidas em um mesmo paciente em dois tempos, foram usadas equações de estimação generalizadas (EEG). Estes modelos podem usar qualquer distribuição da família exponencial para representar as variáveis respostas, e não somente a distribuição normal ${ }^{87}$.

Para a análise do comportamento dos índices da variabilidade da freqüência cardíaca ao longo do tempo, foram controlados os seguintes fatores: sexo, idade, freqüência cardíaca média, pressão arterial e uso de medicação anti-hipertensiva. Para a idade, foram consideradas 4 faixas etárias: menos de 30 anos, entre 30 e 39 anos, entre 40 e 49 anos, e 50 
anos ou mais. Quanto à pressão arterial, os pacientes foram divididos em duas categorias, conforme a média das cinco últimas aferições da fase de repouso do teste de inclinação ortostática: pressão arterial maior ou igual a $140 / 90 \mathrm{~mm} \mathrm{Hg}$ e pressão arterial menor que $140 / 90 \mathrm{~mm} \mathrm{Hg}$. Para o controle da freqüência cardíaca, a sua influência foi estimada através do cálculo do coeficiente de correlação de Pearson entre a freqüência cardíaca média e cada índice da variabilidade avaliado.

Para análise dos resultados do teste de inclinação ortostática, foi realizado um modelo para cada tipo de resposta encontrado, considerando a sua presença ou ausência. Para a hipotensão ortostática foi avaliado a influência do sexo, idade maior ou igual a 50 anos e uso de medicação antihipertensiva.

$\mathrm{Na}$ avaliação das medidas antropométricas e dos resultados da glicemia e insulina de jejum foi realizado um modelo para cada medida controlando os fatores sexo e idade.

Para os demais resultados laboratoriais os modelos consideraram apenas a diferença entre o pré e o pós-operatório.

Coeficientes de Pearson foram calculados para avaliar as correlações entre as alterações das medidas da variabilidade da freqüência cardíaca e as alterações do peso, índice de massa corpórea, circunferência abdominal e insulinemia de jejum. Foram considerados os valores absolutos das diferenças entre as fases pré e pós-operatória.

Foi considerado um nível de significância de $5 \%(p<0,05)$. Todos os cálculos foram realizados pelo programa "The SAS system for windows" 
versão 8.02 (SAS Institute, Cary, Carolina do Norte, Estados Unidos). Para a elaboração de gráficos foi utilizado o programa "SPSS 12.0 for Windows" (SPSS Inc., Chicago, Illinois, Estados Unidos). 


\section{RESULTADOS}

As características dos pacientes em relação à pressão arterial de repouso e o uso de medicação anti-hipertensiva mudaram da fase préoperatória para seis meses após a cirurgia. O número de pacientes com pressão elevada (maior ou igual a $140 / 90 \mathrm{~mm} \mathrm{Hg}$ ) e o uso de medicação anti-hipertensiva foi menor após a cirurgia (Tabela 3).

Tabela 3 - Número de pacientes conforme as categorias de pressão arterial e medicação anti-hipertensiva, nas fases pré e pós-operatória

\begin{tabular}{lcc}
\hline $\begin{array}{c}\text { PRESSÃO ARTERIAL E } \\
\text { MEDICAÇÃO ANTI-HIPERTENSIVA }\end{array}$ & $\begin{array}{c}\text { Pré- } \\
\text { operatório }\end{array}$ & $\begin{array}{c}\text { Pós- } \\
\text { operatório }\end{array}$ \\
\hline Pressão arterial & & \\
$<140 / 90 \mathrm{~mm} \mathrm{Hg}^{(1)}$ & 60 & 61 \\
$\geq 140 / 90 \mathrm{~mm} \mathrm{Hg}^{(2)}$ & 11 & 10 \\
& & \\
Uso de medicação anti-hipertensiva & & \\
Não & 46 & 65 \\
Sim & 25 & 6 \\
& & \\
Medicações anti-hipertensivas & 16 & 3 \\
Diurético & 10 & 1 \\
Inibidor da ECA & & \\
Betabloqueador & 9 & 3 \\
Bloqueador de cálcio & 5 & 1 \\
Bloqueador de AT ${ }_{1}^{(4)}$ & 3 & 0 \\
Agonista alfa central & 3 & 0 \\
\hline
\end{tabular}

${ }^{(1)}$ Indica menor que $140 / 90 \mathrm{~mm} \mathrm{Hg} .{ }^{(2)}$ Indica maior ou igual a $140 / 90 \mathrm{~mm}$ Hg. ${ }^{(3)} E C A$ indica enzima de conversão da angiotensina. ${ }^{(4)} A T_{1}$ indica receptores $A T_{1}$ da angiotensina II.

Dez pacientes apresentavam pressão arterial elevada após a cirurgia. Destes, apenas seis estavam nesta categoria antes da cirurgia. Os outros 
quatro apresentaram-se com pressão arterial elevada apenas na avaliação pós-operatória. Um deles suspendeu o uso da medicação anti-hipertensiva após a cirurgia, porém os outros três não faziam uso de medicação e não apresentaram nenhum fator evidente que justificasse a mudança para a categoria de pressão elevada no pós-operatório.

\subsection{Medidas antropométricas}

Entre a avaliação pré-operatória e aquela efetuada seis meses após a cirurgia, os pacientes apresentaram redução de peso que variou de $12,87 \%$ a 38,13\%, com média de $25,46 \%$. Houve redução da circunferência abdominal, que variou de 8,77\% a 33,04\%, com média de 20,4\%. O índice de massa corpórea, que antes da cirurgia apresentava média de 42,87 $\mathrm{kg} / \mathrm{m}^{2}$, variando de $37,11 \mathrm{~kg} / \mathrm{m}^{2}$ a $56,2 \mathrm{~kg} / \mathrm{m}^{2}$, após a cirurgia apresentou média de $32,94 \mathrm{~kg} / \mathrm{m}^{2}$, variando de $22,96 \mathrm{~kg} / \mathrm{m}^{2}$ a $39,74 \mathrm{~kg} / \mathrm{m}^{2}$.

Os homens eram mais pesados do que as mulheres $(p<0,001)$, não havendo diferença em relação à idade. A perda de peso no período de acompanhamento não foi igual para todos os pacientes. Houve diferença de evolução entre homens e mulheres, e também entre as faixas etárias. Os homens apresentaram maior perda de peso em comparação com as mulheres $(p=0,004)$ e os pacientes mais jovens apresentaram maior perda de peso em comparação com os de mais idade $(p=0,001)$ (Tabela 4).

O índice de massa corpórea não foi diferente entre homens e mulheres e entre as faixas etárias. Seis meses após a cirurgia houve redução significativa do índice, com diferença de evolução em relação às faixas 
etárias (Tabela 5). Os mais jovens apresentaram maior redução em comparação com os de mais idade $(p=0,018)$. Não houve diferença de evolução em relação aos sexos.

Tabela 4 - Comparação do peso entre as fases pré e pós-operatória de forma geral e de acordo com os fatores sexo e idade

\begin{tabular}{|c|c|c|c|c|c|c|}
\hline \multirow[t]{2}{*}{ FATO } & \multirow{2}{*}{$\begin{array}{l}\text { Pré- } \\
\text { operatório }{ }^{(1)} \\
(\mathrm{kg})\end{array}$} & \multirow{2}{*}{$\begin{array}{l}\text { Pós- } \\
\text { operatório(1) } \\
(\mathrm{kg})\end{array}$} & \multirow{2}{*}{$\begin{array}{l}\text { Média da } \\
\text { diferença } \\
(\mathrm{kg})\end{array}$} & \multicolumn{2}{|c|}{ IC 95\% ${ }^{(2)}$} & \multirow{2}{*}{$\begin{array}{l}\text { Valor } d e \\
\qquad p\end{array}$} \\
\hline & & & & $\begin{array}{l}\text { Limite } \\
\text { inf. }{ }^{(3)}\end{array}$ & $\begin{array}{l}\text { Limite } \\
\text { sup. }{ }^{(4)}\end{array}$ & \\
\hline Geral & $119,3 \pm 1,5$ & $89,2 \pm 1,2$ & 30,1 & 28,3 & & 101 \\
\hline \multicolumn{7}{|l|}{ Sexo } \\
\hline Fem & & 82,2 & 27 & 25,7 & 29,4 & $<0,0$ \\
\hline $\begin{array}{l}\text { Mas } \\
\text { dade }\end{array}$ & $12 \varepsilon$ & 96,2 & & 29,6 & 35,5 & \\
\hline & 128,3 & $92,9 \pm$ & & 32,4 & 38,3 & $<0,001$ \\
\hline & & $8,9=$ & & 28,1 & 32,9 & $<0,001$ \\
\hline $40 \mathrm{e}$ & $115,6 \pm 2,8$ & $87,4 \pm 2,5$ & 28,2 & 24,5 & 31,9 & $<0,001$ \\
\hline & $113,9 \pm 2,8$ & $87,7 \pm 2,6$ & 26,2 & 22,4 & 29,0 & $<0,001$ \\
\hline
\end{tabular}

${ }^{(1)}$ Os valores estão colocados como média e erro padrão da média. (2) Intervalo de $95 \%$ de confiança para a diferença entre as médias do préoperatório e pós-operatório. ${ }^{(3)}$ Limite inferior do intervalo de confiança. ${ }^{(4)}$ Limite superior do intervalo de confiança. ${ }^{(5)}$ Indica menor que 30 anos.

${ }^{(6)}$ Indica maior ou igual a 50 anos.

Tabela 5 - Comparação do índice de massa corpórea entre as fases pré e pós-operatória de forma geral e de acordo as faixas etárias

\begin{tabular}{|c|c|c|c|c|c|c|}
\hline \multirow[t]{2}{*}{ FATORES } & \multirow{2}{*}{$\begin{array}{c}\text { Pré- } \\
\text { operatório } \\
\left(\mathrm{kg} / \mathrm{m}^{2}\right)\end{array}$} & \multirow{2}{*}{$\begin{array}{c}\text { Pós- } \\
\text { operatório }{ }^{(1)} \\
\left(\mathrm{kg} / \mathrm{m}^{2}\right)\end{array}$} & \multirow{2}{*}{$\begin{array}{l}\text { Média da } \\
\text { diferença } \\
\left(\mathrm{kg} / \mathrm{m}^{2}\right)\end{array}$} & \multicolumn{2}{|c|}{ IC 95\%(2) } & \multirow{2}{*}{$\begin{array}{c}\text { Valor de } \\
\text { p }\end{array}$} \\
\hline & & & & $\begin{array}{l}\text { Limite } \\
\text { inf. }^{(3)}\end{array}$ & $\begin{array}{l}\text { Limite } \\
\text { sup. }^{(4)}\end{array}$ & \\
\hline $\begin{array}{l}\text { Geral } \\
\text { Idade (a }\end{array}$ & $42,69 \pm 0,46$ & $31,98 \pm 0,40$ & 10,71 & 10,12 & 11,29 & $<0,001$ \\
\hline$<30^{(5)}$ & $43,85 \pm$ & $31,80=$ & & 11,13 & 12,97 & $<0,001$ \\
\hline & & & & 10,14 & 11,81 & $<0,001$ \\
\hline & $41,42 \pm$ & $31,23 \pm$ & & 8 & 11,57 & $<0,001$ \\
\hline$\geq 50^{(6)}$ & $42,56 \pm 1,07$ & $32,93 \pm 0,98$ & 9,62 & 8,23 & 11,01 & $<0,001$ \\
\hline
\end{tabular}

${ }^{(1)}$ Os valores estão colocados como média e erro padrão da média. (2) Intervalo de $95 \%$ de confiança para a diferença entre as médias do préoperatório e pós-operatório. ${ }^{(3)}$ Limite inferior do intervalo de confiança. ${ }^{(4)}$ Limite superior do intervalo de confiança. ${ }^{(5)}$ Indica menor que 30 anos.

${ }^{(6)}$ Indica maior ou igual a 50 anos. 
Quanto à circunferência abdominal, os homens apresentaram maior valor que as mulheres $(p<0,001)$, sem diferença em relação à idade. Durante o período de acompanhamento houve diferença na intensidade de redução da circunferência abdominal entre as faixas etárias (Tabela 6). Os pacientes mais jovens apresentaram maior redução em comparação com os de mais idade $(p<0,001)$. Em relação aos sexos, a redução apresentou a mesma intensidade para homens e mulheres.

Tabela 6 - Comparação da circunferência abdominal entre as fases pré e pós-operatória de forma geral e de acordo as faixas etárias

\begin{tabular}{|c|c|c|c|c|c|c|}
\hline \multirow[t]{2}{*}{ FATO } & \multirow{2}{*}{$\begin{array}{l}\text { Pré- } \\
\text { operatório(1) } \\
(\mathrm{cm})\end{array}$} & \multirow{2}{*}{$\begin{array}{c}\text { Pós- } \\
\text { operatório (1) } \\
\text { (cm) }\end{array}$} & \multirow{2}{*}{$\begin{array}{c}\text { Média da } \\
\text { diferença } \\
(\mathrm{cm})\end{array}$} & \multicolumn{2}{|c|}{ IC 95\% ${ }^{(2)}$} & \multirow{2}{*}{$\begin{array}{c}\text { Valor de } \\
p\end{array}$} \\
\hline & & & & $\begin{array}{l}\text { Limite } \\
\text { inf. }^{(3)}\end{array}$ & $\begin{array}{l}\text { Limite } \\
\text { sup. }{ }^{(4)}\end{array}$ & \\
\hline $\begin{array}{l}\text { Geral } \\
\text { Idade (anos) }\end{array}$ & $124,1 \pm 1,3$ & & & 22,0 & 25,9 & $<0,001$ \\
\hline$<3$ & 128, & 99 & & 26,2 & 33,0 & \\
\hline & 124 & & & 22,7 & 28,4 & $<0,001$ \\
\hline $40 \mathrm{e}$ & $123,1 \pm 2$ & $100,1 \pm 2,5$ & 23 , & 20,1 & 25,9 & $<0,001$ \\
\hline & $120,3 \pm 2,0$ & $100,6 \pm 2,8$ & 19,7 & 16,0 & 22,4 & $<0,001$ \\
\hline
\end{tabular}

${ }^{(1)}$ Os valores estão colocados como média e erro padrão da média. (2) Intervalo de $95 \%$ de confiança para a diferença entre as médias do préoperatório e pós-operatório. ${ }^{(3)}$ Limite inferior do intervalo de confiança. ${ }^{(4)}$ Limite superior do intervalo de confiança. ${ }^{(5)}$ Indica menor que 30 anos. ${ }^{(6)}$ Indica maior ou igual a 50 anos.

\subsection{Variabilidade da freqüência cardíaca.}

Foi possível a análise da variabilidade da freqüência cardíaca, antes e seis meses após a cirurgia, em 68 pacientes. Uma paciente recusou-se a submeter-se à gravação do eletrocardiograma de 24 horas após a cirurgia e dois outros não apresentaram exames com boa qualidade. 
Quanto ao intervalo NN médio, as estatísticas descritivas dispostas de forma geral e de acordo com sexo, idade, pressão arterial e uso de medicação anti-hipertensiva, sugeriram aumento do valor desta variável no período de tempo entre o pré-operatório e seis meses após a cirurgia (Tabela 7), indicando redução da freqüência sinusal média.

O intervalo NN médio foi menor nos pacientes mais jovens $(p=0,003)$, indicando que eles apresentaram freqüência sinusal média mais elevada. Os fatores sexo, pressão arterial e uso de medicação anti-hipertensiva não apresentaram efeito significativo.

A comparação entre as duas fases do estudo mostrou que o aumento do intervalo NN médio, sugerido na análise descritiva, foi significativo, indicando redução significativa da freqüência sinusal média. A média no préoperatório foi $732 \mathrm{~ms}$, com erro padrão da média de $11 \mathrm{~ms}$. Seis meses após a cirurgia a média foi de $831 \mathrm{~ms}$, com erro padrão de $13 \mathrm{~ms}$. O intervalo de confiança de $95 \%$ para a diferença encontrada apresentou limite inferior de $82 \mathrm{~ms}$ e superior de $116 \mathrm{~ms}$. O valor de $\mathrm{p}$ foi menor que 0,001 . Não houve diferença de evolução entre os sexos e entre as faixas etárias. 
Tabela 7 - Estatísticas descritivas para o intervalo NN médio

\begin{tabular}{|c|c|c|c|c|c|c|c|c|}
\hline \multirow{2}{*}{\multicolumn{2}{|c|}{$\begin{array}{l}\text { FATORES } \\
\text { ANALISADOS }\end{array}$}} & \multirow{2}{*}{ Tempo } & \multicolumn{5}{|c|}{$\begin{array}{c}\text { INTERVALO NN MÉDIO } \\
\text { (milissegundos) }\end{array}$} & \multirow[t]{2}{*}{$\mathrm{N}^{(1)}$} \\
\hline & & & Menor & Mediana & Maior & Média & $\begin{array}{l}\text { Desvio- } \\
\text { padrão }\end{array}$ & \\
\hline Geral & & $\begin{array}{l}\text { Pré( } \\
\text { Pós }^{(3)}\end{array}$ & $\begin{array}{l}598 \\
667\end{array}$ & $\begin{array}{l}708 \\
82 ?\end{array}$ & $\begin{array}{c}987 \\
1040\end{array}$ & $\begin{array}{l}723 \\
821\end{array}$ & $\begin{array}{l}73 \\
78\end{array}$ & $\begin{array}{l}68 \\
68\end{array}$ \\
\hline \multirow[t]{4}{*}{ Sexo } & Feminino & Pré & 598 & 728 & 874 & 733 & 67 & 40 \\
\hline & & & 667 & 825 & 983 & 821 & 74 & 40 \\
\hline & Masculino & Pré & 602 & 699 & 987 & 709 & 79 & 28 \\
\hline & iviascuminto & Pós & 672 & 806 & 1040 & 820 & 84 & 28 \\
\hline \multirow{8}{*}{$\begin{array}{l}\text { Faixa etária } \\
\text { (anos) }\end{array}$} & Menos de & Pré & 643 & 693 & 774 & 694 & 36 & 19 \\
\hline & & Pós & 692 & 782 & 902 & 788 & 55 & 19 \\
\hline & 30 a 39 & Pré & 602 & 708 & 987 & 724 & 83 & 25 \\
\hline & & Pós & 667 & 829 & 952 & 827 & 74 & \\
\hline & $10=10$ & Pré & 598 & 734 & 820 & 720 & 76 & 14 \\
\hline & 40 a 49 & Pós & 672 & 828 & 1040 & 827 & 103 & 14 \\
\hline & 50 ou mais & is Pré & 669 & 796 & 874 & 779 & 66 & 10 \\
\hline & & & & & & & & \\
\hline \multirow{4}{*}{$\begin{array}{l}\text { Pressão arteria } \\
(\mathrm{mm} \mathrm{Hg})\end{array}$} & $<140 / 90^{(4)}$ & Pré & 598 & 708 & 987 & 722 & 74 & 57 \\
\hline & $<140 / 90$ & Pós & 667 & 816 & 983 & 813 & 73 & 58 \\
\hline & $>140 / 90^{(5)}$ & Pré & 619 & 703 & 829 & 730 & 70 & 11 \\
\hline & $\geq 140 / 90$ & Pós & 745 & 852 & 1040 & 868 & 91 & 10 \\
\hline \multirow{4}{*}{$\begin{array}{l}\text { Medicação ant } \\
\text { hipertensiva }\end{array}$} & i- Não & Pré & 635 & 708 & 857 & 718 & 52 & 44 \\
\hline & Nao & Pós & 667 & 822 & 1040 & 819 & 75 & 62 \\
\hline & Sim & Pré & 598 & 716 & 987 & 732 & 101 & 24 \\
\hline & SIII & Pós & 705 & 814 & 983 & 839 & 108 & 6 \\
\hline
\end{tabular}

\subsubsection{SDNN}

A observação das estatísticas descritivas indicou aumento do índice SDNN entre o pré-operatório e seis meses após a cirurgia (Tabela 8). 
Tabela 8 - Estatísticas descritivas para o índice SDNN

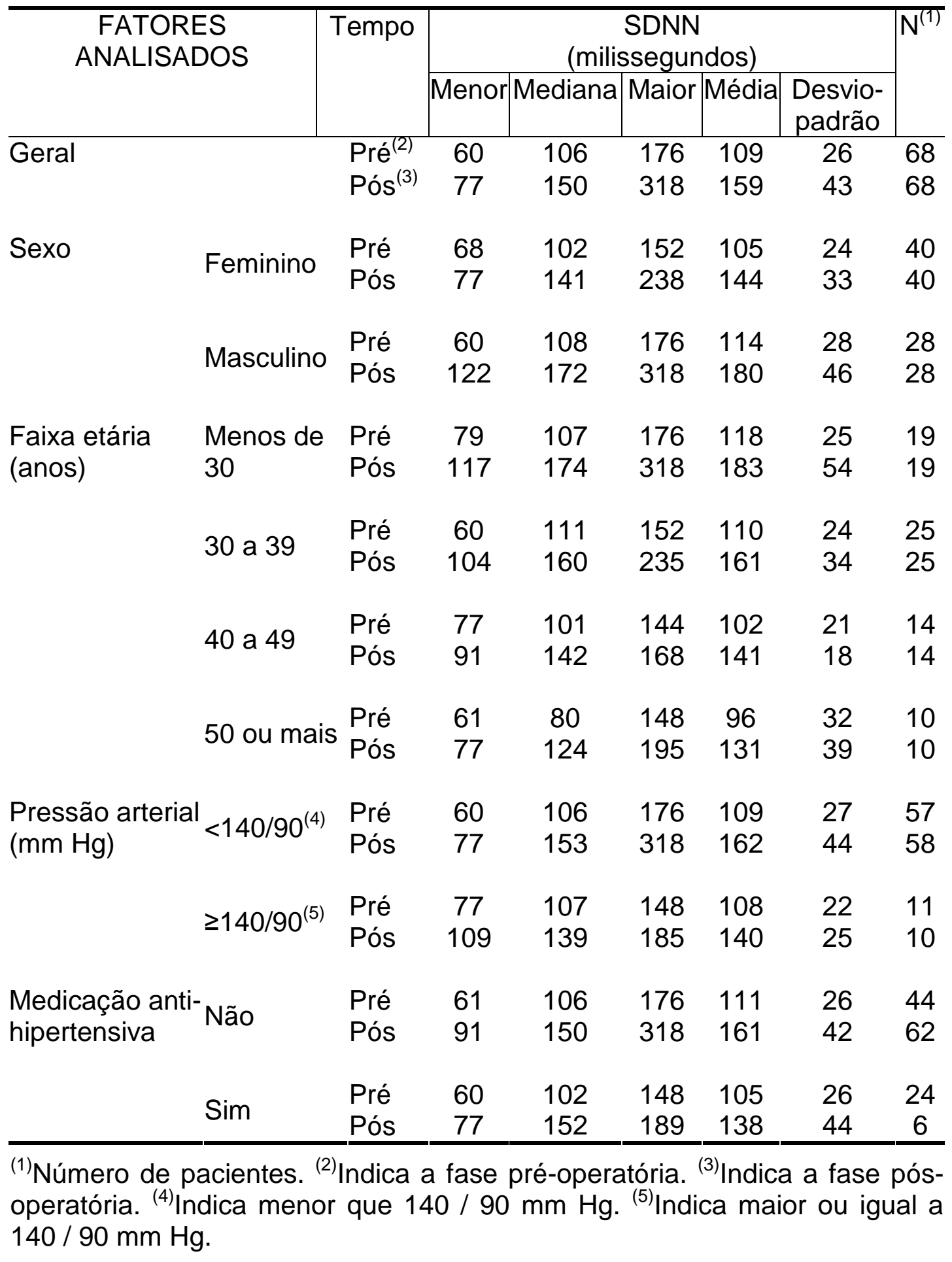

A análise mostrou que o efeito do fator sexo foi significativo, com valores maiores do SDNN para o sexo masculino em relação ao feminino ( $p$ $=0,006)$. O fator idade também foi significativo, com valores mais elevados 
entre os mais jovens $(p=0,029)$. A freqüência cardíaca apresentou igualmente efeito significativo ( $p<0,001$ ), indicando que o aumento da freqüência influenciou no sentido de reduzir o valor do SDNN. A pressão arterial e o uso de medicação anti-hipertensiva não apresentaram efeito significativo.

O cálculo da diferença entre o pré-operatório e seis meses após a cirurgia mostrou que o aumento do SDNN sugerido pelo análise descritiva foi significativo. A diferença entre os sexos, que não foi significativa antes da cirurgia ( $p=0,180)$, tornou-se significativa na fase pós-operatória ( $p=$ 0,001), evidenciando que a evolução não foi igual para homens e mulheres (Tabela 9). Os homens apresentaram aumento maior do SDNN ao longo do tempo $(p=0,006)$ (Figura 13). Com relação à idade, não houve diferença de evolução entre as faixas etárias durante o período de acompanhamento.

Tabela 9 - Comparação do SDNN entre as fases pré e pós-operatória de forma geral e de acordo com o fator sexo

\begin{tabular}{|c|c|c|c|c|c|c|}
\hline \multirow[t]{2}{*}{ FATORES } & \multirow{2}{*}{$\begin{array}{l}\text { Pré- } \\
\text { operatório }^{(1)} \\
(\mathrm{ms})\end{array}$} & \multirow{2}{*}{$\begin{array}{l}\text { Pós- } \\
\text { operatório }^{(1)} \\
\text { (ms) }\end{array}$} & \multirow{2}{*}{$\begin{array}{c}\text { Média da } \\
\text { diferença } \\
\text { (ms) }\end{array}$} & \multicolumn{2}{|c|}{ IC 95\%(2) } & \multirow{2}{*}{$\begin{array}{c}\text { Valor de } \\
\text { p }\end{array}$} \\
\hline & & & & $\begin{array}{l}\text { Limite } \\
\text { inf. }{ }^{(3)}\end{array}$ & $\begin{array}{l}\text { Limite } \\
\text { sup. }^{(4)}\end{array}$ & \\
\hline & & & & & 1 & \\
\hline
\end{tabular}

Sexo

$\begin{array}{lllllll}\text { Feminino } & 111 \pm 4 & 134 \pm 6 & 23 & 15 & 31 & <0,001 \\ \text { Masculino } & 120 \pm 6 & 163 \pm 7 & 43 & 31 & 56 & <0,001\end{array}$

${ }^{(1)}$ Os valores estão colocados como média e erro padrão da média. ${ }^{(2)}$ Intervalo de $95 \%$ de confiança para a diferença entre as médias do préoperatório e pós-operatório. ${ }^{(3)}$ Limite inferior do intervalo de confiança.

(4) Limite superior do intervalo de confiança. 
Figura 13 - Gráfico da evolução do índice SDNN conforme os sexos

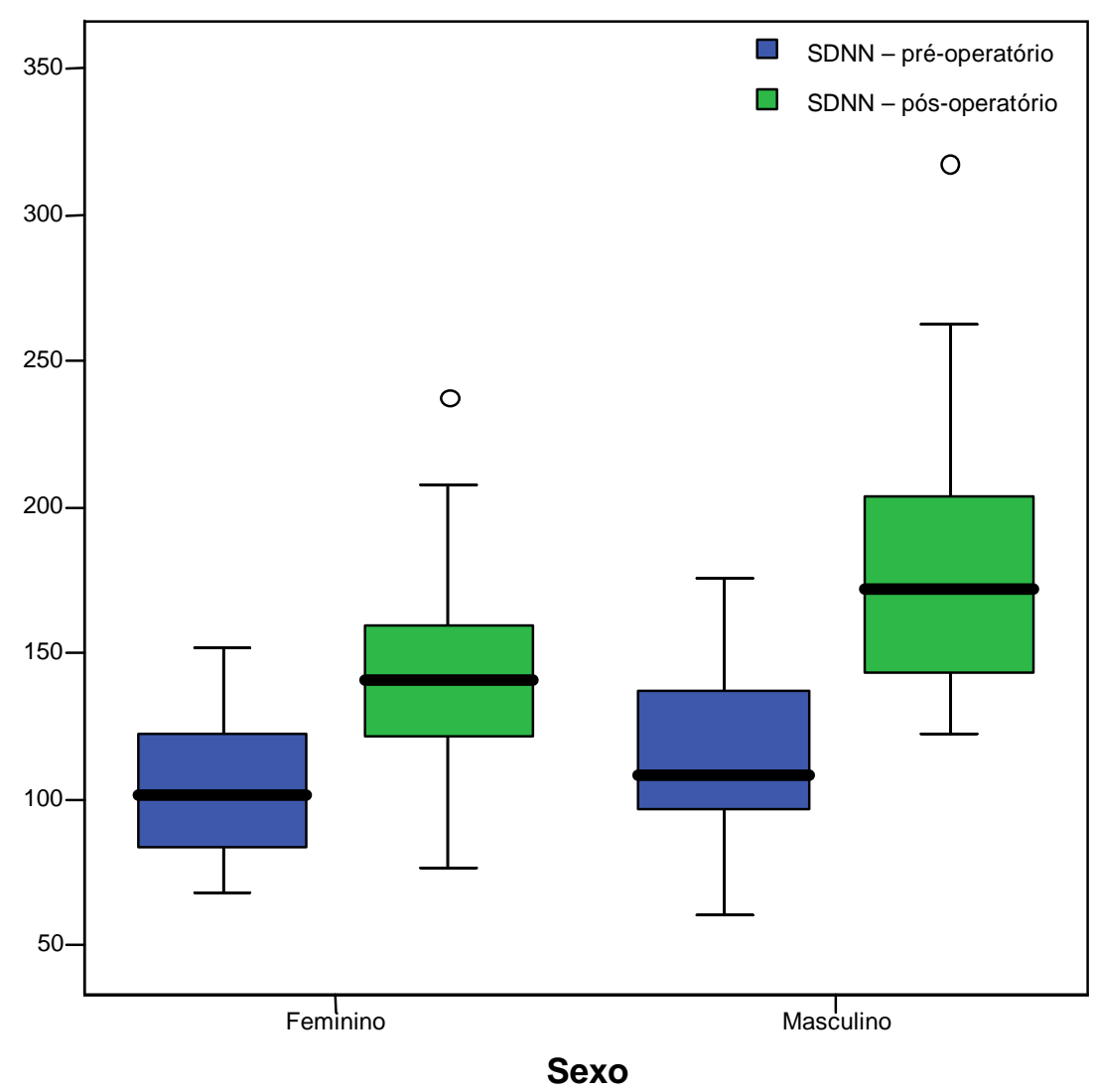

Gráfico de caixas mostrando os valores do SDNN conforme os sexos, nas fases pré e pós-operatória.

As caixas representam $50 \%$ dos valores encontrados, seus limites superiores representam o percentil 75 e os inferiores o percentil 25. O traço horizontal no meio da caixa representa a mediana. Os traços verticais indicam o intervalo entre os valores mais baixos e mais altos. Os pequenos círculos representam valores extremos (ou estranhos), maiores que uma vez e meia a altura da caixa.

\subsubsection{SDANN}

As estatísticas descritivas indicaram aumento dos valores após a cirurgia (Tabela 10). 
Tabela 10 - Estatísticas descritivas para o índice SDANN

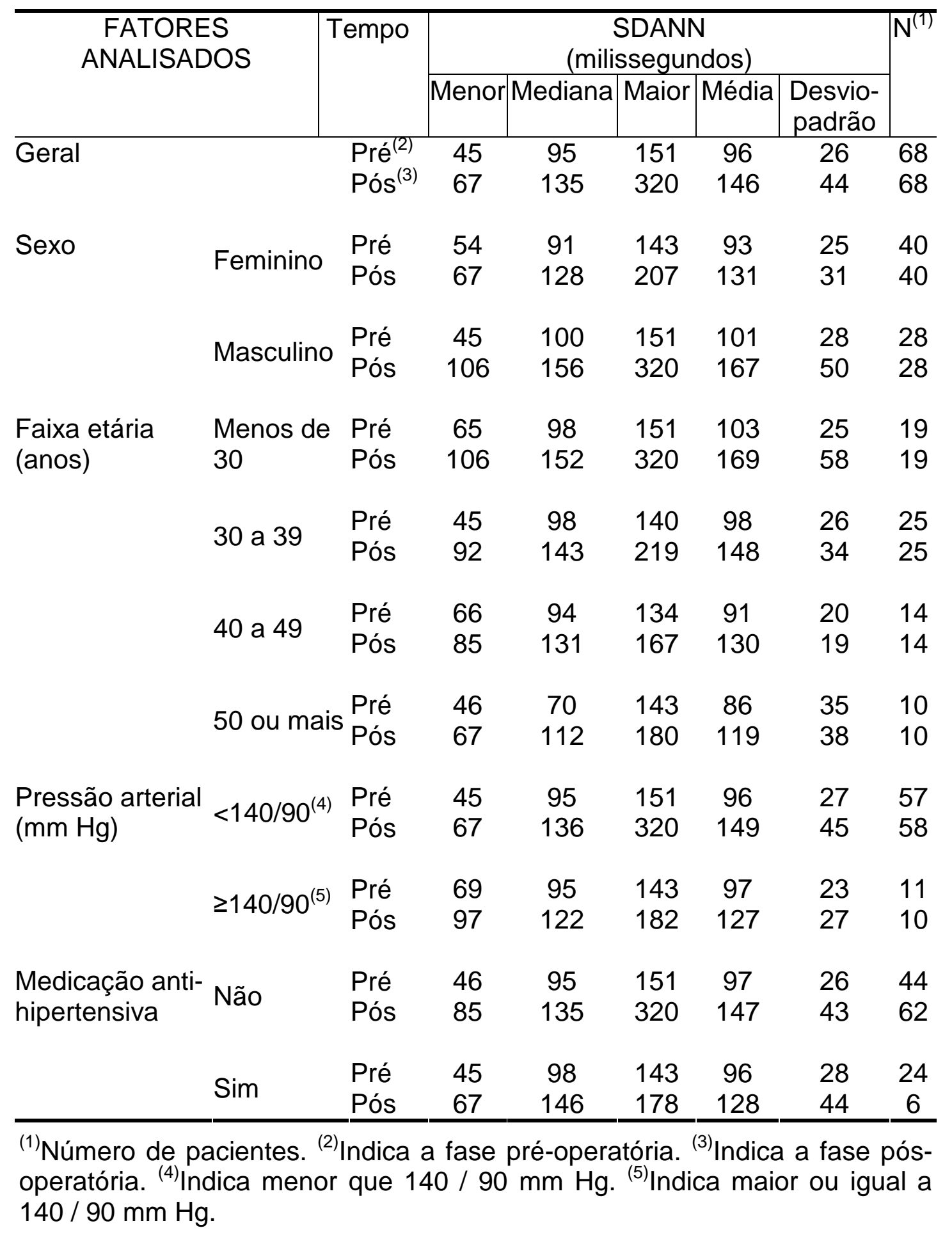

O fator sexo apresentou efeito significativo, com maior valor de SDANN para os homens $(p=0,010)$. A freqüência cardíaca também foi fator significativo $(p<0,001)$, indicando que o aumento da freqüência cardíaca 
contribuiu para a redução do SDANN. Os fatores idade, pressão arterial e uso de medicação anti-hipertensiva não foram significativos.

A análise do período de tempo entre o pré-operatório e seis meses após a cirurgia mostrou que o aumento sugerido pelas estatísticas descritivas foi significativo. Antes da cirurgia não houve diferença entre os sexos $(p=0,259)$ e após a cirurgia a diferença tornou-se significativa ( $p=$ 0,001 ), mostrando que a evolução não foi igual para ambos os sexos (Tabela 11). Os homens apresentaram maior elevação do SDANN ao longo do tempo, em comparação com as mulheres $(p=0,007)$ (Figura 14). Não houve diferença de evolução entre as faixas etárias durante o período de acompanhamento.

Tabela 11 - Comparação do SDANN entre o pré e o pós-operatório de forma geral e de acordo com o fator sexo

\begin{tabular}{|c|c|c|c|c|c|c|}
\hline \multirow[t]{2}{*}{ FATORES } & \multirow{2}{*}{$\begin{array}{l}\text { Pré- } \\
\text { operatório( }^{(1)} \\
(\mathrm{ms})\end{array}$} & \multirow{2}{*}{$\begin{array}{l}\text { Pós- } \\
\text { operatório(1) } \\
\text { (ms) }\end{array}$} & \multirow{2}{*}{$\begin{array}{c}\text { Média da } \\
\text { diferença } \\
\text { (ms) }\end{array}$} & \multicolumn{2}{|c|}{ IC 95\% ${ }^{(2)}$} & \multirow{2}{*}{$\begin{array}{l}\text { Valor de } \\
\text { p }\end{array}$} \\
\hline & & & & $\begin{array}{l}\text { Limite } \\
\text { inf. }{ }^{(3)}\end{array}$ & $\begin{array}{l}\text { Limite } \\
\text { sup. }(4)\end{array}$ & \\
\hline $\begin{array}{l}\text { Geral } \\
\text { Sexo }\end{array}$ & $102 \pm 4$ & $139 \pm 5$ & 37 & 28 & 46 & $<0,001$ \\
\hline Feminino & $98 \pm 5$ & $124 \pm 6$ & 26 & 17 & 35 & $<0,001$ \\
\hline Masculino & $107 \pm 6$ & $155 \pm 8$ & 48 & 34 & 62 & $<0,001$ \\
\hline
\end{tabular}


Figura 14 - Gráfico da evolução do índice SDANN conforme os sexos

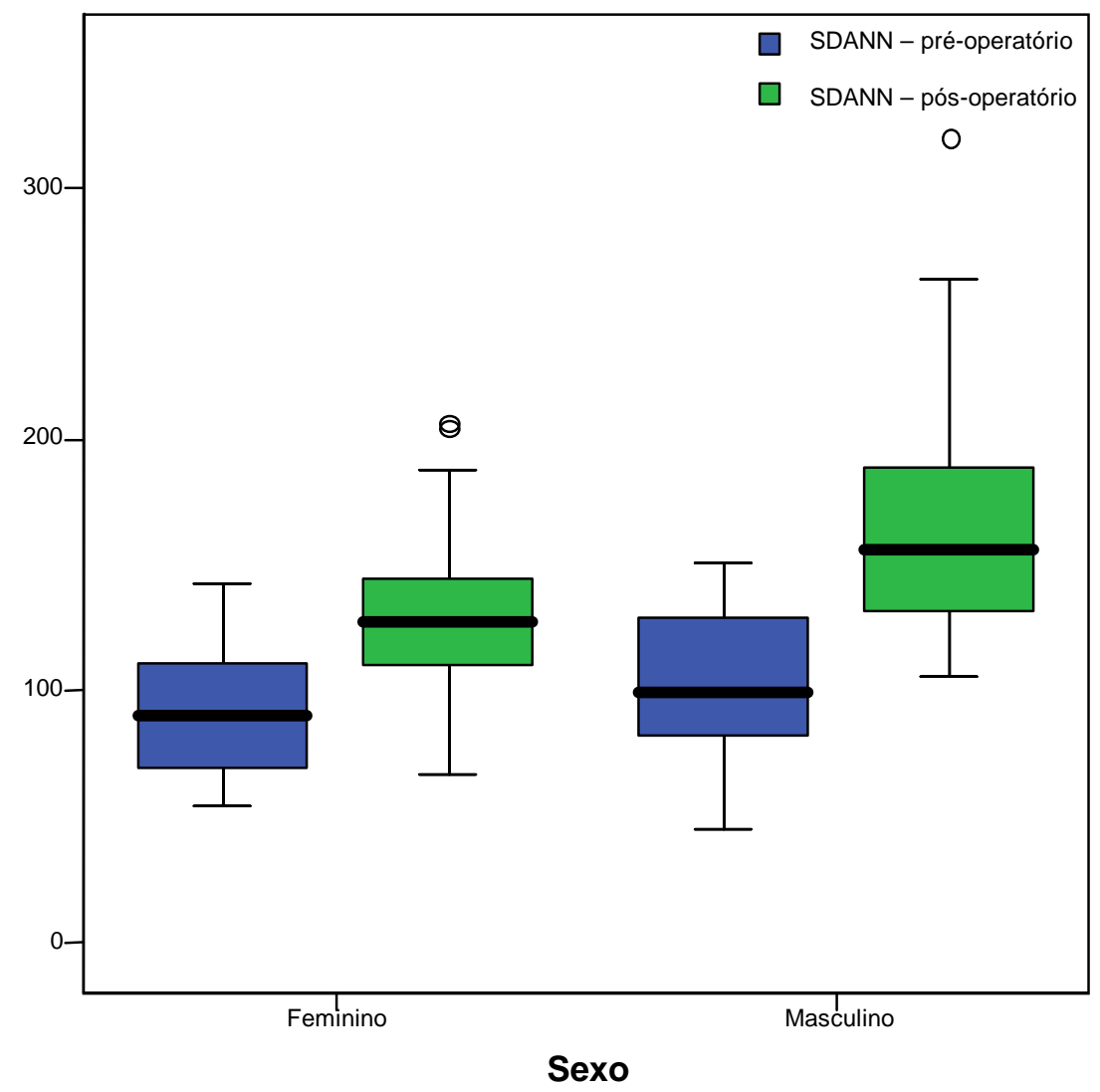

Gráfico de caixas mostrando os valores do SDANN conforme os sexos, nas fases pré e pós-operatória.

As caixas representam $50 \%$ dos valores encontrados, seus limites superiores representam o percentil 75 e os inferiores o percentil 25 . O traço horizontal no meio da caixa representa a mediana. Os traços verticais indicam o intervalo entre os valores mais baixos e mais altos. Os pequenos círculos representam valores extremos (ou estranhos), maiores que uma vez e meia a altura da caixa.

\subsubsection{SDNN index}

As estatísticas descritivas também sugerem aumento do SDNN index após a cirurgia (Tabela 12). 
Tabela 12 - Estatísticas descritivas para o SDNN index

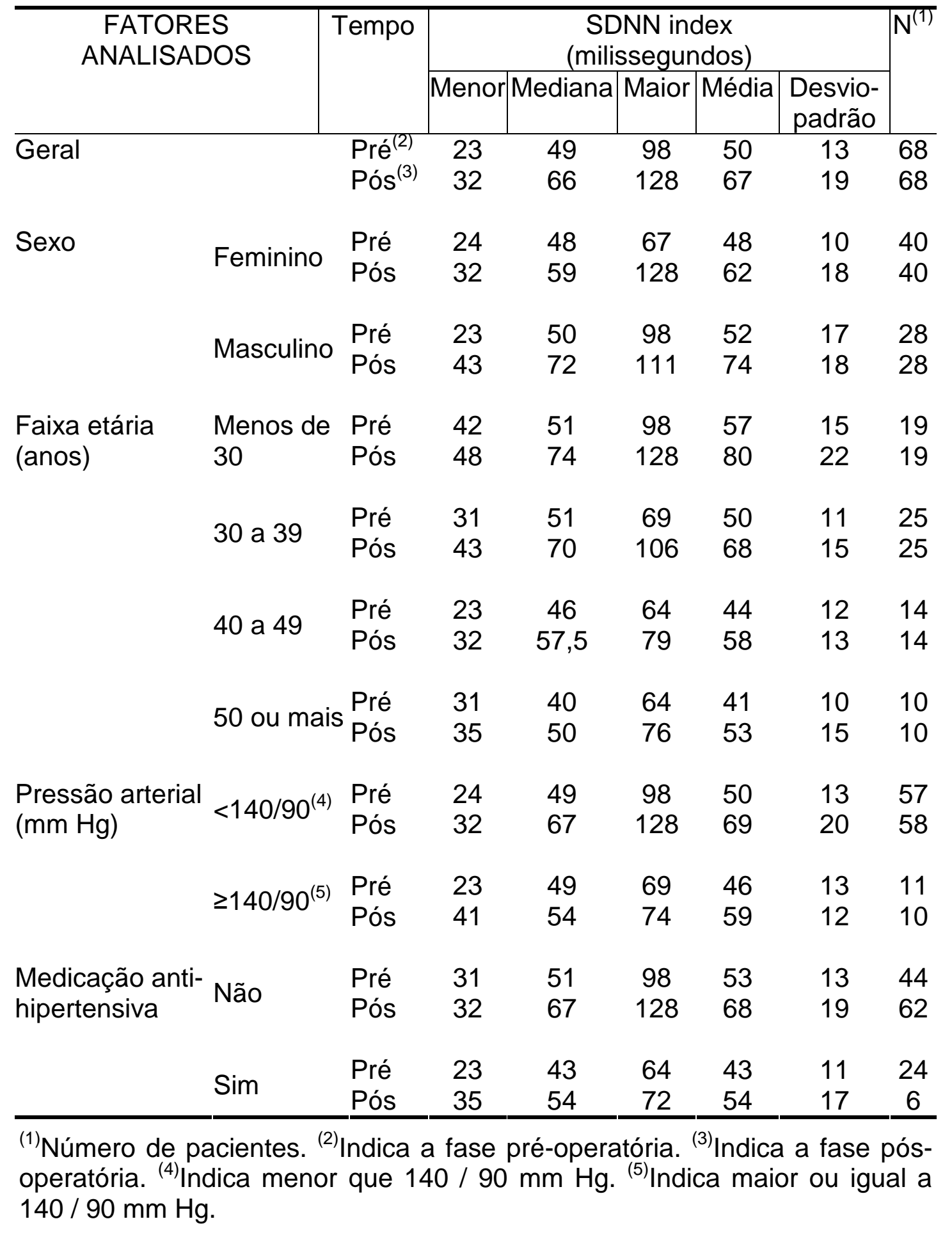

Os fatores idade, pressão arterial, uso de medicação anti-hipertensiva e freqüência cardíaca apresentaram efeito significativo. Os mais jovens apresentaram maior valor em relação aos com mais idade $(p<0,001)$. Os 
pacientes com pressão menor que 140 / 90 mm Hg apresentaram maior valor em relação aos com pressão arterial elevada $(p=0,006)$. Aqueles que não usavam medicação anti-hipertensiva apresentaram maior valor do índice em relação aos que usavam $(p=0,010)$. O aumento da freqüência cardíaca influenciou no sentido de redução do SDNN index $(p<0,001)$. O fator sexo não foi significativo.

A análise do período de acompanhamento entre as duas fases do estudo demonstrou que o aumento sugerido pela análise descritiva foi significativo. Não houve diferença de evolução entre homens e mulheres. Quanto à idade, os mais jovens apresentaram aumento significativo, enquanto que para os demais o aumento foi progressivamente menor com o avanço da idade, não apresentando diferença estatisticamente significativa (Tabela 13). Estes resultados mostraram que a evolução foi diferente para as faixas etária $(p=0,015)$ (Figura 15).

Tabela 13 - Comparação do SDNN index entre as fases pré e pós-operatória de forma geral e em relação ao fator idade

\begin{tabular}{|c|c|c|c|c|c|c|}
\hline \multirow[t]{2}{*}{ FATORES } & \multirow{2}{*}{$\begin{array}{l}\text { Pré- } \\
\text { operatório } \\
\text { (1) }\end{array}$} & \multirow{2}{*}{$\begin{array}{l}\text { Pós- } \\
\text { operatório }^{(1)} \\
\text { (ms) }\end{array}$} & \multirow{2}{*}{$\begin{array}{c}\text { Média da } \\
\text { diferença } \\
\text { (ms) }\end{array}$} & \multicolumn{2}{|c|}{ IC 95\% ${ }^{(2)}$} & \multirow{2}{*}{$\begin{array}{c}\text { Valor de } \\
\text { p }\end{array}$} \\
\hline & & & & $\begin{array}{l}\text { Limite } \\
\text { inf. }{ }^{(3)}\end{array}$ & $\begin{array}{l}\text { Limite } \\
\text { sup. }\end{array}$ & \\
\hline $\begin{array}{l}\text { Geral } \\
\text { Idade (anos) }\end{array}$ & $50 \pm 2$ & $55 \pm 1$ & 5 & 2 & 8 & 0,002 \\
\hline$<30^{(5)}$ & $59 \pm 3$ & $71 \pm 4$ & 12 & 6 & 17 & $<0,001$ \\
\hline 30 a 39 & $55 \pm 2$ & $59 \pm 3$ & 5 & (1) & 10 & 0,101 \\
\hline 40 a 49 & $47 \pm 2$ & $49 \pm 2$ & 1 & (3) & 6 & 0,533 \\
\hline$\geq 50^{6}$ & $41 \pm 2$ & $43 \pm 3$ & 2 & (1) & 6 & 0,170 \\
\hline
\end{tabular}

${ }^{(1)}$ Os valores estão colocados como média e erro padrão da média. ${ }^{(2)}$ Intervalo de $95 \%$ de confiança para a diferença entre as médias do préoperatório e pós-operatório. ${ }^{(3)}$ Limite inferior do intervalo de confiança. (4) Limite superior do intervalo de confiança. ${ }^{(5)}$ Indica menor que 30 anos. ${ }^{(6)}$ Indica maior ou igual a 50 anos. Os dados entre parênteses indicam valores negativos. 
Figura 15 - Gráfico da evolução do SDNN index conforme as faixas de idade

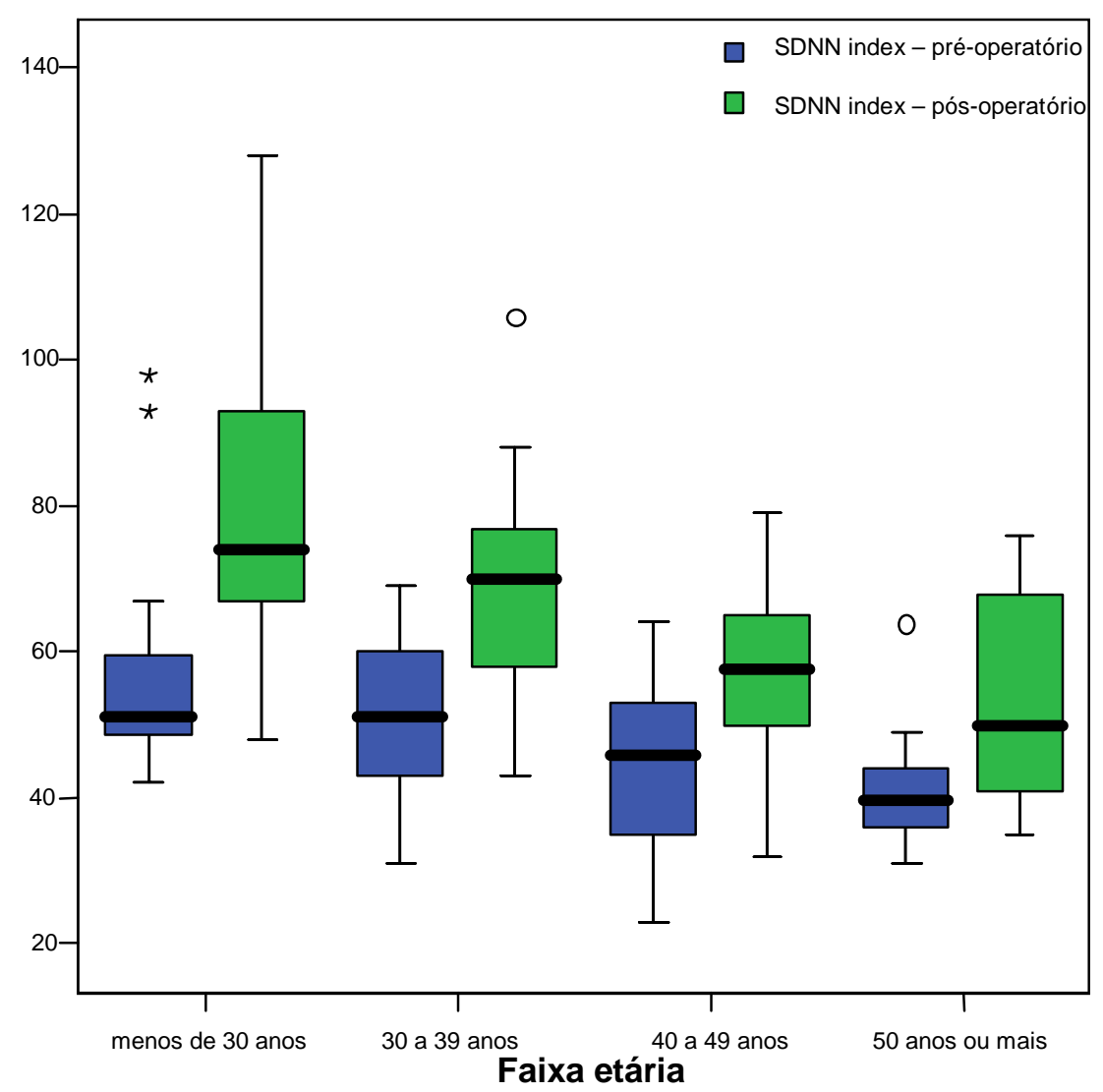

Gráfico de caixas mostrando os valores do SDNN index conforme as faixas de idade, nas fases pré e pós-operatória.

As caixas representam $50 \%$ dos valores encontrados, seus limites superiores representam o percentil 75 e os inferiores o percentil 25. O traço horizontal no meio da caixa representa a mediana. Os traços verticais indicam o intervalo entre os valores mais baixos e mais altos. Os pequenos círculos representam valores extremos (ou estranhos), maiores que uma vez e meia a altura da caixa. Os asteriscos representam valores extremos, maiores que três vezes a altura da caixa.

\subsection{4 pNN50}

As estatísticas descritivas para o índice pNN50 também sugerem aumento após a cirurgia (Tabela 14). 
Tabela 14 - Estatísticas descritivas para o índice pNN50

\begin{tabular}{|c|c|c|c|c|c|c|c|c|}
\hline \multirow{2}{*}{\multicolumn{2}{|c|}{$\begin{array}{r}\text { FATORES } \\
\text { ANALISADO }\end{array}$}} & \multirow{2}{*}{ Tempo } & \multicolumn{5}{|c|}{$\begin{array}{c}\text { PNN50 } \\
(\%)\end{array}$} & \multirow[t]{2}{*}{$\mathrm{N}^{(1)}$} \\
\hline & & & & & Maior & Média & $\begin{array}{l}\text { Desvio- } \\
\text { padrão }\end{array}$ & \\
\hline Geral & & $\begin{array}{l}\text { Préé(z) } \\
D^{\prime}(3)\end{array}$ & 0,10 & 4,88 & 35,20 & 6,92 & 6,68 & 68 \\
\hline \multirow{4}{*}{ Sexo } & & Pré & 0,10 & 4,91 & 23,17 & 6,83 & 5,90 & 40 \\
\hline & reminino & Pós & 0,61 & 12,17 & 39,16 & 13,68 & 9,53 & 40 \\
\hline & Masculino & Pré & 0,10 & 4,88 & 35,20 & 7,04 & 7,77 & 28 \\
\hline & iviascuminto & Pós & 1,37 & 15,69 & 35,87 & 15,45 & 8,89 & 28 \\
\hline \multirow{8}{*}{$\begin{array}{l}\text { Faixa etária } \\
\text { (anos) }\end{array}$} & Menos de & Pré & 1,04 & 6,22 & 35,20 & 9,05 & 8,86 & 19 \\
\hline & & Pós & 3,16 & 18,85 & 39,16 & 18,56 & 10,60 & 19 \\
\hline & 30 a 39 & Pré & 0,65 & 5,06 & 23,17 & 6,95 & 5,56 & 25 \\
\hline & & Pos & 1,37 & 15,47 & 32,43 & 15,89 & & \\
\hline & $10=19$ & Pré & 0,10 & 3,64 & 13,74 & 4,92 & 4,34 & 14 \\
\hline & 40 a 49 & Pós & 0,61 & 8,86 & 25,17 & 11,43 & 7,51 & 14 \\
\hline & 50 o mais & Pré & 0,18 & 1,86 & 19,08 & 5,57 & 6,90 & 10 \\
\hline & 50 ou mille & Pós & 1,26 & 5,64 & 19,43 & 7,00 & 6,43 & 10 \\
\hline \multirow{4}{*}{$\begin{array}{l}\text { Pressão arterial } \\
(\mathrm{mm} \mathrm{Hg})\end{array}$} & $140 / 90^{(4)}$ & Pré & 0,10 & 5,06 & 35,20 & 7,28 & 6,89 & 57 \\
\hline & & Pós & 0,61 & 15,25 & 39,16 & 15,30 & 9,43 & 58 \\
\hline & $\geq 140 / 90^{(5)}$ & Pré & 0,10 & 4,75 & 19,08 & 5,01 & 5,33 & 11 \\
\hline & & POS & 1,46 & 9,39 & 21,14 & 9,25 & 6,22 & 10 \\
\hline \multirow{4}{*}{$\begin{array}{l}\text { Medicação anti } \\
\text { hipertensiva }\end{array}$} & $n$ & Pré & 0,18 & 5,63 & 35,20 & 7,47 & 7,06 & 44 \\
\hline & & Pós & 0,61 & 14,37 & 39,16 & 15,16 & 9,19 & 62 \\
\hline & $\operatorname{sim}$ & Pré & 0,10 & 4,21 & 19,08 & 5,89 & 5,91 & 24 \\
\hline & & Pós & 2 & & 15,47 & 6,68 & 6,00 & 6 \\
\hline
\end{tabular}

(1) Número de pacientes. ${ }^{(2)}$ Indica fase pré-operatória. ${ }^{(3)}$ Indica fase pósoperatória. ${ }^{(4)}$ Indica menor que $140 / 90 \mathrm{~mm} \mathrm{Hg} .{ }^{(5)}$ Indica maior ou igual a 140 / $90 \mathrm{~mm} \mathrm{Hg}$.

Os fatores sexo, idade, pressão arterial e freqüência cardíaca apresentaram efeito significativo. Os homens apresentaram maior valor do que as mulheres $(p=0,013)$. Os mais jovens apresentaram maior valor em 
relação aos com mais idade $(p<0,001)$. Os pacientes com pressão arterial menor que 140 / 90 mm Hg apresentaram maior valor em relação àqueles com pressão arterial mais elevada $(p<0,001)$. Quanto à freqüência cardíaca, seu aumento influiu na redução da pNN50 ( $p<0,001)$. O fator medicação anti-hipertensiva não foi significativo.

A análise do período de acompanhamento mostrou que o aumento sugerido pelas estatísticas descritivas foi significativo. A média do pNN50 no pré-operatório foi $8,00 \%$, com erro padrão da média de $0,81 \%$. Seis meses após a cirurgia a média foi $10,42 \%$, com erro padrão da média de $0,84 \%$. O intervalo de confiança de $95 \%$ para a diferença encontrada apresentou limite inferior de $1,05 \%$ e superior de 3,81\%. O valor de $p$ foi igual a 0,001 .

A evolução não foi diferente para os sexos. Quanto à idade, embora os dados tenham sugerido aumento progressivamente menor com o avanço da idade, características próprias da variável não permitiram que o modelo estatístico afirmasse esta característica (Figura 16). 
Figura 16 - Gráfico da evolução da variável pNN50 conforme as faixas etárias

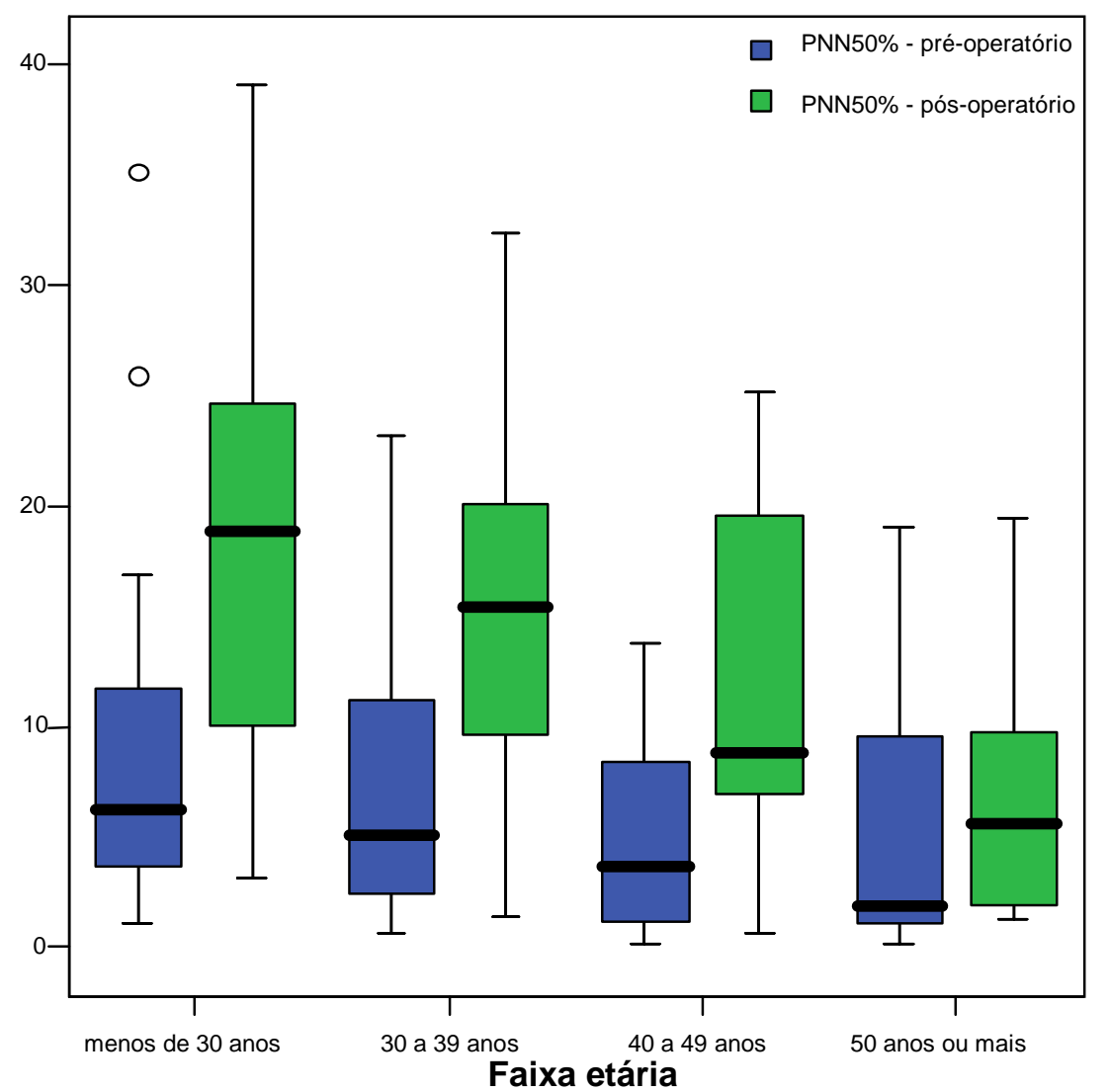

Gráfico de caixas mostrando os valores do pNN50 conforme as faixas de idade, nas fases pré e pós-operatória.

As caixas representam $50 \%$ dos valores encontrados, seus limites superiores representam o percentil 75 e os inferiores o percentil 25. O traço horizontal no meio da caixa representa a mediana. Os traços verticais indicam o intervalo entre os valores mais baixos e mais altos. Os pequenos círculos representam valores extremos (ou estranhos), maiores que uma vez e meia a altura da caixa.

\subsection{5 rMSSD}

As estatísticas descritivas para o índice rMSSD também sugeriram aumento após a cirurgia (Tabela 15). 
Tabela 15 - Estatísticas descritivas para o índice rMSSD

\begin{tabular}{|c|c|c|c|c|c|c|c|c|}
\hline \multirow{2}{*}{\multicolumn{2}{|c|}{$\begin{array}{l}\text { FATORES } \\
\text { ANALISADOS }\end{array}$}} & \multirow{4}{*}{$\begin{array}{c}\text { Tempo } \\
\text { Pré(2) } \\
\text { Pós }^{(3)}\end{array}$} & \multicolumn{5}{|c|}{$\begin{array}{c}\text { rMSSD } \\
\text { (milissegundos) }\end{array}$} & \multirow[t]{2}{*}{$N^{(1)}$} \\
\hline & & & Menor & Mediana & Maior & \multicolumn{2}{|c|}{$\begin{array}{l}\text { Média } \begin{array}{l}\text { Desvio } \\
\text { padrão }\end{array}\end{array}$} & \\
\hline Geral & & & 10 & 27 & 95 & 30 & 16 & 68 \\
\hline & & & 14 & 41 & 115 & 44 & 21 & 68 \\
\hline \multirow[t]{4}{*}{ Sexo } & Fominin & Pré & 10 & 28 & 62 & 30 & 13 & 40 \\
\hline & reminino & Pós & 14 & 39 & 115 & 42 & 21 & 40 \\
\hline & & Pré & 10 & 26 & 95 & 30 & 19 & 28 \\
\hline & IMasculino & Pós & 17 & 43 & 99 & 47 & 21 & 28 \\
\hline \multirow{8}{*}{$\begin{array}{l}\text { Faixa etária } \\
\text { (anos) }\end{array}$} & Menos de & Pré & 16 & 30 & 95 & 37 & 21 & 19 \\
\hline & & Pós & 24 & 51 & 115 & 58 & 28 & 19 \\
\hline & 30 a 39 & Pré & 11 & 31 & 60 & 30 & 12 & 25 \\
\hline & & Pós & 17 & 43 & 75 & 44 & 14 & 25 \\
\hline & & Pré & 10 & 22 & 38 & 24 & 10 & 14 \\
\hline & 40 a 49 & Pós & 14 & 32 & 72 & 36 & 15 & 14 \\
\hline & 50 u maic & ic Pré & 11 & 21 & 62 & 26 & 15 & 10 \\
\hline & 50 ou mals & IS Pós & 19 & 26 & 71 & 31 & 16 & 10 \\
\hline \multirow{4}{*}{$\begin{array}{l}\text { Pressão arterial } \\
(\mathrm{mm} \mathrm{Hg})\end{array}$} & $<140 / 90^{(4)}$ & ) Pré & 10 & 27 & 95 & 31 & 16 & 57 \\
\hline & $<140 / 90$ & Pós & 14 & 43 & 115 & 47 & 22 & 58 \\
\hline & $\geq 140 / 90^{(5)}$ & ) Pré & 10 & 27 & 62 & 28 & 15 & 11 \\
\hline & & & & & & & & \\
\hline \multirow{4}{*}{$\begin{array}{l}\text { Medicação anti- } \\
\text { hipertensiva }\end{array}$} & ฤว̃ก & Pré & 11 & 28 & 95 & 32 & 16 & 44 \\
\hline & nao & Pós & 14 & 42 & 115 & 45 & 21 & 62 \\
\hline & sim & Pré & 10 & 24 & 62 & 27 & 14 & 24 \\
\hline & गIIII & Pós & 17 & 27 & 72 & 34 & 21 & 6 \\
\hline
\end{tabular}

(1) Número de pacientes. ${ }^{(2)}$ Indica fase pré-operatória. ${ }^{(3)}$ Indica fase pósoperatória. ${ }^{(4)}$ Indica menor que $140 / 90 \mathrm{~mm} \mathrm{Hg} .{ }^{(5)}$ Indica maior ou igual a $140 / 90 \mathrm{~mm} \mathrm{Hg}$.

Os fatores idade, pressão arterial e freqüência cardíaca apresentaram efeito significativo. O mais jovens apresentaram maior valor em relação aos com mais idade $(p<0,001)$. Os pacientes com pressão arterial menor que 
140 / 90 mm Hg apresentaram maior valor em relação aos com pressão arterial mais elevada $(p<0,001)$. O aumento da freqüência cardíaca contribuiu para a redução da rMSSD $(p<0,001)$. Os fatores sexo e uso de medicação anti-hipertensiva não foram significativos.

A análise do período de acompanhamento mostrou que o aumento sugerido pela análise descritiva foi significativo. Não houve diferença de evolução entre os sexos. Quanto à idade, o aumento foi maior para os mais jovens, enquanto que para os demais o aumento foi progressivamente menor com o avanço da idade, não atingindo diferença estatística significativa (Tabela 16), indicando que a evolução foi diferente entre as idades $(p=0,002)$ (Figura 17).

Tabela 16 - Comparação do índice rMSSD entre as fase pré e pós-operatória de forma geral e conforme o fator idade

\begin{tabular}{|c|c|c|c|c|c|c|}
\hline \multirow[t]{2}{*}{ FATORES } & \multirow{2}{*}{$\begin{array}{c}\text { Pré- } \\
\text { operatório } \\
\text { (1) }\end{array}$} & \multirow{2}{*}{$\begin{array}{c}\text { Pós- } \\
\text { operatório }^{(1)} \\
\text { (ms) }\end{array}$} & \multirow{2}{*}{$\begin{array}{c}\text { Média da } \\
\text { diferença } \\
(\mathrm{ms})\end{array}$} & \multicolumn{2}{|c|}{ IC 95\% $\%^{(2)}$} & \multirow{2}{*}{$\begin{array}{c}\text { Valor de } \\
\text { p }\end{array}$} \\
\hline & & & & $\begin{array}{l}\text { Limite } \\
\text { inf. }^{(3)}\end{array}$ & \begin{tabular}{|l|} 
Limite \\
sup.
\end{tabular} & \\
\hline $\begin{array}{l}\text { Geral } \\
\text { ldade (anos) }\end{array}$ & $31 \pm 2$ & $36 \pm 2$ & 5 & 2 & 8 & 0,002 \\
\hline$<30^{(5)}$ & $39 \pm 4$ & $50 \pm 5$ & 11 & 6 & 16 & $<0,001$ \\
\hline 30 a 39 & $33 \pm 2$ & $38 \pm 3$ & 5 & (1) & 11 & 0,119 \\
\hline 40 a 49 & $27 \pm 2$ & $31 \pm 2$ & 3 & (1) & 8 & 0,132 \\
\hline$\geq 50^{(6)}$ & $23 \pm 4$ & $23 \pm 4$ & 0 & (3) & 3 & 0,965 \\
\hline
\end{tabular}

${ }^{(1)}$ Os valores estão colocados como média e erro padrão da média. ${ }^{(2)}$ Intervalo de $95 \%$ de confiança para a diferença entre as médias do préoperatório e pós-operatório. ${ }^{(3)}$ Limite inferior do intervalo de confiança. ${ }^{(4)}$ Limite superior do intervalo de confiança. ${ }^{(5)}$ Indica menor que 30 anos. ${ }^{(6)}$ Indica maior ou igual a 50 anos. Os dados entre parênteses indicam valores negativos. 
Figura 17 - Gráfico da evolução do índice rMSSD conforme as faixas de idade

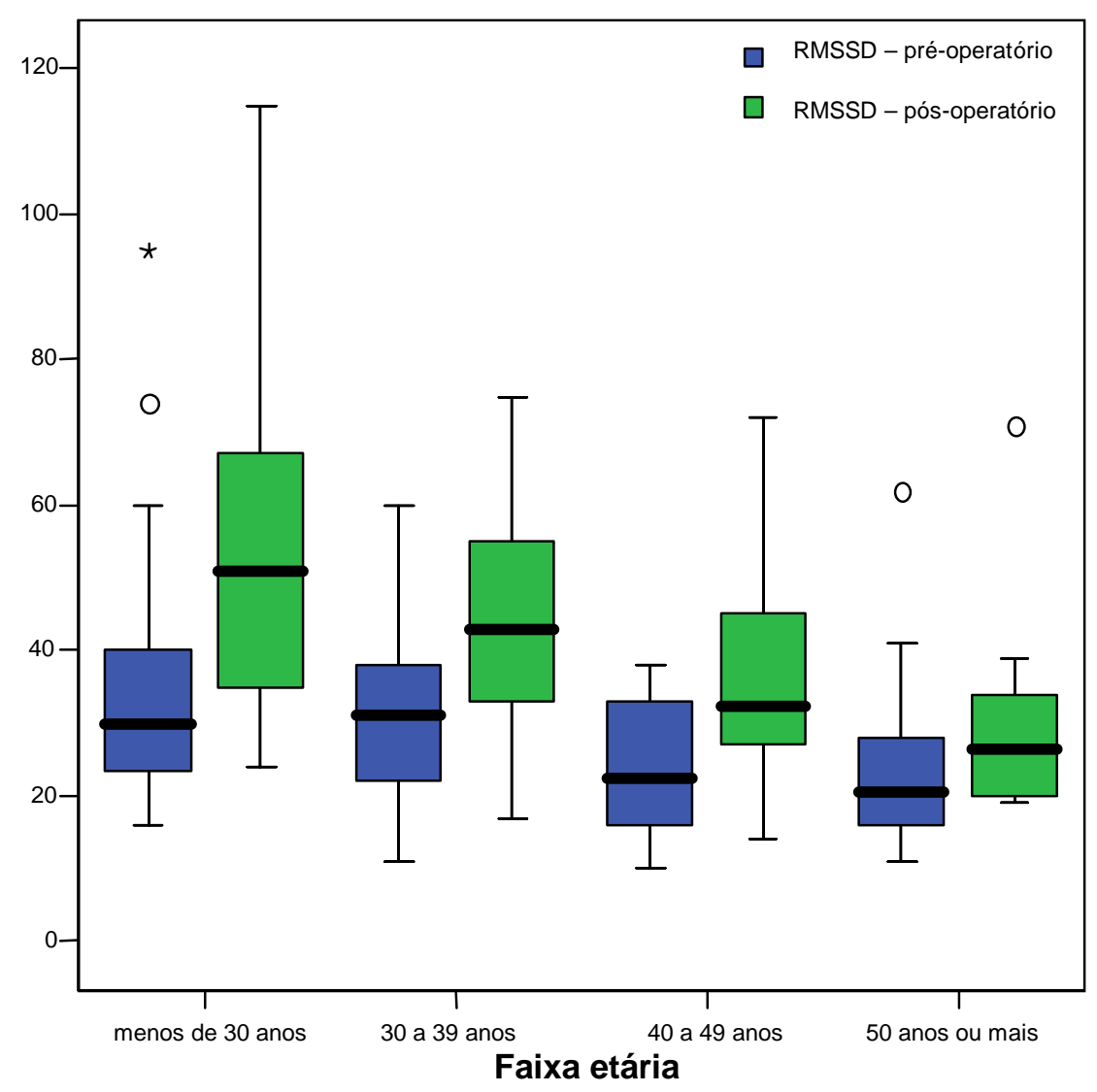

Gráfico de caixas mostrando os valores da rMSSD conforme as faixas de idade, nas fases pré e pós-operatória.

As caixas representam $50 \%$ dos valores encontrados, seus limites superiores representam o percentil 75 e os inferiores o percentil 25 . O traço horizontal no meio da caixa representa a mediana. Os traços verticais indicam o intervalo entre os valores mais baixos e mais altos. Os pequenos círculos representam valores extremos (ou estranhos), maiores que uma vez e meia a altura da caixa. $O$ asterisco representa valor extremo maior que três vezes a altura da caixa.

\subsection{Teste de inclinação ortostática}

Os 71 pacientes da casuística foram submetidos ao teste de inclinação ortostática nas fases pré-operatória e seis meses após a cirurgia. A Tabela 17 descreve os resultados encontrados, dispostos de forma geral e de 
acordo com sexo, idade, pressão arterial e uso de medicação antihipertensiva.

Tabela 17 - Descrição dos resultados do teste de inclinação ortostática

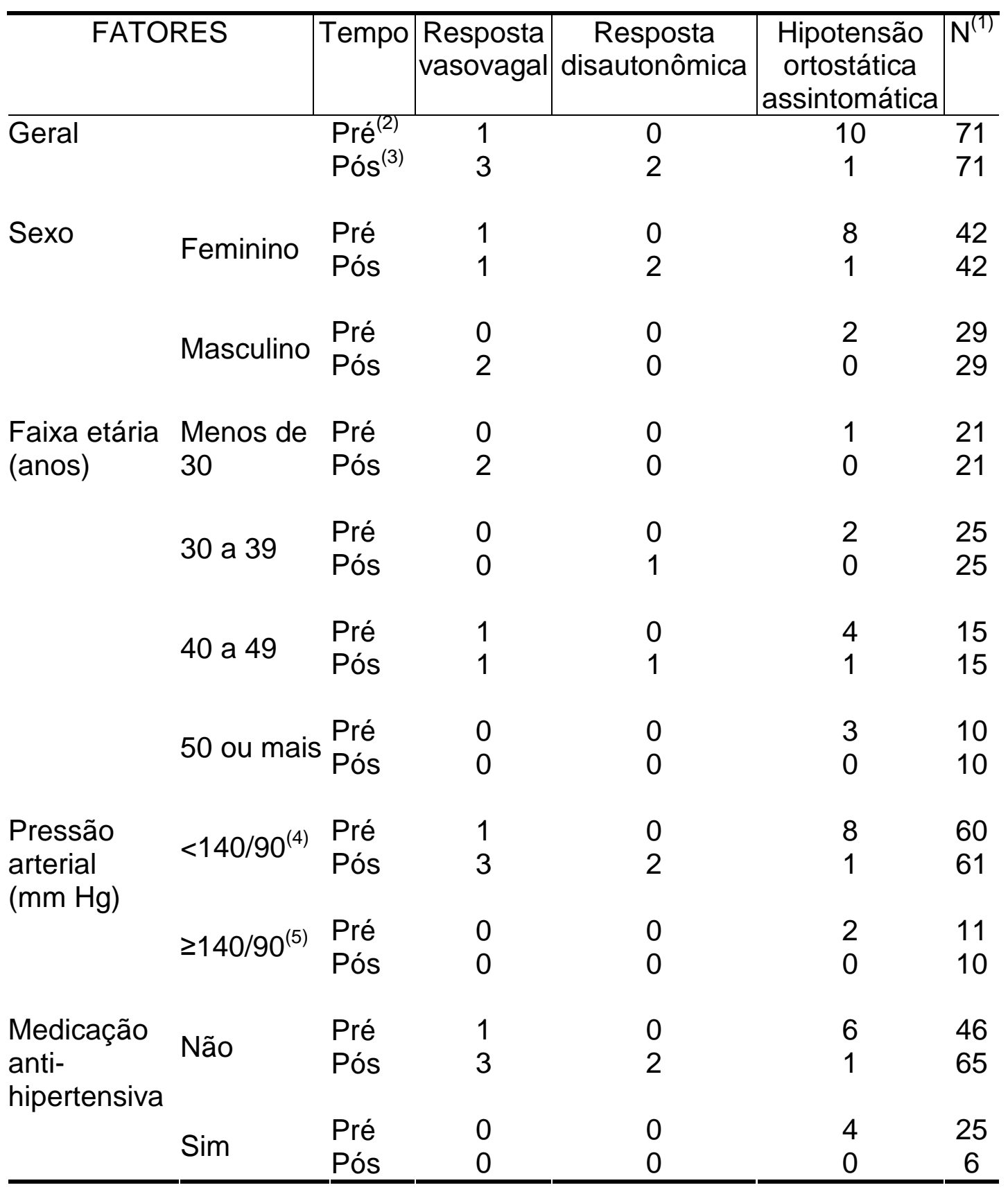

${ }^{(1)}$ Número de pacientes. ${ }^{(2)}$ Indica fase pré-operatória. ${ }^{(3)}$ Indica fase pósoperatória. ${ }^{(4)}$ Indica menor que $140 / 90 \mathrm{~mm} \mathrm{Hg} .{ }^{(5)}$ Indica maior ou igual a 140 / 90 mm Hg. 
Apenas um paciente apresentava história de pré-síncope antes da cirurgia, sendo o único a apresentar teste positivo na fase pré-operatória, com resposta vasovagal. Seis meses após a cirurgia cinco pacientes apresentaram teste positivo, sendo dois com resposta disautonômica e três com resposta vasovagal. O paciente que já apresentava sintoma e teste positivo no pré-operatório manteve sintoma e teste positivo após a cirurgia, porém com mudança do padrão, passando para resposta disautonômica. Não houve nenhum outro paciente com queixa de síncope ou pré-síncope após a cirurgia.

Nenhum paciente apresentou taquicardia postural ortostática ou hipotensão ortostática sintomática no pré-operatório e após a cirurgia.

A comparação entre pré e pós-operatório, para a resposta vasovagal, não mostrou diferença significativa (Tabela 18). Para a resposta disautonômica, a ausência no pré-operatório, com a ocorrência de apenas dois casos no pós-operatório, não permitiu a elaboração de um teste estatístico para verificar a diferença.

Tabela 18 - Análise das respostas ao teste de inclinação ortostática após a cirurgia, em comparação com o pré-operatório

\begin{tabular}{|c|c|c|c|c|c|}
\hline \multirow[t]{2}{*}{ RESPOSTAS } & \multirow{2}{*}{$\begin{array}{l}\text { Razão de } \\
\text { chance }\end{array}$} & \multirow{2}{*}{$\begin{array}{c}\text { Erro } \\
\text { padrão }\end{array}$} & \multicolumn{2}{|c|}{ IC $95 \%{ }^{(1)}$} & \multirow{2}{*}{$\begin{array}{c}\text { Valor de } \\
p\end{array}$} \\
\hline & & & $\begin{array}{l}\text { Limite } \\
\text { inferior }\end{array}$ & $\begin{array}{c}\text { Limite } \\
\text { superior }\end{array}$ & \\
\hline Vasovagal & 3,00 & 3,46 & 0,31 & 28,84 & 0,341 \\
\hline Disautonômica & $\ldots$ & $\ldots$ & $\ldots$ & $\ldots$ & $\ldots$ \\
\hline
\end{tabular}


Foram observados casos de hipotensão ortostática assintomática, não acompanhados de qualquer outra alteração durante o exame. Ocorreram 10 casos na fase pré-operatória e apenas um após a cirurgia (Tabela 19).

Tabela 19 - Características clínicas dos pacientes com hipotensão ortostática assintomática

\begin{tabular}{ccccccc}
\hline $\begin{array}{c}\text { PACIENTE } \\
\text { (iniciais) }^{(1)}\end{array}$ & Sexo $^{(2)}$ & $\begin{array}{c}\text { Idade } \\
(\text { anos })\end{array}$ & $\begin{array}{c}\text { PA } \\
\text { repouso } \\
(\mathrm{mm} \mathrm{Hg})\end{array}$ & $\begin{array}{c}\text { PA } \\
\text { inclinação } \\
(\mathrm{mm} \mathrm{Hg})\end{array}$ & MEDICAÇÃO $^{(5)}$ \\
\hline $\begin{array}{c}\text { Antes da cirurgia } \\
\text { GOB }\end{array}$ & Fem. & 47 & $116 / 68$ & $106 / 54$ & $\begin{array}{c}\text { Diurético + } \\
\text { betabloqueador }\end{array}$ \\
PCV & Fem. & 49 & $148 / 80$ & $150 / 68$ & Betabloqueador \\
AR & Fem. & 50 & $120 / 76$ & $100 / 80$ & Sem medicação \\
SSO & Fem. & 42 & $106 / 70$ & $106 / 60$ & Sem medicação \\
DCTA & Fem. & 39 & $96 / 70$ & $82 / 60$ & Sem medicação
\end{tabular}

AB Fem. $58 \quad 144 / 100 \quad 134 / 90 \quad$ Diurético + bloqueador de cálcio + bloqueador

$A T_{1}+$ alfa agonista central

MRB Masc. $28 \quad 138 / 90 \quad 120 / 80 \quad$ Sem medicação

OLC Masc. $37 \quad 130 / 90 \quad 118 / 80 \quad$ Sem medicação

MHT Fem. $49 \quad 116 / 74 \quad 94 / 68 \quad$ Sem medicação

LCL Fem. $50 \quad 110 / 72 \quad 90 / 76 \quad$ Inibidor da ECA + bloqueador de cálcio

Após a cirurgia

ILF $\quad$ Fem. $49 \quad 106 / 80 \quad 96 / 66 \quad$ Sem medicação

${ }^{(1)}$ Indica as iniciais do nome do paciente. ${ }^{(2)}$ Sexo feminino indicado por "Fem." e masculino por "Masc.". ${ }^{(3)}$ Pressão arterial após 20 minutos de repouso em decúbito horizontal. ${ }^{(4)} \mathrm{A}$ menor pressão arterial registrada nos primeiros 3 minutos após a inclinação. Os dados da pressão arterial estão indicados com os valores sistólicos seguidos dos diastólicos, separados pelo sinal "“". ${ }^{(5)}$ Indica o uso ou não de medicação anti-hipertensiva, descrevendo as categorias de medicações usadas; $\mathrm{AT}_{1}$ indica receptores tipo 1 da angiotensina II; ECA indica enzima conversora da angiotensina. 
Houve diminuição significativa dos casos de hipotensão ortostática assintomática após a cirurgia. Os fatores idade maior ou igual a 50 anos, medicação anti-hipertensiva e sexo não foram significativos (Tabela 20).

Tabela 20 - Razão de chance de hipotensão ortostática após a cirurgia e influência dos fatores idade maior ou igual a 50 anos, uso de medicação anti-hipertensiva e sexo feminino

\begin{tabular}{|c|c|c|c|c|}
\hline \multirow{2}{*}{$\begin{array}{c}\text { HIPOTENSÃO } \\
\text { ORTOSTÁTICA } \\
\text { ASSINTOMÁTICA }\end{array}$} & \multirow{2}{*}{$\begin{array}{c}\text { Razão de } \\
\text { chance }\end{array}$} & \multicolumn{2}{|c|}{ IC 95\% ${ }^{(1)}$} & \multirow[t]{2}{*}{ Valor de $p$} \\
\hline & & $\begin{array}{l}\text { Limite } \\
\text { inferior }\end{array}$ & $\begin{array}{c}\text { Limite } \\
\text { superior }\end{array}$ & \\
\hline Após a cirurgia & 0,10 & 0,01 & 0,80 & 0,030 \\
\hline Idade $\geq 50$ anos $^{(2)}$ & 1,95 & 0,56 & 6,74 & 0,292 \\
\hline Uso de anti-hipertensiva & 1,00 & 0,30 & 3,33 & 0,999 \\
\hline Sexo feminino & 2,88 & 0,66 & 12,49 & 0,159 \\
\hline
\end{tabular}

${ }^{(1)}$ Intervalo de confiança de $95 \%$. ${ }^{(2)}$ Indica maior ou igual a 50 anos.

\subsection{Noradrenalina urinária}

A comparação da dosagem de noradrenalina em urina de 24 horas entre o pré-operatório e seis meses após a cirurgia foi possível em 49 pacientes.

A Tabela 21 mostra as estatísticas descritivas para os valores de noradrenalina urinária no pré e pós-operatório.

Tabela 21 - Estatísticas descritivas para noradrenalina urinária

\begin{tabular}{c|c|c|c|c|c|c|c}
\hline TEMPO & Menor & Mediana & Maior & Média & $\begin{array}{c}\text { Desvio- } \\
\text { padrão }\end{array}$ & $\begin{array}{c}\text { Erro } \\
\text { padrão(2) }\end{array}$ & $\mathrm{N}^{(1)}$ \\
\hline Pré-operatório & 5,9 & 27,0 & 80,5 & 29,7 & 16,2 & 2,3 & 49 \\
Pós-operatório & 2,5 & 19,1 & 66,9 & 28,0 & 18,3 & 2,6 & 49 \\
\hline
\end{tabular}

${ }^{(1)}$ Número de pacientes. ${ }^{(2)}$ Erro padrão da média. 
A análise estatística não mostrou diferença significativa entre os valores de noradrenalina urinária do pré-operatório e seis meses após a cirurgia. $\mathrm{O}$ intervalo de confiança de $95 \%$ para a diferença encontrada apresentou limite inferior de $-8,5$ e superior de 5,0. O valor de $p$ foi igual a 0,611 .

\subsection{Outros exames}

As análises bioquímicas no sangue mostraram que, seis meses após a cirurgia, os pacientes apresentaram redução dos níveis de insulina, glicemia e melhora do perfil lipídico. Houve redução significativa do nível de proteína C-reativa. O fibrinogênio não apresentou alteração (Tabela 22). Os cálculos referentes à glicemia, insulina, colesterol total e triglicérides foram realizados com 70 pacientes. Para HDL-colesterol, LDL-colesterol e proteína C-reativa os cálculos foram realizados com 69 pacientes e para o fibrinogênio com 68 pacientes.

A insulinemia de jejum foi mais elevada nos pacientes mais jovens em relação aos mais velhos $(p=0,001)$, sem diferença em relação ao sexo. Durante o período de acompanhamento, a redução da insulinemia não foi igual para todas as faixas de idade, sendo menor para as idades mais avançadas $(p=0,024)$, embora todas a faixas tenham mostrado significância estatística $(p<0,001)$. Não houve diferença na evolução da glicemia em relação a idade e sexo. 
Tabela 22 - Comparação dos resultados das análises bioquímicas no sangue entre as fases pré e pós-operatória

\begin{tabular}{|c|c|c|c|c|c|c|}
\hline FATORES & $\begin{array}{c}\text { Pré- } \\
\text { operatório }^{(1)}\end{array}$ & $\begin{array}{c}\text { Pós- } \\
\text { operatório }^{(1)}\end{array}$ & $\begin{array}{l}\text { Média da } \\
\text { diferença }\end{array}$ & $\begin{array}{c}\text { IC 95 } \\
\text { Limite } \\
\text { inf. }^{(3)}\end{array}$ & $\begin{array}{l}5 \%{ }^{(2)} \\
\text { Limite } \\
\text { sup. }\end{array}$ & $\begin{array}{c}\text { Valor de } \\
p\end{array}$ \\
\hline icemia & $, 6 \pm 1,4$ & $32,7 \pm 0,8$ & 7,9 & 5,3 & 10,5 & $<0,00$ \\
\hline $\begin{array}{l}\text { sulina } \\
\mathrm{UI} / \mathrm{mL} \text { ) }\end{array}$ & $18,17 \pm 1,06$ & $7,15 \pm 0,43$ & 11,02 & 9,13 & 12,91 & $<0,001$ \\
\hline erol total & $188,6 \pm 4,9$ & $143,8 \pm 3,5$ & 44,9 & 37,3 & 52,4 & $<0,001$ \\
\hline sterol & $44,1 \pm 1,3$ & $46,9 \pm 1,2$ & 2,8 & 0,8 & 4,8 & 0,005 \\
\hline lesterol & $115,0 \pm 4,1$ & $78,0 \pm 2,78$ & 37,0 & 31,0 & 43,1 & $<0,001$ \\
\hline $\begin{array}{l}\text { iglicérides } \\
\text { gg/dL) }\end{array}$ & $147,7 \pm 8,9$ & $94,52 \pm 5,0$ & 53,2 & 38,6 & 67,8 & $<0,001$ \\
\hline $\mathrm{CR}^{(5)^{\prime}}$ & $7,95 \pm 0,97$ & $3,82 \pm 0,53$ & 4,13 & 2,14 & 6,13 & $<0,001$ \\
\hline $\begin{array}{l}\text { orinogênio } \\
\text { (L) }\end{array}$ & $3,44 \pm 0,09$ & $3,46 \pm 0,11$ & 0,02 & $-0,21$ & 0,25 & 0,885 \\
\hline
\end{tabular}

${ }^{(1)}$ Os valores estão colocados como média e erro padrão da média. (2) Intervalo de $95 \%$ de confiança para a diferença entre as médias do préoperatório e pós-operatório. ${ }^{(3)}$ Limite inferior do intervalo de confiança. ${ }^{(4)}$ Limite superior do intervalo de confiança. ${ }^{(5)}$ Proteína C-reativa de alta sensibilidade.

A avaliação da qualidade de vida foi realizada em 51 pacientes no préoperatório e seis meses após a cirurgia. Houve melhora significativa dos oito domínios avaliados (Tabela 23).

Os dados dos exames de monitorização ambulatorial da pressão arterial não foram analisados. $O$ exame foi realizado em 55 pacientes, com grande dificuldade técnica devido a obesidade importante, gerando números elevados de medidas inválidas e resultados pouco confiáveis. Para a maioria dos demais 16 pacientes não foi possível a realização do exame, pela constatação, no momento da instalação do equipamento, da impossibilidade 
da adequação do manguito às dimensões do braço. Os outros se recusaram a submeter-se ao exame.

Tabela 23 - "Raw Scale" dos oito domínios avaliados pelo questionário de qualidade de vida SF-36

\begin{tabular}{|c|c|c|c|c|c|c|}
\hline \multirow[t]{2}{*}{ DOMÍNIOS } & \multirow{2}{*}{$\begin{array}{c}\text { Pré- } \\
\text { operatório }^{(1)}\end{array}$} & \multirow{2}{*}{$\begin{array}{c}\text { Pós- } \\
\text { operatório }^{(1)}\end{array}$} & \multirow{2}{*}{$\begin{array}{l}\text { Média da } \\
\text { diferença }\end{array}$} & \multicolumn{2}{|c|}{ IC 95\%(2) } & \multirow{2}{*}{$\begin{array}{l}\text { Valor } \\
\text { de } p\end{array}$} \\
\hline & & & & $\begin{array}{l}\text { Limite } \\
\inf ^{(3)}\end{array}$ & $\begin{array}{l}\text { Limite } \\
\text { Sun (4) }\end{array}$ & \\
\hline $\begin{array}{l}\text { Capacidade } \\
\text { funcional }\end{array}$ & $47,1 \pm 3,0$ & $92,2 \pm 1,6$ & 45,1 & 39,2 & 51,0 & $<0,001$ \\
\hline $\begin{array}{l}\text { Aspectos } \\
\text { físicos }\end{array}$ & $41,2 \pm 5,4$ & $88,7 \pm 3,8$ & 47,6 & 36,0 & 59,1 & $<0,001$ \\
\hline Dor & $50,4 \pm 3,5$ & $78,2 \pm 2,6$ & 27,8 & 21,8 & 33,8 & $<0,001$ \\
\hline $\begin{array}{l}\text { Estado geral } \\
\text { de saúde }\end{array}$ & $62,7 \pm 2,9$ & $82,6 \pm 2,5$ & 19,9 & 13,6 & 26,2 & $<0,001$ \\
\hline Vitalidade & $50,6 \pm 3,0$ & $75,5 \pm 2,5$ & 25,0 & 19,0 & 30,9 & $<0,001$ \\
\hline $\begin{array}{l}\text { Aspectos } \\
\text { sociais }\end{array}$ & $62,2 \pm 4,4$ & $87,8 \pm 2,8$ & 25,5 & 16,7 & 34,2 & $<0,001$ \\
\hline $\begin{array}{l}\text { Aspectos } \\
\text { emocionais }\end{array}$ & $45,7 \pm 6,1$ & $85,3 \pm 4,2$ & 39,6 & 27,1 & 52,0 & $<0,001$ \\
\hline Saúde mental & $56,9 \pm 2,9$ & $77,4 \pm 2,5$ & 20,5 & 14,4 & 26,7 & $<0,001$ \\
\hline
\end{tabular}

${ }^{(1)}$ Os valores estão colocados como média e erro padrão da média. (2) Intervalo de $95 \%$ de confiança para a diferença entre as médias do préoperatório e pós-operatório. ${ }^{(3)}$ Limite inferior do intervalo de confiança. (4) Limite superior do intervalo de confiança.

\subsection{Correlações}

A relação entre a alteração dos índices de variabilidade da freqüência cardíaca e a alteração do peso, circunferência abdominal e insulinemia de jejum foi avaliada através do coeficiente de correlação de Pearson. Para a 
análise foi considerada a variação dos valores que ocorreu entre as duas fases do estudo, em números absolutos (Tabela 24).

Tabela 24 - Coeficientes de correlação de Pearson entre a variação das medidas da variabilidade da freqüência cardíaca e as variações de peso, circunferência abdominal e insulinemia de jejum

\begin{tabular}{|c|c|c|c|c|}
\hline & COMPARAÇÕES & $\begin{array}{l}\text { Coeficiente de } \\
\text { correlação }(r)\end{array}$ & Valor de $p$ & $\begin{array}{c}\text { Número de } \\
\text { paciente }\end{array}$ \\
\hline SDNN & $\begin{array}{l}\text { Peso } \\
\text { Circunferência abdominal } \\
\text { Índice de massa corpórea } \\
\text { Insulinemia }\end{array}$ & $\begin{array}{l}(0,48) \\
(0,49) \\
(0,35) \\
(0,16)\end{array}$ & $\begin{array}{l}<0,001 \\
<0,001 \\
0,002 \\
0,104\end{array}$ & $\begin{array}{l}68 \\
68 \\
68 \\
67\end{array}$ \\
\hline SDANN & $\begin{array}{l}\text { Peso } \\
\text { Circunferência abdominal } \\
\text { Îndice de massa corpórea } \\
\text { Insulinemia }\end{array}$ & $\begin{array}{l}(0,49) \\
(0,47) \\
(0,34) \\
(0,18)\end{array}$ & $\begin{array}{l}<0,001 \\
<0,001 \\
0,002 \\
0,078\end{array}$ & $\begin{array}{l}68 \\
68 \\
68 \\
67\end{array}$ \\
\hline $\begin{array}{l}\text { SDNN } \\
\text { index }\end{array}$ & $\begin{array}{l}\text { Peso } \\
\text { Circunferência abdominal } \\
\text { Índice de massa corpórea } \\
\text { Insulinemia }\end{array}$ & $\begin{array}{l}(0,28) \\
(0,37) \\
(0,20) \\
(0,02)\end{array}$ & $\begin{array}{l}0,011 \\
0,001 \\
0,051 \\
0,422\end{array}$ & $\begin{array}{l}68 \\
68 \\
68 \\
67\end{array}$ \\
\hline pNN50 & $\begin{array}{l}\text { Peso } \\
\text { Circunferência abdominal } \\
\text { Índice de massa corpórea } \\
\text { Insulinemia }\end{array}$ & $\begin{array}{l}(0,17) \\
(0,29) \\
(0,12) \\
(0,06)\end{array}$ & $\begin{array}{l}0,086 \\
0,009 \\
0,168 \\
0,320\end{array}$ & $\begin{array}{l}68 \\
68 \\
68 \\
67\end{array}$ \\
\hline rMSSD & $\begin{array}{l}\text { Peso } \\
\text { Circunferência abdominal } \\
\text { Índice de massa corpórea } \\
\text { Insulinemia }\end{array}$ & $\begin{array}{l}(0,22) \\
(0,36) \\
(0,16) \\
(0,03) \\
\end{array}$ & $\begin{array}{l}0,039 \\
0,001 \\
0,100 \\
0,395 \\
\end{array}$ & $\begin{array}{l}68 \\
68 \\
68 \\
67 \\
\end{array}$ \\
\hline
\end{tabular}

Os dados entre parênteses indicam valores negativos.

A redução da circunferência abdominal apresentou correlação significativa com a elevação de todos os índices da variabilidade da freqüência cardíaca. A alteração do peso também apresentou correlação significativa com a alteração dos índices, com exceção da alteração da 
pNN50, que não foi significativa. A redução do índice de massa corpórea apresentou correlação significativa apenas com as alterações do SDNN e SDANN.

Entre os índices de variabilidade, o SDNN e o SDANN foram os que apresentaram melhor coeficiente de correlação com as medidas antropométricas.

A redução da insulinemia de jejum não apresentou correlação significativa com o aumento de nenhum dos índices de variabilidade. 


\section{DISCUSSÃO}

\subsection{Caracterização da casuística}

O objetivo primário do presente estudo foi avaliar a influência dos resultados da gastroplastia com derivação gastrojejunal em $Y$ de Roux sobre a modulação autonômica cardíaca e sobre a tolerância ortostática. Os pacientes foram selecionados a partir de critérios de inclusão baseados nas indicações para cirurgia bariátrica recomendadas pelas diretrizes internacionais e critérios de exclusão elaborados com a finalidade de evitar fatores que poderiam comprometer a interpretação dos resultados, sem tornar inviável a composição de uma casuística com tamanho adequado.

Foram excluídos pacientes com diagnóstico de doença cardíaca ou anormalidade eletrocardiográfica, situações que podem alterar a variabilidade da freqüência cardíaca ou prejudicar a sua análise.

Os pacientes com diagnóstico de diabetes melito, aqueles com glicemia de jejum igual ou superior a $126 \mathrm{mg} / \mathrm{dL}$ na avaliação da rotina pré-operatória ou no exame realizado na fase pré-operatória do estudo, e ainda aqueles com história de uso de medicação hipoglicemiante, foram excluídos, na tentativa de evitar a presença de neuropatia autonômica diabética.

A influência de distúrbios da função tireoideana e de sua terapêutica sobre o ritmo cardíaco também foi evitada. Para isso, foram excluídos os pacientes com diagnóstico de disfunção de tireóide, os que estavam em uso de hormônio tireoideano e aqueles com resultado anormal do exame de 
dosagem do hormônio estimulante da tireóide (TSH) realizado na avaliação de rotina pré-operatória.

Os pacientes com resultados de exames de uréia e creatinina séricas alterados também foram excluídos, na intenção principal de evitar a influência da disfunção renal sobre a excreção urinária de noradrenalina.

O número de pacientes da casuística foi superior ao de boa parte dos estudos relacionados à cirurgia bariátrica. Além disso, o presente estudo diferenciou-se do trabalho anterior que estudou a influência da cirurgia bariátrica sobre o padrão autonômico do coração (Karason et al. ${ }^{54}$ ), por avaliar exclusivamente a técnica da gastroplastia com derivação gastrojejunal em $\mathrm{Y}$ de Roux. Outro diferencial importante e inédito da pesquisa foi o estudo da tolerância ortostática.

Os resultados da avaliação antropométrica mostraram importante perda de peso ao longo dos seis meses de acompanhamento pós-operatório. Os homens apresentaram maior perda de peso, embora no que se refira ao índice de massa corpórea e à redução da circunferência abdominal não tenha havido diferença em relação aos sexos. Os mais jovens apresentaram maior redução de peso, índice de massa corpórea e circunferência abdominal, mostrando que a idade é um fator que influencia os resultados do tratamento cirúrgico da obesidade.

\subsubsection{Variabilidade da freqüência cardíaca}

A avaliação dos resultados do estudo da variabilidade da freqüência cardíaca foi realizada com o cuidado que cabe a todos os estudos que 
avaliam esta questão. Foram controlados os fatores que potencialmente pudessem influenciar os resultados, como sexo, idade, freqüência cardíaca, pressão arterial e uso de medicação anti-hipertensiva.

A análise do comportamento da freqüência cardíaca mostrou que os pacientes apresentaram modificação da influência do sistema nervoso autônomo sobre o coração após o tratamento cirúrgico para perda de peso. A freqüência sinusal se reduziu, como demonstrado pelo aumento do intervalo NN médio, e sua variabilidade aumentou, indicando que a mudança da modulação autonômica cardíaca ocorreu no sentido de aumento da influência parassimpática.

Houve aumento tanto dos índices baseados na medida individual dos intervalos RR (SDNN, SDANN e SDNN index) quanto dos baseados nas comparações dos intervalos RR adjacentes (pNN50 e rMSSD).

O SDNN indicou aumento da variabilidade ocorrida durante todo o exame, o que inclui a variabilidade decorrente de ciclos maiores do que 5 minutos, indicada pelo SDANN, e a produzida por ciclos de variação menores que 5 minutos, indicada pelo SDNN index. Este resultado, de uma maneira geral, pode ser interpretado como mudança da modulação autonômica no sentido de aumento da atividade parassimpática, em relação à simpática ${ }^{25,29,30}$.

O aumento dos índices pNN50 e rMSSD, relacionados às mudanças rápidas dos ciclos cardíacos, indicou, de forma mais clara, o aumento da influência parassimpática. 
O comportamento do SDNN indicou que seu aumento ocorreu mais à custa da variabilidade produzida por ciclos maiores do que 5 minutos, visto que sua evolução foi semelhante à do SDANN, que mostrou maior aumento para os homens, em comparação com as mulheres, sem diferença em relação à idade.

Este resultado poderia sugerir que o SDANN e, por conseqüência, o SDNN, foram influenciados mais pela redução do peso corpóreo total, maior no sexo masculino, que pelas reduções da circunferência abdominal e do índice de massa corpórea, que não apresentaram diferença em relação aos sexos. Não obstante, esta associação não fica clara, pois a evolução destes índices de variabilidade não mostrou relação com a idade, que foi um fator que influenciou a evolução do peso, assim como das demais medidas antropométricas.

Não existe um entendimento claro em relação ao significado fisiopatológico das variações da freqüência cardíaca produzidas por ciclos de muito longa duração, neste estudo refletidas pelo SDANN. Existe a sugestão na literatura de que provavelmente sofram influências de outros fatores além do sistema nervoso autonômico, como, por exemplo, os sistemas renina-angiotensina-aldosterona e de termorregulação ${ }^{25}$. Modificações destes fatores, após a perda de peso, poderiam atuar sobre o SDANN de forma a evidenciar a diferença entre os sexos e atenuar a influência da idade.

Informações na literatura indicam que os homens têm maior atividade simpática do que as mulheres ${ }^{88}$, o que Ihes atribui menor variabilidade da 
freqüência cardíaca. Esta diferença é mais bem expressa pelos índices que refletem as oscilações rápidas dos ciclos cardíacos (pNN50 e rMSSD), não sendo evidente em relação aos índices relacionados à variabilidade que ocorre em longos períodos (SDNN e SDANN $)^{89}$. No caso particular da obesidade, os dados de literatura são escassos e pouco esclarecedores. Endim et al. ${ }^{41}$, em estudo em que compararam a variabilidade da freqüência cardíaca, através da análise espectral (domínio da freqüência), entre obesos e não obesos, comentaram, rapidamente, que a variabilidade foi maior entre os homens, sem especificar se foi no grupo de obesos, atribuindo esta diferença à maior bradicardia no sexo masculino. No nosso estudo, controlando o efeito da freqüência cardíaca, demonstramos que o fator sexo foi significativo para os índices SDNN e SDANN devido à evolução diferente no pós-operatório, não havendo diferença antes da cirurgia. O pNN50 foi maior para os homens, sem diferença de evolução no pós-operatório. Já o SDNN index e a rMSSD não mostraram diferença entre os sexos.

Em relação à idade, de maneira geral, todos os índices de variabilidade diminuem com o avanço da idade ${ }^{89}$. No atual estudo, com a característica de avaliar grandes obesos, todos os índices diminuíram com o aumento da idade, exceto o SDANN.

Quanto ao SDNN, é conhecido que sua redução está relacionada a maior risco de morte por causas cardíacas em algumas situações, como no caso de pacientes que sofreram infarto do miocárdio e portadores de insuficiência cardíaca ${ }^{29}, 32-34,90$. Apesar de o excesso de peso estar associado a maior risco de morte cardiovascular ${ }^{1,4,6,16}$, a importância do 
SDNN na obesidade não é conhecida. O seu aumento, após o tratamento cirúrgico da obesidade, poderia ser um indicativo de redução do risco de morte, principalmente para pacientes com doença cardíaca associada.

Em relação aos índices que refletem a variabilidade da freqüência cardíaca que ocorre em períodos mais curtos de tempo, os resultados do presente estudo mostraram um padrão de evolução, entre o pré e o pósoperatório, dependente da idade, não sendo evidenciada diferença de evolução em relação aos sexos.

O SDNN index e a rMSSD apresentaram aumento significativo após a cirurgia apenas para os pacientes com menos de 30 anos. Para os demais, a diferença entre as fases de pré e pós-operatório foi progressivamente menor com o avanço da idade, sem ser estatisticamente significativa. Este resultado indicou que a resposta parassimpática ao tratamento cirúrgico da obesidade diminuiu com o avanço da idade.

Quanto ao pNN50, o modelo não permitiu a demonstração da relação com a idade, porém a observação do gráfico da Figura 16 sugere que ela possa existir. Esta questão não prejudicou os resultados pelo fato deste índice ser considerado inferior à rMSSD para estimar a variação de ciclo curto da freqüência cardíaca ${ }^{30}$.

Os resultados sugerem que as diferenças de redução do peso e da circunferência abdominal relacionadas à idade influenciaram mais os índices que refletem melhor os ciclos mais rápidos de variação da freqüência cardíaca, mais claramente relacionados à atividade parassimpática. Esta relação, associada ao fato de que a variabilidade naturalmente diminui com 
o aumento da idade, apresentando queda mais acentuada até a terceira década de vida ${ }^{89}$, contribuiu para a ausência de diferença estatística para os pacientes com mais de 30 anos. É provável que o aumento do tamanho da casuística, às custas de pacientes com mais idade, poderia tornar as diferenças significativas, pelo menos para aqueles entre 30 e 49 anos.

Os resultados, de uma forma geral, foram concordantes com a informação de outros estudos que avaliaram a perda de peso por meios não cirúrgicos $^{42-45}$, apesar de alguns não terem conseguido identificar mudança significativa nas medidas mais relacionados à atividade parassimpática ${ }^{27,41}$.

Embora o emprego de dietas hipocalóricas, associadas ou não com atividade física e medicação, tenha o mesmo objetivo que a cirurgia bariátrica, são medidas diferentes. O procedimento cirúrgico é reservado para casos de obesidade grave; muda a estrutura e funcionamento do tubo digestivo e leva a perda de peso rápida, intensa e mais mantida ${ }^{60,61,69}$. Por este motivo é importante que seja avaliado, independentemente dos resultados de outras intervenções.

O efeito da redução de peso induzida pela cirurgia bariátrica sobre a variabilidade da freqüência cardíaca também foi estudado anteriormente por Karason et al. ${ }^{54}$. Vinte e sete obesos foram avaliados antes e 12 meses após a cirurgia, através de gravações de eletrocardiograma com 24 horas de duração, em fitas magnéticas. Os resultados das medidas no domínio do tempo foram pouco expressivos. O SDNN e o SDANN não apresentaram aumento significativo após a cirurgia. O único índice que aumentou foi o SDNN index, interpretado como indicativo de aumento da atividade 
parassimpática. A pNN50 e a rMSSD não foram mencionadas. A análise espectral também foi utilizada, sendo demonstrando aumento da faixa de baixa freqüência (LF), influenciada pelo simpático e parassimpático. A faixa de alta freqüência (HF), relacionada à atividade parassimpática, aumentou apenas durante o dia, sem diferença significativa nas 24 horas.

Diferente do estudo anterior, a pesquisa atual demonstrou mais claramente o aumento dos índices de variabilidade no domínio do tempo, inclusive daqueles relacionados mais especificamente à atividade parassimpática (pNN50 e rMSSD). Além disso, forneceu informações no que se refere às influências do sexo e da idade, não estudadas anteriormente. 0 fato de a casuística ter sido maior e composta por pacientes mais jovens contribuiu para os resultados.

A análise espectral não foi empregada no presente estudo. Esta opção foi feita porque foram utilizadas gravações de eletrocardiograma com 24 horas de duração. Nesta condição a análise espectral não é melhor que o domínio do tempo, além de poder fornecer resultados de mais difícil interpretação ${ }^{30}$. É um método mais apropriado para gravações de curta duração, em ambiente de laboratório ${ }^{30}$.

Apesar de os tempos de acompanhamento pós-operatório terem sido diferentes nos dois estudos, a redução média de peso não foi muito diferente. No estudo de Karason et al. ${ }^{54}$ a redução média de peso foi de 28\%, 12 meses após a cirurgia, enquanto que neste estudo a redução foi de $25 \%$, após seis meses. Provavelmente isso se tenha devido à utilização de técnicas cirúrgicas diferentes. Na publicação de Karason et al. não fica clara 
a técnica cirúrgica empregada, mas os paciente foram recrutados de outro estudo maior, multicêntrico ("Swedish Obese Subjects study") 91, visando a outros desfechos relacionados à cirurgia bariátrica, em que a técnica cirurgica mais empregada, na época, era a gastroplastia vertical com bandagem. No presente estudo a técnica empregada foi a gastroplastia com derivação gastrojejunal em Y de Roux ("Roux-en-Y gastric bypass"), atualmente a mais utilizada.

A atual pesquisa avaliou também as correlações entre as alterações dos índices de variabilidade da freqüência cardíaca e as alterações de peso, circunferência abdominal, índice de massa corpórea e insulinemia de jejum.

Peso e circunferência abdominal apresentaram melhor correlação com a variabilidade da freqüência cardíaca que o índice de massa corpórea. Apesar de os coeficientes indicarem correlações fracas, elas foram significativas, mostrando que a variabilidade da freqüência aumenta à medida que peso e circunferência abdominal diminuem.

O SDNN e o SDANN foram os índices que apresentaram melhor correlação com as medidas antropométricas. É possível que isso tenha ocorrido pela possibilidade, já comentada, de o aumento destes índices ter refletido outros fatores além do sistema nervoso autônomo, os quais também podem ter sido modificados com a redução do peso.

À medida que avaliamos a variação da freqüência cardíaca que ocorre em ciclos de menor duração, melhor associada à influência parassimpática, a correlação passou a ser discretamente melhor com a alteração da circunferência abdominal, em relação à alteração do peso, o que pode estar 
relacionado ao maior benefício cardiovascular da redução da gordura visceral.

Apesar de a hiperinsulinemia estar associada à estimulação simpática ${ }^{41}$, 92, 93, não foi demonstrada correlação significativa entre as alterações da insulinemia de jejum e dos índices de variabilidade da freqüência cardíaca. Talvez a dosagem da insulina de jejum não seja a melhor medida para esta avaliação, visto que representa apenas um momento específico dentro das 24 horas em que a variabilidade da freqüência cardíaca foi avaliada. Além disso, é possível que a mudança da modulação autonômica relacionada à perda de peso envolva outros mecanismos além da redução da insulinemia.

\subsubsection{Tolerância ortostática}

Apesar de relatos de intolerância ortostática possivelmente associada ao emagrecimento produzido por procedimentos gástricos ${ }^{76-78}$, o presente estudo não mostrou piora significativa deste parâmetro. Embora tenham ocorrido mais testes de inclinação ortostática positivos após a cirurgia, o número foi pequeno e não apresentou um padrão hemodinâmico uniforme. Além disso, não houve aparecimento de queixas novas de síncope ou présíncope.

No que se refere à suscetibilidade a síncope vasovagal, não houve diferença entre as duas fases do estudo. $O$ fato de não ter surgido nenhum caso novo com sintoma associado à especificidade do exame, que é aceita como próxima de $90 \%{ }^{46,94,95}$, torna o pequeno número de respostas vasovagal, após a cirurgia, sem importância clínica. 
Quanto à resposta disautonômica, a ausência de casos antes e a ocorrência de apenas dois após a cirurgia não permitiram a elaboração de um modelo estatístico, portanto, não foi possível avaliar este tipo de resposta. Não obstante, o pequeno número de casos após a cirurgia, sem correlação clínica, indica que, se a perda de peso após seis meses da cirurgia induz a intolerância ortostática, é uma complicação rara.

Em relação ainda ao teste de inclinação ortostática, houve um número maior de pacientes com hipotensão ortostática assintomática antes da cirurgia em relação à avaliação pós-operatória, indicando melhora desta condição após a diminuição do peso. Entretanto, a redução da pressão arterial não foi grande (Tabela 19) e todos estes pacientes toleraram bem a fase de inclinação prolongada do exame, o que torna questionável a importância deste achado em relação à tolerância ortostática.

O diagnóstico de hipotensão ortostática foi baseado na definição da Sociedade Americana de Neurologia ${ }^{81}$, porém nem todos os autores seguem exatamente os mesmos critérios $^{47,} 50,96$. Alguns consideram, para 0 diagnóstico, redução da pressão arterial maior do que a encontrada na maioria dos pacientes do presente estudo ${ }^{47}$. Outra questão a ser considerada seria o uso de medicação anti-hipertensiva, que é reconhecido como potencial causador de hipotensão ortostática ${ }^{47}$. Embora este fator não tenha sido estatisticamente significativo para o diagnóstico, é possível que tenha contribuído, sobretudo nos casos com associações de drogas.

Apesar destas considerações, os resultados poderiam ser correlacionados com a informação na literatura de que obesidade está 
associada a menor resistência vascular periférica e menor resposta barorreflexa $^{13,15-17,27,41}$. Esta situação poderia predispor à hipotensão ortostática. A reversão destas alterações após perda de peso, conforme demostrado por Emdin et al. ${ }^{41}$, explicaria a redução do número de casos de hipotensão ortostática seis meses após a cirurgia.

As publicações sobre intolerância ortostática relacionada à perda de peso após cirurgia bariátrica são raras. Hoeldtke et al. ${ }^{76}$ relataram quatro casos de hipotensão ortostática sintomática após redução rápida de peso, porém apenas um deles estava associado à cirurgia bariátrica. Tratava-se de uma mulher com 39 anos de idade, submetida a gastroplastia um ano antes dos sintomas. Rubinshtein et al. ${ }^{77}$ descreveram o caso de outra paciente, com 45 anos de idade, submetida a gastroplastia vertical com bandagem, 8 meses antes do início da investigação dos sintomas. Lascano et al. ${ }^{78}$ também relataram o caso de um homem com 57 anos de idade, submetido a gastroplastia com derivação gastrojejunal em $\mathrm{Y}$ de Roux sete meses antes do início da investigação das queixas. Tendo em conta o grande número de pacientes submetidos a este tipo de tratamento no mundo todo, podemos considerar a possibilidade de outras causas para a intolerância ortostática, além da perda de peso. Lascano et al. ${ }^{78}$ sugeriram que, nestes pacientes, a pressão arterial elevada antes da cirurgia poderia ter mascarado sintomas de disfunção autonômica causada por doença associada à obesidade, como diabetes melito, já presente antes da cirurgia, mas com sintomas manifestados apenas após a redução dos níveis de pressão arterial relacionada à grande perda de peso. A presença de hipertensão arterial e 
diabetes antes da cirurgia foi relatada nos dois últimos casos citados acima. No primeiro não há referência às condições pré-operatórias da paciente.

Os resultados do presente estudo se referem a pacientes sem diagnóstico de diabetes melito, evitando-se a presença de neuropatia autonômica diabética. É possível que este seja um fator que tenha contribuído para ausência de novos sintomas de intolerância ortostática e para o pequeno número de testes de inclinação alterados após a cirurgia. Outra questão é que os pacientes foram reavaliados seis meses após a cirurgia. Apesar da perda de peso ser rápida nesse período, ainda continua ocorrendo por pelo menos mais seis meses ${ }^{68}$.

\subsubsection{Atividade simpática geral}

Quanto à avaliação da atividade simpática geral, apesar da falta de uniformidade dos resultados dos estudos que avaliaram a diferença entre obesos e não obesos através da dosagem de noradrenalina plasmática ou urinária $^{13,15,23,41,54,56-59}$, a redução da dosagem plasmática foi demonstrada após perda de peso induzida por dieta ${ }^{15}$. Quanto à excreção urinária, a redução com a perda de peso através de dieta hipocalórica não está clara ${ }^{41}$.

No atual estudo foi utilizada a avaliação urinária de noradrenalina, na tentativa de reproduzir os resultados de estudos anteriores que demonstraram redução significativa do resultado deste exame após perda de peso decorrente da cirurgia bariátrica ${ }^{54,55}$.

Apesar de dificuldades como recusa de alguns pacientes, coletas inadequadas e falta de tempo antes da cirurgia para o preparo e coleta do 
material terem reduzido o número de pacientes para a análise, ainda foi possível compor uma casuística maior do que as dos outros estudos com pacientes submetidos a cirurgia. Mesmo assim não foi demonstrada diferença entre o pré-operatório e seis meses após o procedimento cirúrgico.

O resultado pode estar relacionado à limitação do método para refletir mudanças autonômicas devido à heterogeneidade regional da atividade simpática, demonstrada pelo método de diluição da noradrenalina marcada com isótopo radioativo ${ }^{20,23}$. As informações fornecidas por este método, que permite avaliação da atividade simpática geral e de alguns órgãos isoladamente, sugerem que alterações regionais importantes podem ocorrer sem modificações significativas dos índices de atividade simpática geral ${ }^{23}$.

Outra questão que deve ser considerada e pode levar a resultados discordantes entre diferentes estudos é a característica do método, que exige cuidados especiais para o preparo e coleta da urina, nem sempre facilmente controlados.

\subsubsection{Outros aspectos}

No presente estudo, foi avaliada também a evolução de outros aspectos, como perfil metabólico, marcadores inflamatórios e qualidade de vida. Apesar de não estarem diretamente relacionados aos objetivos do estudo, tais aspectos forneceram informações que permitem uma observação mais ampla dos efeitos do tratamento cirúrgico da obesidade.

Entre a avaliação pré-operatória e aquela efetuada seis meses após a cirurgia houve redução da insulinemia de jejum e melhora do perfil lipídico. 
Estas modificações confirmam os resultados já indicados na literatura ${ }^{70,71,97-}$ 102.

Foi demonstrada também redução da proteína C-reativa de alta sensibilidade, que é um marcador inflamatório cuja elevação está associada a maior risco de morte e infarto agudo do miocárdio em pacientes portadores de aterosclerose coronária ${ }^{103-106}$. Outros autores já tinham demonstrado redução deste marcador, 12 a 24 meses após a cirurgia bariátrica ${ }^{107-110}$. Van Dielen et al. ${ }^{108}$, em avaliações seriadas, aos três, seis, 12 e 24 meses após a cirurgia, encontraram redução significativa da proteína C-reativa apenas a partir de 12 meses de pós-operatório, sem diferença aos seis meses. 0 resultado do atual estudo mostra que, mesmo após seis meses, pode ocorrer redução deste marcador inflamatório. O número maior de pacientes avaliados, submetidos a uma técnica cirúrgica que leva a maior perda de peso que as utilizadas no estudo anterior, provavelmente concorreu para a diferença dos resultados.

Quanto à dosagem de fibrinogênio, que também é um marcador inflamatório associado a eventos $\operatorname{coronarianos}^{104}$, não foi encontrada alteração seis meses após a cirurgia. Kopp et al. ${ }^{107}$ demonstraram redução significativa do fibrinogênio em 37 pacientes, 14 meses após a cirurgia. Diferenças em relação ao tempo de seguimento e ao tipo de população estudada (muitos pacientes do estudo anterior eram diabéticos) podem ter influenciado os resultados.

A melhora da qualidade de vida dos pacientes seis meses após a cirurgia foi evidenciada pelo aumento significativo dos valores atribuídos aos 
oito domínios avaliados pelo questionário SF-36. Os demais estudos que analisaram a qualidade de vida após a cirurgia bariátrica, com períodos diferentes de acompanhamento (de 6 a 86 meses) e instrumentos diferentes de avaliação, são concordantes em relação à melhora dos pacientes após a perda de peso $0^{65,111-114}$. Apesar de o SF-36 ser um questionário genérico e existirem instrumentos específicos para obesidade ${ }^{111}, 112,115-119$, ele é amplamente usado em pesquisas, inclusive relacionadas à obesidade e à cirurgia bariátrica, além de ser validado para o nosso idioma ${ }^{86}$.

\subsection{Considerações finais}

Alguns aspectos do presente estudo podem ser considerados limitações da pesquisa e merecem alguns esclarecimentos. Outros levantam a necessidade de novos estudos para complementar as informações referentes aos efeitos da cirurgia bariátrica sobre o sistema cardiovascular.

Como não foi utilizada a dosagem de glicemia duas horas após administração de glicose por via oral, não é possível afirmar que foram excluídos da casuística todos os pacientes diabéticos; porém, se alguns apresentavam diabetes melito, estariam em estágio inicial da doença e sem hiperglicemia importante, o que poderia reduzir a possibilidade de complicações da doença ${ }^{120-122}$.

Em relação à pressão arterial, o controle do seu efeito sobre a variabilidade da freqüência cardíaca foi realizado, nas duas fases do estudo, considerando-se aferições em repouso, no dia da realização da monitorização eletrocardiográfica. A medida de 140 / 90 mm Hg foi utilizada 
para separar os pacientes com pressão arterial elevada, baseada nas classificações das diretrizes de hipertensão arterial $^{123}$. Não foi possível estratificação maior dos níveis pressóricos por questões relacionadas à viabilidade do trabalho estatístico. Também não foi possível avaliar o efeito da hipertensão arterial sobre a evolução da variabilidade da freqüência cardíaca entre as duas fases do estudo, porque nem todos os pacientes que foram classificados na categoria de pressão arterial maior ou igual a 140 / 90 mm Hg após a cirurgia estavam nesta categoria antes da cirurgia.

Talvez a média da pressão arterial em 24 horas seria mais adequada que a pressão arterial de repouso, para o uso no modelo estatístico da variabilidade da freqüência cardíaca, porém não foi possível pela baixa qualidade dos exames de monitorização ambulatorial da pressão arterial. Além disso, também o número de pacientes submetidos a este exame foi bem inferior àquele dos pacientes avaliados pela monitorização eletrocardiográfica, o que implicaria em redução significativa da casuística para análise da variabilidade da freqüência cardíaca.

A dificuldade para a realização da monitorização ambulatorial da pressão arterial também merece comentários. Antes da cirurgia, muitos pacientes apresentavam braços muito largos e, muitas vezes, de pequeno comprimento. Este tipo de anatomia, freqüente nos grandes obesos, prejudica a adaptação do manguito e a sua manutenção na posição adequada por tempo prolongado. Talvez esta característica da obesidade, representando um fator militante importante para a realização da monitorização ambulatorial da pressão arterial $^{84}$, seja o motivo do pequeno 
número de estudos que avaliaram o efeito da cirurgia bariátrica sobre 0 comportamento da pressão arterial nas 24 horas $^{55,124}$. Como a população que se submete a este tipo de tratamento é composta de grandes obesos, é difícil a realização de exames de boa qualidade.

O desenvolvimento e validação de equipamentos de monitorização ambulatorial da pressão arterial apropriados para a avaliação de grandes obesos seriam importantes para a realização de novos estudos. Além disso, o uso de medicação anti-hipertensiva e sua freqüente redução e suspensão após a cirurgia é um fator que pode prejudicar a avaliação dos resultados de trabalhos que se proponham a estudar este tema, sendo difícil compor uma casuística, com tamanho adequado, de grandes obesos sem uso de medicação anti-hipertensiva ou, no caso de uso, que sua suspensão seja aceitável, sem prejuízo para o paciente.

Quanto ao uso de medicação anti-hipertensiva no presente estudo, não foi possível considerar individualmente cada tipo, pelo fato de que houve diversos tipos de medicação e associações. Além disso, apenas seis pacientes faziam uso de medicação após a cirurgia. Em relação ao uso de betabloqueador, nove pacientes faziam uso antes da cirurgia e apenas três após. Apesar de esta medicação apresentar maior potencial para reduzir a freqüência cardíaca e aumentar a sua variabilidade, não há indícios de que este fator tenha alterado o resultado, considerando-se que o menor número de pacientes usando a medicação após a cirurgia poderia, teoricamente, influenciar no sentido de aumento da freqüência cardíaca e redução da variabilidade, o contrário do que ocorreu. 
A modificação do padrão autonômico cardiovascular, as mudanças do perfil metabólico e a redução da proteína C-reativa de alta sensibilidade são alterações aparentemente favoráveis no sentido de prevenção de eventos cardiovasculares; porém apenas estudos maiores, objetivando desfechos clínicos poderão responder esta questão.

Não é possível, também, saber se as modificações da variabilidade da freqüência cardíaca observadas seis meses após a cirurgia são mantidas após a estabilização do peso. Esta questão somente poderá ser respondida com a realização de outros estudos com períodos longos de acompanhamento.

Em relação à tolerância ortostática, a análise dos resultados encontrados no presente estudo e dos relatos de casos da literatura fornece algumas sugestões para futuras pesquisas. Casuísticas maiores incluindo pacientes diabéticos poderiam fornecer informações adicionais em relação à resposta disautonômica. Avaliações mais precoces que seis meses e também após período maior de tempo poderiam estudar perdas diferentes de peso e fases diferentes de adaptação às mudanças orgânicas impostas pela cirurgia.

Por fim, outra questão importante a ser colocada é a dificuldade de separar os efeitos decorrentes unicamente da redução da gordura corporal dos possivelmente produzidos pela mudança da estrutura e funcionamento do tubo digestivo decorrentes da cirurgia. A utilização de um grupo-controle com pacientes submetidos a tratamento com medidas convencionais, não cirúrgicas, poderia ser uma estratégia, porém esbarra na pouca eficiência 
destas medidas para atingir perdas importantes de peso e mantê-las por períodos maiores de tempo ${ }^{54}$. 


\section{CONCLUSÕES}

O tratamento cirúrgico da obesidade através da gastroplastia com derivação gastrojejunal em $\mathrm{Y}$ de Roux modificou a modulação autonômica do coração, no sentido de aumento da ação parassimpática.

O aumento da atividade parassimpática após a cirurgia diminuiu com o avanço da idade, seguindo o comportamento da redução do peso e da circunferência abdominal.

O tratamento cirúrgico da obesidade não piorou clinicamente a tolerância ortostática e não aumentou a suscetibilidade à síncope vasovagal, aos seis meses de pós-operatório.

A dosagem de noradrenalina em urina de 24 horas não refletiu a mudança da modulação autonômica após o tratamento cirúrgico da obesidade. 


\section{QUESTIONÁRIO GENÉRICO DE QUALIDADE DE VIDA "MEDICAL OUTCOMES STUDY 36-ITEM SHORT-FORM HEALTH SURVEY (SF-36)"}

Instruções: Esta pesquisa questiona você sobre sua saúde. Estas informações nos manterão informados de como você se sente e quão bem você é capaz de fazer suas atividades de vida diária. Caso você esteja inseguro em como responder, por favor tente responder o melhor que puder.

1. Em geral, você diria que sua saúde é:

(circule uma)

. Excelente. 1

Muito boa.

2

. Boa 3

Ruim 4

Muito ruim 5

2. Comparada há um ano atrás, como você classificaria a sua saúde em geral, agora? (circule uma)

. Muito melhor agora do que há um ano atrás. 1

. Um pouco melhor agora do que há um ano atrás.

2

. Quase a mesma de um ano atrás. 3

. Um pouco pior agora do que há um ano atrás. 4

. Muito pior do que há um ano atrás. 
3. Os seguintes itens são sobre atividades que você poderia fazer atualmente durante um dia comum. Devido a sua saúde, você tem dificuldade para fazer essa atividades? Neste caso, quanto?

(circule um nome em cada linha)

\begin{tabular}{|l|c|c|c|}
\hline Atividades & $\begin{array}{c}\text { Sim. } \\
\text { Dificulta } \\
\text { muito }\end{array}$ & $\begin{array}{c}\text { Sim. } \\
\text { Dificulta } \\
\text { um pouco }\end{array}$ & $\begin{array}{c}\text { Não. Não } \\
\text { dificulta } \\
\text { de modo } \\
\text { algum }\end{array}$ \\
\hline $\begin{array}{l}\text { a. Atividades vigorosas, que exigem } \\
\text { muito esforço, tais como correr, levantar } \\
\text { objetos pesados, participar em esportes } \\
\text { árduos }\end{array}$ & 1 & 2 & 3 \\
\hline $\begin{array}{l}\text { b. Atividade moderadas, tais como } \\
\text { mover uma mesa, passar aspirador de } \\
\text { pó, jogar bola, varrer a casa }\end{array}$ & 1 & 2 & 3 \\
\hline $\begin{array}{l}\text { c. Levantar ou carregar mantimento } \\
\text { d. Subir vários lances de escada }\end{array}$ & 1 & 2 & 3 \\
\hline e. Subir um lance de escada & 1 & 2 & 3 \\
\hline f. Curvar-se, ajoelhar-se ou dobrar-se & 1 & 2 & 3 \\
\hline g. Andar mais de 1 quilômetro & 1 & 2 & 3 \\
\hline h. Andar vários quarteirões & 1 & 2 & 3 \\
\hline i. Andar um quarteirão & 1 & 2 & 3 \\
\hline j. Tomar banho ou vestir-se & 1 & 2 & 3 \\
\hline
\end{tabular}


4. Durante as últimas quatro semanas, você teve algum dos seguinte problemas com o seu trabalho ou com alguma atividade diária regular, como conseqüência de sua saúde física?

(circule uma em cada linha)

\begin{tabular}{|l|c|c|}
\hline & Sim & Não \\
\hline $\begin{array}{l}\text { a. Você diminuiu a quantidade de tempo que se dedicava a } \\
\text { seu trabalho ou a outras atividade? }\end{array}$ & 1 & 2 \\
\hline b. Realizou menos tarefas do que você gostaria? & 1 & 2 \\
\hline $\begin{array}{l}\text { c. Esteve limitado no seu tipo de trabalho ou em outras } \\
\text { atividades? }\end{array}$ & 1 & 2 \\
\hline $\begin{array}{l}\text { d. Teve dificuldade de fazer seu trabalho ou outras } \\
\text { atividades (por exemplo: necessitou de um esforço extra)? }\end{array}$ & 1 & 2 \\
\hline
\end{tabular}

5. Durante as últimas quatro semanas, você teve algum dos seguintes problemas com o seu trabalho ou outra atividade regular diária, como conseqüência de algum problema emocional (como sentir-se deprimido ou ansioso)?

(circule uma em cada linha)

\begin{tabular}{|l|c|c|}
\hline & $\operatorname{Sim}$ & Não \\
\hline $\begin{array}{l}\text { a. Você diminuiu a quantidade de tempo que se dedicava } \\
\text { ao seu trabalho ou a outras atividades? }\end{array}$ & 1 & 2 \\
\hline $\begin{array}{l}\text { b. Realizou menos tarefas do que você gostaria? } \\
\begin{array}{l}\text { c. Não trabalhou ou não fez qualquer das atividades com } \\
\text { tanto cuidado como geralmente faz? }\end{array}\end{array}$ & 1 & 2 \\
\hline
\end{tabular}


6. Durante as últimas quatro semanas, de que maneira sua saúde física ou problemas emocionais interferiram nas suas atividades sociais normais, em relação à família, vizinhos, amigos ou em grupo?

(circule uma)

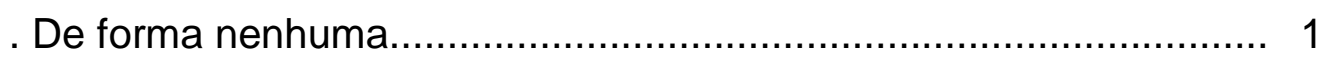

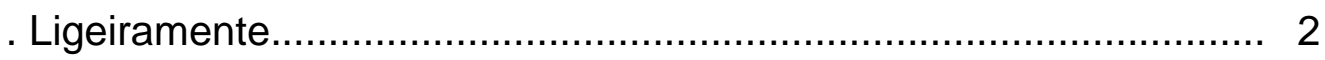

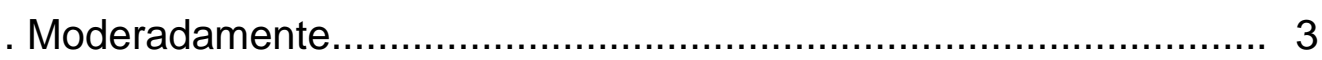

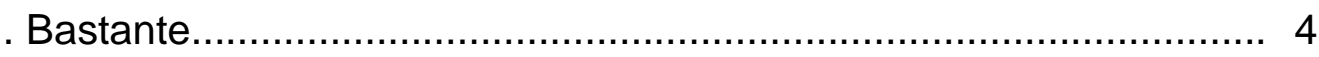

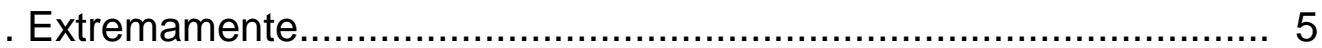

7. Quanta dor no corpo você teve durante as últimas quatro semanas?

(circule uma)

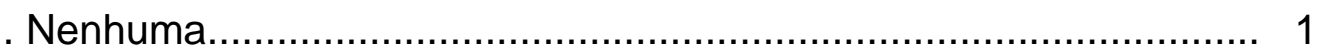

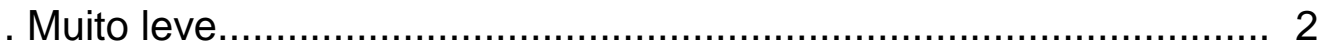

. Leve

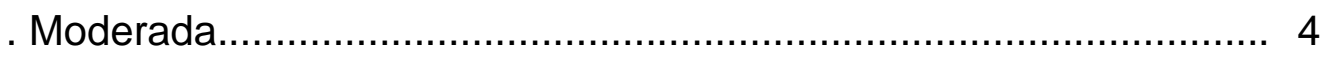

. Grave

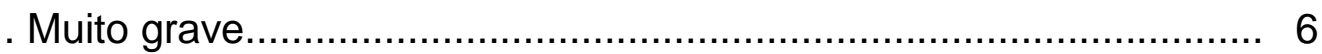


8. Durante as últimas quatro semanas, quanto a dor interferiu com o seu trabalho normal (incluindo tanto o trabalho fora de casa como dentro de casa)?

(circule uma)

. De maneira alguma...................................................................... 1

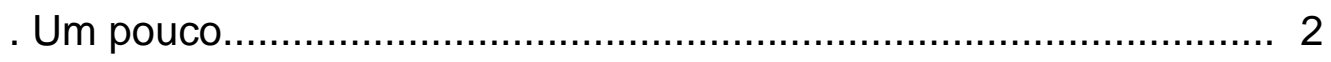

. Moderadamente.................................................................... 3

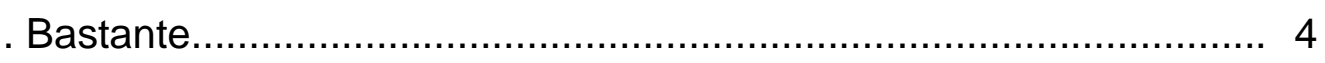

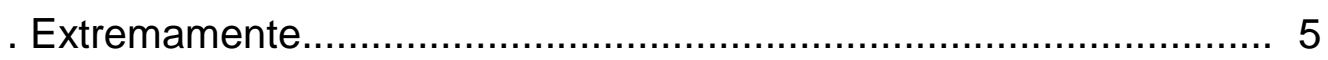


9. Estas questões são sobre como você se sente e como tudo tem acontecido com você durante as últimas quatro semanas. Para cada questão, por favor dê uma resposta que mais se aproxime da maneira como você se sente. Em relação às últimas quatro semanas.

(circule um número para cada linha)

\begin{tabular}{|l|c|c|c|c|c|c|}
\hline & $\begin{array}{c}\text { Todo } \\
\text { tempo }\end{array}$ & $\begin{array}{c}\text { A } \\
\text { maior } \\
\text { parte } \\
\text { do } \\
\text { tempo }\end{array}$ & $\begin{array}{c}\text { Uma } \\
\text { boa } \\
\text { parte } \\
\text { do } \\
\text { tempo }\end{array}$ & $\begin{array}{c}\text { Alguma } \\
\text { parte } \\
\text { do } \\
\text { tempo }\end{array}$ & $\begin{array}{c}\text { Uma } \\
\text { peque- } \\
\text { na } \\
\text { parte } \\
\text { do } \\
\text { tempo }\end{array}$ & Nunca \\
\hline $\begin{array}{l}\text { a. Quanto tempo você } \\
\text { tem se sentido cheio } \\
\text { de vigor, cheio de } \\
\text { vontade, cheio de } \\
\text { força? }\end{array}$ & 1 & 2 & 3 & 4 & 5 & 6 \\
\hline $\begin{array}{l}\text { b. Quanto tempo você } \\
\text { tem se sentido uma } \\
\text { pessoa muito } \\
\text { nervosa? }\end{array}$ & 1 & 2 & 3 & 4 & 5 & 6 \\
\hline $\begin{array}{l}\text { c. Quanto tempo você } \\
\text { tem se sentido tão } \\
\text { deprimido que nada } \\
\text { pode animá-lo? }\end{array}$ & 1 & 2 & 3 & 4 & 5 & 6 \\
\hline $\begin{array}{l}\text { d. Quanto tempo você } \\
\text { tem se sentido calmo } \\
\text { o tranqüilo? }\end{array}$ & 1 & 2 & 3 & 4 & 5 & 6 \\
\hline $\begin{array}{l}\text { e. Quanto tempo você } \\
\text { tem se sentido com } \\
\text { muita energia? }\end{array}$ & 1 & 2 & 3 & 4 & 5 & 6 \\
\hline $\begin{array}{l}\text { f. Quanto tempo você } \\
\text { tem se sentido } \\
\text { desanimado e } \\
\text { abatido? }\end{array}$ & 1 & 2 & 3 & 4 & 5 & 6 \\
\hline $\begin{array}{l}\text { g. Quanto tempo você } \\
\text { tem se sentido } \\
\text { esgotado? }\end{array}$ & 1 & 2 & 3 & 4 & 5 & 6 \\
\hline $\begin{array}{l}\text { h. Quanto tempo você } \\
\text { tem se sentido uma } \\
\text { pessoa feliz? }\end{array}$ & 1 & 2 & 3 & 4 & 5 & 6 \\
\hline $\begin{array}{l}\text { i. Quanto tempo você } \\
\text { tem se sentido } \\
\text { cansado? }\end{array}$ & 1 & 2 & 3 & 4 & 5 & 6 \\
\hline
\end{tabular}


10. Durante as últimas quatro semanas, quanto do seu tempo a sua saúde física ou problemas emocionais interferiram com as suas atividades sociais (como visitar amigos, parentes, etc.)?

(circule uma)

. Todo o tempo

1

A maior parte do tempo.......................................................... 2

Alguma parte do tempo.................................................... 3

. Uma pequena parte do tempo........................................... 4

. Nenhuma parte do tempo...................................................... 5

11. O quanto verdadeiro ou falso é cada uma das afirmações para você?

(circule um número em cada linha)

\begin{tabular}{|l|c|c|c|c|c|}
\hline & $\begin{array}{c}\text { Definitiva- } \\
\text { mente } \\
\text { verdadeiro }\end{array}$ & $\begin{array}{c}\text { A maioria } \\
\text { das vezes } \\
\text { verdadei- } \\
\text { ro }\end{array}$ & $\begin{array}{c}\text { Não } \\
\text { sei }\end{array}$ & $\begin{array}{c}\text { A } \\
\text { maioria } \\
\text { das } \\
\text { vezes } \\
\text { falsa }\end{array}$ & $\begin{array}{c}\text { Definitiva- } \\
\text { mente } \\
\text { falsa }\end{array}$ \\
\hline $\begin{array}{l}\text { a. Eu costumo adoecer } \\
\text { um pouco mais } \\
\text { facilmente que as } \\
\text { outras pessoas }\end{array}$ & 1 & 2 & 3 & 4 & 5 \\
\hline $\begin{array}{l}\text { b. Eu sou tão saudável } \\
\text { quanto qualquer } \\
\text { pessoa que eu } \\
\text { conheço }\end{array}$ & 1 & 2 & 3 & 4 & 5 \\
\hline $\begin{array}{l}\text { c. Eu acho que a minha } \\
\text { saúde vai piorar }\end{array}$ & 1 & 2 & 3 & 4 & 5 \\
\hline $\begin{array}{l}\text { d. Minha saúde é } \\
\text { excelente }\end{array}$ & 1 & 2 & 3 & 4 & 5 \\
\hline
\end{tabular}




\section{Pontuação do questionário SF-36}

Para cada resposta é atribuído uma pontuação

\begin{tabular}{|c|c|c|}
\hline Questão & Resposta & Pontuação \\
\hline 01 & & $\begin{array}{l}5,0 \\
4,4 \\
3,4 \\
2,0 \\
1,0\end{array}$ \\
\hline 02 & \multicolumn{2}{|l|}{ Manter o mesmo valor da resposta } \\
\hline 03 & \multicolumn{2}{|l|}{ Soma de todos os valores } \\
\hline 04 & \multicolumn{2}{|l|}{ Soma de todos os valores } \\
\hline 05 & \multicolumn{2}{|l|}{ Soma de todos os valores } \\
\hline 06 & 2. & $\begin{array}{l}5 \\
4 \\
3 \\
2 \\
1\end{array}$ \\
\hline 07 & (1) & $\begin{array}{l}6 \\
5,4 \\
4,2 \\
3,1 \\
2,2 \\
1,0\end{array}$ \\
\hline 08 & 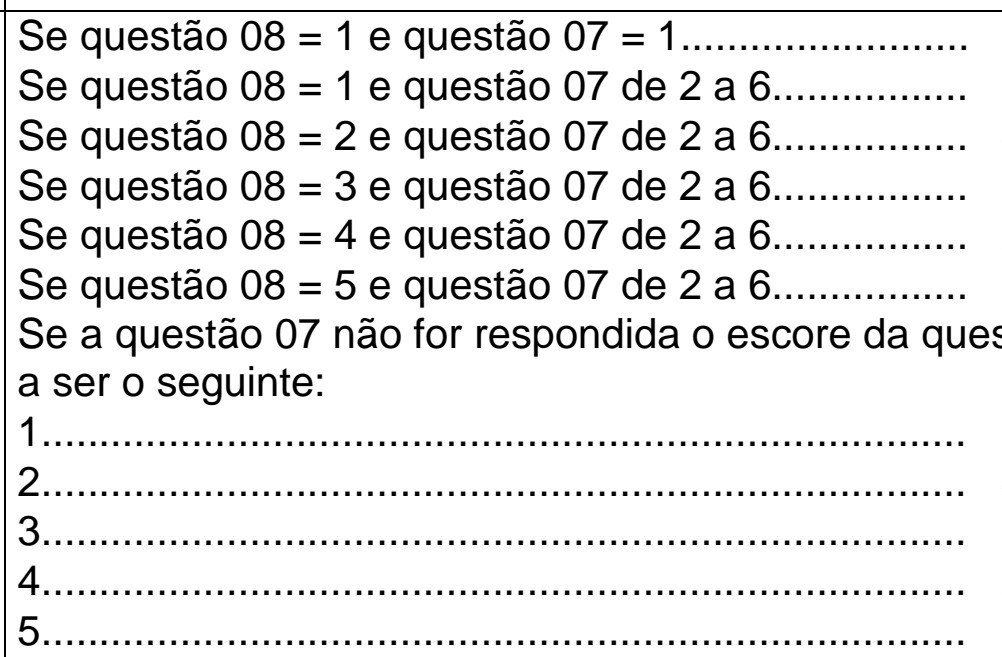 & $\begin{array}{l}6 \\
5 \\
4 \\
3 \\
2 \\
1 \\
\text { stão } 08 \text { passa } \\
\\
6 \\
4,75 \\
3,5 \\
2,25 \\
1,0\end{array}$ \\
\hline
\end{tabular}




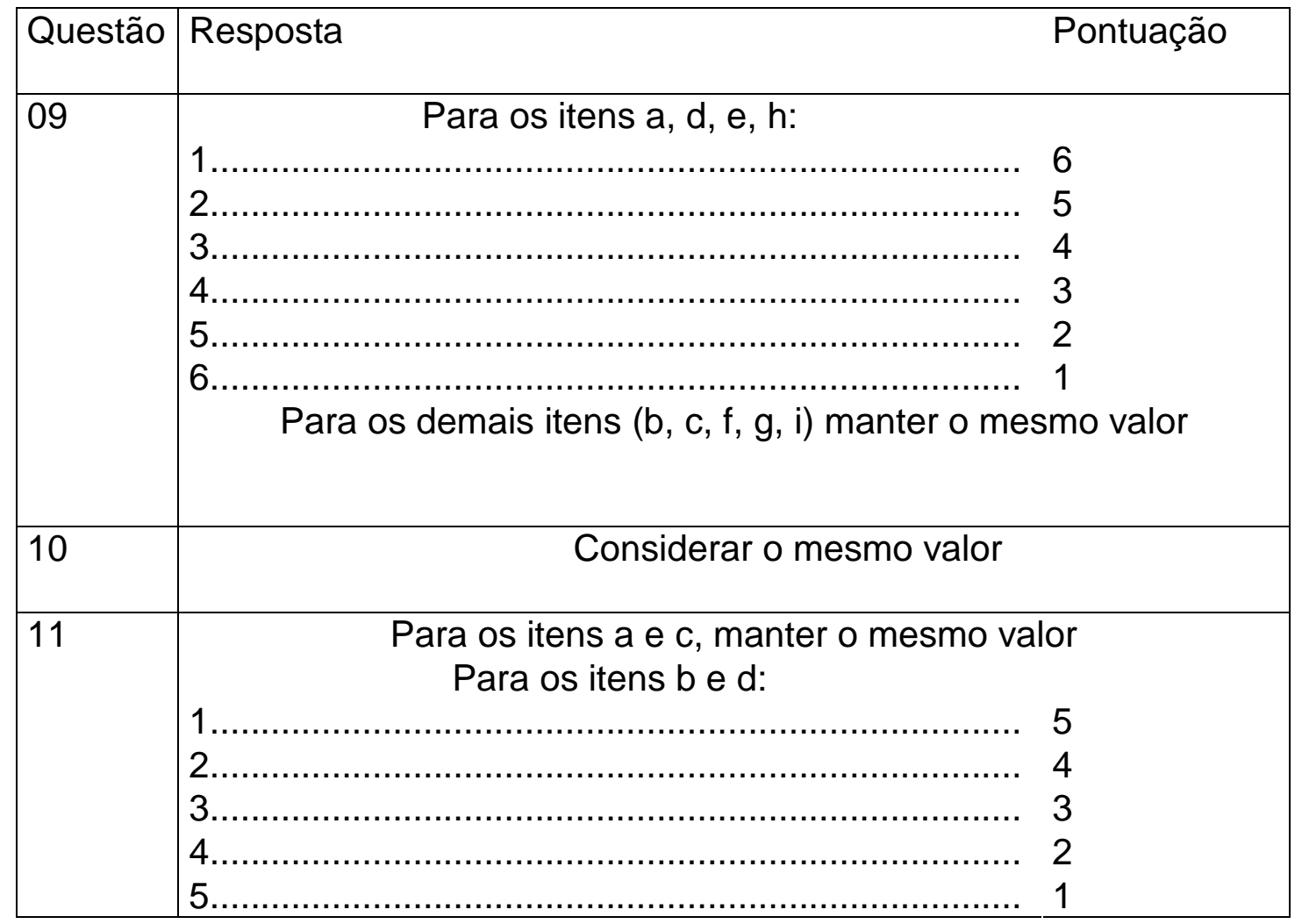




\section{Cálculo do "Raw Scale"}

Calcula-se, para cada domínio, um valor, de 0 (zero) a 100 (cem), onde zero e o pior e 100 o melhor. Para o cálculo, leva-se em consideração os dados do quadro abaixo.

\begin{tabular}{|l|c|c|c|}
\hline Domínios & $\begin{array}{c}\text { Pontuação } \\
\text { das questões }\end{array}$ & $\begin{array}{c}\text { Limite } \\
\text { inferior }\end{array}$ & $\begin{array}{c}\text { Variação } \\
\text { ("Score Range") }\end{array}$ \\
\hline Capacidade funcional & 03 & 10 & 20 \\
\hline Aspectos físicos & 04 & 4 & 4 \\
\hline Dor & $07+08$ & 2 & 10 \\
\hline Estado geral de saúde & $1+11$ & 5 & 20 \\
\hline Vitalidade & $09(\mathrm{a}+\mathrm{e}+\mathrm{g}+\mathrm{i})$ & 4 & 20 \\
\hline Aspectos sociais & $06+10$ & 2 & 8 \\
\hline Aspectos emocionais & $05(\mathrm{a}+\mathrm{b}+\mathrm{c})$ & 3 & 3 \\
\hline Saúde mental & $09(\mathrm{~b}+\mathrm{c}+\mathrm{d}+\mathrm{f}+\mathrm{h})$ & 5 & 25 \\
\hline
\end{tabular}

Fórmula para o cálculo de cada domínio:

(pontuação das questões correspondentes - limite inferior) $\times 100$ Variação ("Score Range") 


\section{REFERÊNCIAS}

1 Kopelman PG. Obesity as a medical problem. Nature 2000;404(6778):635-43.

2 Calle EE, Thun MJ, Petrelli JM, Rodriguez C, Heath CW, Jr. Body-mass index and mortality in a prospective cohort of U.S. adults. N Engl J Med 1999;341(15):1097-105.

3 Willett WC, Dietz WH, Colditz GA. Guidelines for healthy weight. N Engl J Med 1999;341(6):427-34.

4 Krauss RM, Winston M, Fletcher BJ, Grundy SM. Obesity : impact on cardiovascular disease. Circulation 1998;98(14):1472-6.

5 Thompson D, Edelsberg J, Colditz GA, Bird AP, Oster G. Lifetime health and economic consequences of obesity. Arch Intern Med 1999;159(18):2177-83 .

6 Clinical Guidelines on the Identification, Evaluation, and Treatment of Overweight and Obesity in Adults--The Evidence Report. Obes Res 1998;6 Suppl 2:51S-209S.

7 National Institutes of Health. National Heart, Lung, and Blood Institute. North American Association for the Study of Obesity. The Practical Guide - Identification, Evaluation, and Treatment of Overweight and Obesity in Adults. NIH Publication Number 00-4084. Bethesda: National Institutes of Health; october 2000. 
8 World Health Organization. Obesity: preventing and managing the global epidemic. Report of a WHO consultation. World Health Organ Tech Rep Ser; 894. Geneva: World Health Organization; 2000.

9 James PT, Leach R, Kalamara E, Shayeghi M. The worldwide obesity epidemic. Obes Res 2001;9 Suppl 4:228S-233S.

10 Consenso Latino-Americano de Obesidade. Arq Bras Endocrinol Metab 1999;43(1):21-67.

11 Third Report of the National Cholesterol Education Program (NCEP) Expert Panel on Detection, Evaluation, and Treatment of High Blood Cholesterol in Adults (Adult Treatment Panel III) final report. Circulation 2002;106(25):3143-421.

12 Snitker S, Macdonald I, Ravussin E, Astrup A. The sympathetic nervous system and obesity: role in aetiology and treatment. Obes Rev $2000 ; 1(1): 5-15$.

13 Grassi G, Seravalle G, Cattaneo BM, Bolla GB, Lanfranchi A, Colombo M, Giannattasio C, Brunani A, Cavagnini F, Mancia G. Sympathetic activation in obese normotensive subjects. Hypertension 1995;25(4 Pt 1):560-3.

14 Huikuri HV, Ylitalo A, Pikkujamsa SM, Ikaheimo MJ, Airaksinen KE, Rantala AO, Lilja M, Kesaniemi YA. Heart rate variability in systemic hypertension. Am J Cardiol 1996;77(12):1073-7.

15 Grassi G, Seravalle G, Colombo M, Bolla G, Cattaneo BM, Cavagnini F, Mancia G. Body weight reduction, sympathetic nerve traffic, and arterial 
baroreflex in obese normotensive humans. Circulation 1998;97(20):203742.

16 Poirier P, Giles TD, Bray GA, Hong Y, Stern JS, Pi-Sunyer FX, Eckel RH. Obesity and cardiovascular disease: pathophysiology, evaluation, and effect of weight loss: an update of the 1997 American Heart Association Scientific Statement on Obesity and Heart Disease from the Obesity Committee of the Council on Nutrition, Physical Activity, and Metabolism. Circulation 2006;113(6):898-918.

17 Klein S, Burke LE, Bray GA, Blair S, Allison DB, Pi-Sunyer X, Hong Y, Eckel $\mathrm{RH}$. Clinical implications of obesity with specific focus on cardiovascular disease: a statement for professionals from the American Heart Association Council on Nutrition, Physical Activity, and Metabolism: endorsed by the American College of Cardiology Foundation. Circulation 2004;110(18):2952-67.

18 Low PA. Testing the autonomic nervous system. Semin Neurol 2003;23(4):407-21.

19 Assessment: Clinical autonomic testing report of the Therapeutics and Technology Assessment Subcommittee of the American Academy of Neurology. Neurology 1996;46(3):873-80.

20 Grassi G, Esler M. How to assess sympathetic activity in humans. J Hypertens 1999;17(6):719-34.

21 De Angelis K, Santos MSB, Irigoyen MC. Sistema nervoso autônomo e doença cardiovascular. Revista da Sociedade de Cardiologia do Rio Grande do Sul [internet]. 2004;3:[7 páginas]. 
22 Coppack SW, Horowitz JF, Paramore DS, Cryer PE, Royal HD, Klein S. Whole body, adipose tissue, and forearm norepinephrine kinetics in lean and obese women. Am J Physiol 1998;275(5 Pt 1):E830-4.

23 Vaz M, Jennings G, Turner A, Cox H, Lambert G, Esler M. Regional sympathetic nervous activity and oxygen consumption in obese normotensive human subjects. Circulation 1997;96(10):3423-9.

24 Rumantir MS, Vaz M, Jennings GL, Collier G, Kaye DM, Seals DR, Wiesner GH, Brunner-La Rocca HP, Esler MD. Neural mechanisms in human obesity-related hypertension. J Hypertens 1999;17(8):1125-33.

25 Eckberg DL. Physiological basis for human autonomic rhythms. Ann Med 2000;32(5):341-9 .

26 Parati G. Arterial baroreflex control of heart rate: determining factors and methods to assess its spontaneous modulation. J Physiol 2005;565(Pt 3):706-7.

27 Laaksonen DE, Laitinen T, Schonberg J, Rissanen A, Niskanen LK. Weight loss and weight maintenance, ambulatory blood pressure and cardiac autonomic tone in obese persons with the metabolic syndrome. $J$ Hypertens 2003;21(2):371-8.

28 Piccirillo G, Vetta F, Viola E, Santagada E, Ronzoni S, Cacciafesta M, Marigliano V. Heart rate and blood pressure variability in obese normotensive subjects. Int J Obes Relat Metab Disord 1998;22(8):74150.

29 Lombardi F. Clinical implications of present physiological understanding of HRV components. Card Electrophysiol Rev 2002;6(3):245-9. 
30 Heart rate variability: standards of measurement, physiological interpretation and clinical use. Task Force of the European Society of Cardiology and the North American Society of Pacing and Electrophysiology. Circulation 1996;93(5):1043-65.

31 Sociedade Brasileira de Cardiologia. Diretrizes para avaliação e tratamento de pacientes com arritmias cardíacas. Arq Bras Cardiol 2002;79(suplemento 5):7-50.

32 Bigger JT, Jr., Fleiss JL, Steinman RC, Rolnitzky LM, Kleiger RE, Rottman JN. Frequency domain measures of heart period variability and mortality after myocardial infarction. Circulation 1992;85(1):164-71.

33 Binder T, Frey B, Porenta G, Heinz G, Wutte M, Kreiner G, Gossinger H, Schmidinger H, Pacher R, Weber H. Prognostic value of heart rate variability in patients awaiting cardiac transplantation. Pacing Clin Electrophysiol 1992;15(11 Pt 2):2215-20.

34 Tsuji H, Venditti FJ, Jr., Manders ES, Evans JC, Larson MG, Feldman $\mathrm{CL}$, Levy D. Reduced heart rate variability and mortality risk in an elderly cohort. The Framingham Heart Study. Circulation 1994;90(2):878-83.

35 Messerli FH, Nunez BD, Ventura HO, Snyder DW. Overweight and sudden death. Increased ventricular ectopy in cardiopathy of obesity. Arch Intern Med 1987;147(10):1725-8.

36 Kannel WB, McGee DL, Schatzkin A. An epidemiological perspective of sudden death. 26-year follow-up in the Framingham Study. Drugs 1984;28 Suppl 1:1-16. 
37 Albert CM, Chae CU, Grodstein F, Rose LM, Rexrode KM, Ruskin JN, Stampfer MJ, Manson JE. Prospective study of sudden cardiac death among women in the United States. Circulation 2003;107(16):2096-101.

38 Sudden cardiac death in obesity and hypertension. Lancet 1988;1(8586):628-9.

39 Hirsch J, Leibel RL, Mackintosh R, Aguirre A. Heart rate variability as a measure of autonomic function during weight change in humans. $A m J$ Physiol 1991;261(6 Pt 2):R1418-23.

40 Arone LJ, Mackintosh R, Rosenbaum M, Leibel RL, Hirsch J. Autonomic nervous system activity in weight gain and weight loss. Am J Physiol 1995;269(1 Pt 2):R222-5.

41 Emdin M, Gastaldelli A, Muscelli E, Macerata A, Natali A, Camastra S, Ferrannini E. Hyperinsulinemia and autonomic nervous system dysfunction in obesity: effects of weight loss. Circulation 2001;103(4):513-9.

42 Rissanen P, Franssila-Kallunki A, Rissanen A. Cardiac parasympathetic activity is increased by weight loss in healthy obese women. Obes Res $2001 ; 9(10): 637-43$.

43 Poirier P, Hernandez TL, Weil KM, Shepard TJ, Eckel RH. Impact of dietinduced weight loss on the cardiac autonomic nervous system in severe obesity. Obes Res 2003;11(9):1040-7.

44 Facchini M, Malfatto G, Sala L, Silvestri G, Fontana P, Lafortuna C, Sartorio A. Changes of autonomic cardiac profile after a 3-week 
integrated body weight reduction program in severely obese patients. $J$ Endocrinol Invest 2003;26(2):138-42.

45 Esposito K, Marfella R, Gualdiero P, Carusone C, Pontillo A, Giugliano G, Nicoletti G, Giugliano D. Sympathovagal balance, nighttime blood pressure, and QT intervals in normotensive obese women. Obes Res 2003;11(5):653-9.

46 Sutton R, Bloomfield DM. Indications, methodology, and classification of results of tilt-table testing. Am J Cardiol 1999;84(8A):10Q-19Q.

47 Grubb BP. Neurocardiogenic syncope and related disorders of orthostatic intolerance. Circulation 2005;111(22):2997-3006.

48 Sealey B, Lui K. Diagnosis and management of vasovagal syncope and dysautonomia. AACN Clin Issues 2004;15(3):462-77.

49 O'Leary DD, Kimmerly DS, Cechetto AD, Shoemaker JK. Differential effect of head-up tilt on cardiovagal and sympathetic baroreflex sensitivity in humans. Exp Physiol 2003;88(6):769-74.

50 Bloomfield DM. Strategy for the management of vasovagal syncope. Drugs Aging 2002;19(3):179-202.

51 Medow MS, Stewart JM. The postural tachycardia syndrome. Cardiol Rev 2007;15(2):67-75.

52 Brunetto AF, Roseguini AT, Silva BM, Hirai DM, Guedes DP. Respostas autonômicas cardíacas à manobra de tilt em adolescentes obesos. Rev Assoc Med Bras 2005;51(5):256-60. 
53 Zahorska-Markiewicz B, Mizia-Stec K, Jastrzebska-Maj E, Mandecki T, Bilewicz-Wyrozumska T, Mucha Z, Gasior Z. Tilt table testing in obesity. Int J Cardiol 2003;88(1):43-8.

54 Karason K, Molgaard H, Wikstrand J, Sjostrom L. Heart rate variability in obesity and the effect of weight loss. Am J Cardiol 1999;83(8):1242-7.

55 van de Borne P, Watrin I, Bouquegneau M, Gilles A, Houben JJ, Fery F, Degaute JP. Ambulatory blood pressure and neuroendocrine control after diet-assisted gastric restrictive surgery. J Hypertens 2000;18(3):301-6.

56 Troisi RJ, Weiss ST, Parker DR, Sparrow D, Young JB, Landsberg L. Relation of obesity and diet to sympathetic nervous system activity. Hypertension 1991;17(5):669-77.

57 Young JB, Macdonald IA. Sympathoadrenal activity in human obesity: heterogeneity of findings since 1980. Int J Obes Relat Metab Disord 1992;16(12):959-67.

58 Grassi G, Dell'Oro R, Facchini A, Quarti Trevano F, Bolla GB, Mancia G. Effect of central and peripheral body fat distribution on sympathetic and baroreflex function in obese normotensives. $J$ Hypertens 2004;22(12):2363-9.

59 Peterson HR, Rothschild M, Weinberg CR, Fell RD, McLeish KR, Pfeifer MA. Body fat and the activity of the autonomic nervous system. $N$ Engl J Med 1988;318(17):1077-83.

60 McTigue KM, Harris R, Hemphill B, Lux L, Sutton S, Bunton AJ, Lohr KN. Screening and interventions for obesity in adults: summary of the 
evidence for the U.S. Preventive Services Task Force. Ann Intern Med 2003;139(11):933-49.

61 Mitka M. Surgery for obesity: demand soars amid scientific, ethical questions. Jama 2003;289(14):1761-2.

62 Steinbrook R. Surgery for severe obesity. $N$ Engl $J$ Med 2004;350(11):1075-9.

63 Livingston EH. Obesity and its surgical management. Am J Surg 2002;184(2):103-13.

64 Capella JF, Capella RF. The weight reduction operation of choice: vertical banded gastroplasty or gastric bypass? Am J Surg 1996;171(1):74-9.

65 Sjostrom L, Lindroos AK, Peltonen M, Torgerson J, Bouchard C, Carlsson B, Dahlgren S, Larsson B, Narbro K, Sjostrom CD, Sullivan M, Wedel H. Lifestyle, diabetes, and cardiovascular risk factors 10 years after bariatric surgery. N Engl J Med 2004;351(26):2683-93.

66 Sjostrom CD, Peltonen M, Wedel H, Sjostrom L. Differentiated long-term effects of intentional weight loss on diabetes and hypertension. Hypertension 2000;36(1):20-5.

67 Sjostrom CD, Peltonen M, Sjostrom L. Blood pressure and pulse pressure during long-term weight loss in the obese: the Swedish Obese Subjects (SOS) Intervention Study. Obes Res 2001;9(3):188-95.

68 Maggard MA, Shugarman LR, Suttorp M, Maglione M, Sugerman HJ, Livingston EH, Nguyen NT, Li Z, Mojica WA, Hilton L, Rhodes S, Morton 
SC, Shekelle PG. Meta-analysis: surgical treatment of obesity. Ann Intern Med 2005;142(7):547-59.

69 Colquitt J, Clegg A, Loveman E, Royle P, Sidhu MK. Surgery for morbid obesity. Cochrane Database Syst Rev 2005(4):CD003641.

70 Buchwald H, Avidor Y, Braunwald E, Jensen MD, Pories W, Fahrbach K, Schoelles K. Bariatric surgery: a systematic review and meta-analysis. Jama 2004;292(14):1724-37.

71 Lara MD, Kothari SN, Sugerman HJ. Surgical management of obesity: a review of the evidence relating to the health benefits and risks. Treat Endocrinol 2005;4(1):55-64.

72 Shekelle PG, Morton SC, Maglione M, Suttorp M, Tu W, Li Z, Maggard M, Mojica WA, Shugarman L, Solomon V. Pharmacological and surgical treatment of obesity. Evid Rep Technol Assess (Summ) 2004(103):1-6.

73 Kushner RF, Noble CA. Long-term outcome of bariatric surgery: an interim analysis. Mayo Clin Proc 2006;81 (10 Suppl):S46-51.

74 Sugerman HJ, Wolfe LG, Sica DA, Clore JN. Diabetes and hypertension in severe obesity and effects of gastric bypass-induced weight loss. Ann Surg 2003;237(6):751-6; discussion 757-8.

75 Christou NV, Sampalis JS, Liberman M, Look D, Auger S, McLean AP, MacLean LD. Surgery decreases long-term mortality, morbidity, and health care use in morbidly obese patients. Ann Surg 2004;240(3):41623; discussion 423-4. 
76 Hoeldtke RD, Dworkin GE, Gaspar SR, Israel BC. Sympathotonic orthostatic hypotension: a report of four cases. Neurology 1989;39(1):3440.

77 Rubinshtein R, Ciubotaru M, Elad H, Bitterman H. Severe orthostatic hypotension following weight reduction surgery. Arch Intern Med 2001;161(17):2145-7.

78 Lascano CA, Szomstein S, Zundel N, Rosenthal RJ. Diabetes mellitusassociated diffuse autonomic dysfunction causing debilitating hypotension manifested after rapid weight loss in a morbidly obese patient: case report and review of the literature. Surg Obes Relat Dis 2005;1(4):443-6.

79 Pickering TG, Hall JE, Appel LJ, Falkner BE, Graves J, Hill MN, Jones DW, Kurtz T, Sheps SG, Roccella EJ. Recommendations for blood pressure measurement in humans and experimental animals: Part 1: blood pressure measurement in humans: a statement for professionals from the Subcommittee of Professional and Public Education of the American Heart Association Council on High Blood Pressure Research. Hypertension 2005;45(1):142-61.

80 Guimaraes JI, Sosa E, Brito FS, Maia I, Pachón Mateos JC, Gizzi J, Fagundes M, Martinelli Filho M, Costa R, d'Ávila A, Lorga Filho A, Pedrosa A, da Costa LB, Peres A, Grupi C, Cirenza C, Moreira D, Sobral D, Hachul D, D'Andréia E, Good God EM, Fenelon G, Lima GG, Brito H, Moura Jorge JC, de Andrade JC, Ribeiro JC, Pimenta J, de Vasconcelos JT, Zimerman L, Figueiredo M, Valente M, Medeiros P, Miranda RC, 
Kunyioshi R, Sá R, Rassi SG, Siqueira S, Galvão S, Nishioka S, Grillo T, Rodrigues TR, Maciel W. Normatização dos equipamentos e técnicas para realização de exames de teste de inclinação ortostática (tilt table test). Arq Bras Cardiol 2002;79(suppl IV):1-18.

81 Consensus statement on the definition of orthostatic hypotension, pure autonomic failure, and multiple system atrophy. The Consensus Committee of the American Autonomic Society and the American Academy of Neurology. Neurology 1996;46(5):1470.

82 Henry JB. Clinical diagnosis and management by laboratory methods. 20th ed. Philadelphia: W.B. Saunders Company; 2001.

83 Jones CR, Taylor K, Chowienczyk P, Poston L, Shennan AH. A validation of the Mobil O Graph (version 12) ambulatory blood pressure monitor. Blood Press Monit 2000;5(4):233-8.

84 Alessi A, Brandao AA, Pierin A, Feitosa AM, Machado CA, de Moraes Forjaz CL, Atie CS, Giorgi DM, Mion Jr D, Rosa EC, Nobre F, Silva GV, Chaves Jr H, Pascoal IJ, Guimaraes JI, Santello JL, Ribeiro JM, Praxedes JN, Ortega KC, da Costa LS, Bortolotto LA, Gomes MA, Wajngarten M, Gus M, Kohlmann Jr O, Jardim PC, Geleilete TJ, Koch V. IV Diretriz para uso da monitorização ambulatorial da pressão arterial. II Diretriz para o uso da monitorização residencial da pressão arterial. IV MAPA/II MRPA. Arq Bras Cardiol 2005;85 Suppl 2:1-18.

85 Friedewald WT, Levy RI, Fredrickson DS. Estimation of the concentration of low-density lipoprotein cholesterol in plasma, without use of the preparative ultracentrifuge. Clin Chem 1972;18(6):499-502. 
86 Ciconelli RM. Tradução para o português e validação do Questionário Genérico de Avaliação de Qualidade de Vida "Medical Outcomes Study 36ltem Short-form Health Survey (SF-36)" [doutorado]. São Paulo: Universidade Federal de São Paulo; 1997.

87 Twisk JWR. Applied longitudinal data analysis for epidemiology: a practical guide. Cambridge: Cambridge University Press; 2003.

88 Dart AM, Du XJ, Kingwell BA. Gender, sex hormones and autonomic nervous control of the cardiovascular system. Cardiovasc Res 2002;53(3):678-87.

89 Antelmi I, de Paula RS, Shinzato AR, Peres CA, Mansur AJ, Grupi CJ. Influence of age, gender, body mass index, and functional capacity on heart rate variability in a cohort of subjects without heart disease. Am J Cardiol 2004;93(3):381-5.

90 La Rovere MT, Bigger JT, Jr., Marcus FI, Mortara A, Schwartz PJ. Baroreflex sensitivity and heart-rate variability in prediction of total cardiac mortality after myocardial infarction. ATRAMI (Autonomic Tone and Reflexes After Myocardial Infarction) Investigators. Lancet 1998;351(9101):478-84.

91 Sjostrom CD, Lissner L, Wedel H, Sjostrom L. Reduction in incidence of diabetes, hypertension and lipid disturbances after intentional weight loss induced by bariatric surgery: the SOS Intervention Study. Obes Res 1999;7(5):477-84 . 
92 Scherrer U, Sartori C. Insulin as a vascular and sympathoexcitatory hormone: implications for blood pressure regulation, insulin sensitivity, and cardiovascular morbidity. Circulation 1997;96(11):4104-13.

93 Paolisso G, Manzella D, Tagliamonte MR, Rizzo MR, Gambardella A, Varricchio M. Effects of different insulin infusion rates on heart rate variability in lean and obese subjects. Metabolism 1999;48(6):755-62.

94 Grubb BP. Clinical practice. Neurocardiogenic syncope. N Engl J Med 2005;352(10):1004-10 .

95 Natale A, Akhtar M, Jazayeri M, Dhala A, Blanck Z, Deshpande S, Krebs A, Sra JS. Provocation of hypotension during head-up tilt testing in subjects with no history of syncope or presyncope. Circulation 1995;92(1):54-8.

96 Goldstein DS, Robertson D, Esler M, Straus SE, Eisenhofer G. Dysautonomias: clinical disorders of the autonomic nervous system. Ann Intern Med 2002;137(9):753-63.

97 Lee WJ, Huang MT, Wang W, Lin CM, Chen TC, Lai IR. Effects of obesity surgery on the metabolic syndrome. Arch Surg 2004;139(10):1088-92.

98 Busetto L, Sergi G, Enzi G, Segato G, De Marchi F, Foletto M, De Luca M, Pigozzo S, Favretti F. Short-term effects of weight loss on the cardiovascular risk factors in morbidly obese patients. Obes Res 2004;12(8):1256-63.

99 Shargorodsky M, Fleed A, Boaz M, Gavish D, Zimlichman R. The effect of a rapid weight loss induced by laparoscopic adjustable gastric banding 
on arterial stiffness, metabolic and inflammatory parameters in patients with morbid obesity. Int J Obes (Lond) 2006;30(11):1632-8.

100 Silvestre V, Ruano M, Dominguez Y, Castro R, Garcia-Lescun MC, Rodriguez A, Marco A, Garcia-Blanch G. Morbid obesity and gastric bypass surgery: biochemical profile. Obes Surg 2004;14(9):1227-32.

101 Nguyen NT, Varela E, Sabio A, Tran CL, Stamos M, Wilson SE. Resolution of hyperlipidemia after laparoscopic Roux-en-Y gastric bypass. J Am Coll Surg 2006;203(1):24-9.

102 Brolin RE, Bradley LJ, Wilson AC, Cody RP. Lipid risk profile and weight stability after gastric restrictive operations for morbid obesity. $J$ Gastrointest Surg 2000;4(5):464-9.

103 Mulvihill NT, Foley JB. Inflammation in acute coronary syndromes. Heart 2002;87(3):201-4.

104 Luc G, Bard JM, Juhan-Vague I, Ferrieres J, Evans A, Amouyel P, Arveiler D, Fruchart JC, Ducimetiere P. C-reactive protein, interleukin-6, and fibrinogen as predictors of coronary heart disease: the PRIME Study. Arterioscler Thromb Vasc Biol 2003;23(7):1255-61.

105 Wolk R, Berger P, Lennon RJ, Brilakis ES, Somers VK. Body mass index: a risk factor for unstable angina and myocardial infarction in patients with angiographically confirmed coronary artery disease. Circulation 2003;108(18):2206-11 .

106 Armstrong EJ, Morrow DA, Sabatine MS. Inflammatory biomarkers in acute coronary syndromes: part II: acute-phase reactants and 
biomarkers of endothelial cell activation. Circulation 2006;113(7):e1525.

107 Kopp HP, Kopp CW, Festa A, Krzyzanowska K, Kriwanek S, Minar E, Roka R, Schernthaner G. Impact of weight loss on inflammatory proteins and their association with the insulin resistance syndrome in morbidly obese patients. Arterioscler Thromb Vasc Biol 2003;23(6):1042-7.

108 van Dielen FM, Buurman WA, Hadfoune M, Nijhuis J, Greve JW. Macrophage inhibitory factor, plasminogen activator inhibitor-1, other acute phase proteins, and inflammatory mediators normalize as a result of weight loss in morbidly obese subjects treated with gastric restrictive surgery. J Clin Endocrinol Metab 2004;89(8):4062-8.

109 Kopp HP, Krzyzanowska K, Mohlig M, Spranger J, Pfeiffer AF, Schernthaner G. Effects of marked weight loss on plasma levels of adiponectin, markers of chronic subclinical inflammation and insulin resistance in morbidly obese women. Int J Obes (Lond) 2005;29(7):76671.

110 Holdstock C, Lind L, Engstrom BE, Ohrvall M, Sundbom M, Larsson A, Karlsson FA. CRP reduction following gastric bypass surgery is most pronounced in insulin-sensitive subjects. Int $J$ Obes (Lond) 2005;29(10):1275-80.

111 Kolotkin RL, Meter K, Williams GR. Quality of life and obesity. Obes Rev 2001;2(4):219-29. 
112 Livingston EH, Fink AS. Quality of life: cost and future of bariatric surgery. Arch Surg 2003;138(4):383-8.

113 Ballantyne $\mathrm{GH}$. Measuring outcomes following bariatric surgery: weight loss parameters, improvement in co-morbid conditions, change in quality of life and patient satisfaction. Obes Surg 2003;13(6):954-64.

114 Mamplekou E, Komesidou V, Bissias C, Papakonstantinou A, Melissas J. Psychological condition and quality of life in patients with morbid obesity before and after surgical weight loss. Obes Surg 2005;15(8):1177-84.

115 Fontaine KR, Barofsky I. Obesity and health-related quality of life. Obes $\operatorname{Rev} 2001 ; 2(3): 173-82$.

116 Weiner S, Sauerland S, Fein M, Blanco R, Pomhoff I, Weiner RA. The Bariatric Quality of Life index: a measure of well-being in obesity surgery patients. Obes Surg 2005;15(4):538-45.

117 Le Pen C, Levy E, Loos F, Banzet MN, Basdevant A. "Specific" scale compared with "generic" scale: a double measurement of the quality of life in a French community sample of obese subjects. J Epidemiol Community Health 1998;52(7):445-50.

118 Mannucci E, Ricca V, Barciulli E, Di Bernardo M, Travaglini R, Cabras PL, Rotella CM. Quality of life and overweight: the obesity related wellbeing (Orwell 97) questionnaire. Addict Behav 1999;24(3):345-57.

119 Butler GS, Vallis TM, Perey B, Veldhuyzen van Zanten SJ, MacDonald AS, Konok G. The Obesity Adjustment Survey: development of a scale 
to assess psychological adjustment to morbid obesity. Int $J$ Obes Relat Metab Disord 1999;23(5):505-11.

120 Maser RE, Lenhard MJ. Cardiovascular autonomic neuropathy due to diabetes mellitus: clinical manifestations, consequences, and treatment. J Clin Endocrinol Metab 2005;90(10):5896-903.

121 Aring AM, Jones DE, Falko JM. Evaluation and prevention of diabetic neuropathy. Am Fam Physician 2005;71(11):2123-8.

122 Boulton AJ, Vinik Al, Arezzo JC, Bril V, Feldman EL, Freeman R, Malik RA, Maser RE, Sosenko JM, Ziegler D. Diabetic neuropathies: a statement by the American Diabetes Association. Diabetes Care 2005;28(4):956-62.

123 Chobanian AV, Bakris GL, Black HR, Cushman WC, Green LA, Izzo JL, Jr., Jones DW, Materson BJ, Oparil S, Wright JT, Jr., Roccella EJ. Seventh report of the Joint National Committee on Prevention, Detection, Evaluation, and Treatment of High Blood Pressure. Hypertension 2003;42(6):1206-52.

124 Czupryniak L, Strzelczyk J, Pawlowski M, Loba J. Circadian blood pressure variation in morbidly obese hypertensive patients undergoing gastric bypass surgery. Am J Hypertens 2005;18(4 Pt 1):446-51. 


\section{APÊNDICE 1}

\section{HOSPITAL DAS CLÍNICAS}

DA

FACULDADE DE MEDICINA DA UNIVERSIDADE DE SÃO PAULO

TERMO DE CONSENTIMENTO LIVRE E ESCLARECIDO

\section{I - DADOS DE IDENTIFICAÇÃO DO SUJEITO DA PESQUISA OU RESPONSÁVEL LEGAL}

1.NOME DO PACIENTE.

DOCUMENTO DE IDENTIDADE № : SEXO : .M $\square$ F $\square$

DATA NASCIMENTO:

ENDEREÇO №

APTO:

BAIRRO: CIDADE

CEP: TELEFONE: DDD

.)

2.RESPONSÁVEL LEGAL

NATUREZA (grau de parentesco, tutor, curador etc.)

DOCUMENTO DE IDENTIDADE : SEXO: $M \square \quad F \square$

DATA NASCIMENTO.:

ENDEREÇO: №

APTO:

BAIRRO: CIDADE:

CEP: TELEFONE: DDD

.).

\section{II - DADOS SOBRE A PESQUISA CIENTÍFICA}

1. TíTULO DO PROTOCOLO DE PESQUISA Padrão autonômico cardiovascular e tratamento cirúrgico da obesidade: Influência da gastroplastia.

PESQUISADOR: Marcos Borges Machado

CARGO/FUNÇÃO: .Médico INSCRIÇÃO CONSELHO REGIONAL № 13837-PR UNIDADE DO HCFMUSP: Emergências Clínicas

3. AVALIAÇÃO DO RISCO DA PESQUISA:

$\begin{array}{lllll}\text { SEM RISCO } & \square & \text { RISCO MÍNIMO } & \mathbf{X} & \text { RISCO MÉDIO } \\ \text { RISCO BAIXO } & \square & \text { RISCO MAIOR } & \square\end{array}$

(probabilidade de que o indivíduo sofra algum dano como consequência imediata ou tardia do estudo)

4.DURAÇÃO DA PESQUISA : 2 ANOS 


\section{III - REGISTRO DAS EXPLICAÇÕES DO PESQUISADOR AO PACIENTE OU SEU REPRESENTANTE LEGAL SOBRE A PESQUISA CONSIGNANDO:}

\section{1 - justificativa e os objetivos da pesquisa :}

O tratamento da obesidade através de cirurgia tem se tornado comum em vários países. É um tratamento efetivo, levando a redução e manutenção do peso. Estudos tem sido realizados para a documentação dos benefícios da cirurgia no que se refere a melhora da saúde geral do paciente. $\mathrm{Na}$ área cardiológica os estudos ainda são poucos, porém sugerem benefício, com melhora da hipertensão arterial e melhor controle de outros fatores de risco para infarto do miocárdio, como diabete melito e dislipidemia.

O objetivo da pesquisa é avaliar o efeito da cirurgia sobre a parte do sistema nervoso que regula os batimentos do coração nas diversas situações a que o organismo é submetido durante o dia e a noite.

\section{2 - Procedimentos que serão utilizados e propósitos, incluindo a identificação dos procedimentos que são experimentais:}

Para esta avaliação, o senhor (ou senhora), que já está com a cirurgia para a redução do estômago marcada, fará alguns exames antes da operação e após 6 meses. São exames de sangue, urina e mais três exames que analisam a frequência dos batimentos do coração e a pressão arterial.

Os exames de sangue servirão para medir colesterol, triglicérides, glicemia (diabete) e outras alterações que podem aumentar o risco para problemas no coração. $\mathrm{O}$ exame de urina será feito com a coleta de urina de 24 horas, ou seja, de um dia inteiro, e servirá para medir substâncias que aumentam a pressão arterial e o número de batidas do coração.

\section{3 - Desconfortos e riscos esperados:}

Será feito um exame chamado eletrocardiografia ambulatorial de 24 horas, que é um eletrocardiograma com 24 horas de duração. Serão colocados, no peito, 4 adesivos pequenos chamados eletrodos, os quais são ligados por fios a um pequeno gravador de eletrocardiograma, que fica preso a um cinto, na cintura. O senhor (ou senhora), será liberado, para manter suas atividades normais, em casa, no trabalho e a noite, retornando no outro dia para retirar o gravador. Este aparelho grava o eletrocardiograma das 24 horas. A gravação será analisada pelo médico que está fazendo a pesquisa.

Outro exame, chamado monitorização ambulatorial da pressão arterial de 24 horas, medirá a pressão arterial automaticamente a cada 20 minutos durante o dia e a cada 30 minutos durante a noite. É feito com a colocação de uma braçadeira no braço esquerdo, semelhante aquelas dos aparelhos comuns de pressão arterial, que é conectada a um aparelho, preso na cintura por um cinto, que realizará e registrará as medidas da pressão arterial. O senhor (ou senhora), será liberado para manter suas atividades normais, retornando no outro dia para retirar o aparelho. As medidas da pressão arterial de todo o dia e noite serão analisadas pelo médico.

Um outro exame que será realizado é o teste da mesa inclinada. É um exame simples, em que o senhor (ou senhora), deitará em uma mesa, com apoio para os pés e cintos de segurança. São realizadas medidas de pressão arterial, dos batimentos cardíacos e eletrocardiograma. A mesa será inclinada para frente até 60 graus, ficando quase em pé. Serão estudas a frequência dos batimentos do coração, o eletrocardiograma e a pressão arterial, que será medida a cada dois minutos. A mesa ficará nesta posição por 40 minutos, ou até surgimento algum sintoma. Alguns pacientes podem apresentar queda da pressão 
arterial e ou redução dos batimentos cardíacos quando colocados nesta posição, podendo levar a sensação de mal estar, escurecimento da visão e perda dos sentidos. Estas alterações são causadas pela falta de capacidade do organismo de se adaptar à posição e sempre melhoram rapidamente com a volta da mesa à posição normal, não apresentando riscos para a saúde. São as mesmas alterações daquelas das pessoas que passam mal quando vêem sangue ou quando estão em lugares fechados.

Será também feito uma entrevista com uma psicóloga, para avaliar a qualidade da sua vida antes e depois de 6 meses da cirurgia. As perguntas serão feitas de acordo com um questionário padronizado, mundialmente conhecido.

\section{4 - Benefícios que poderão ser obtidos:}

Os exames a serem realizados são bem conhecidos na área de cardiologia e não oferecem perigo á sua saúde. Podem trazer informações muito importantes sobre as condições da sua pressão arterial e do seu coração. O fato deles serem feitos antes e após 6 meses da cirurgia, vai oferecer condições de medir o efeito da cirurgia sobre a pressão arterial, frequência dos batimentos cardíacos e sobre os resultados dos exames de sangue e urina.

5 - procedimentos alternativos que possam ser vantajosos para o indivíduo

\section{IV - ESCLARECIMENTOS DADOS PELO PESQUISADOR SOBRE GARANTIAS DO SUJEITO DA PESQUISA CONSIGNANDO:}

\section{1. acesso, a qualquer tempo, às informações sobre procedimentos, riscos e benefícios relacionados à pesquisa, inclusive para dirimir eventuais dúvidas.}

O senhor, ou senhora, terá acesso, a qualquer tempo, às informações sobre os exames a que será submetido, riscos e benefícios relacionados à pesquisa, inclusive para tirar eventuais dúvidas.

2. liberdade de retirar seu consentimento a qualquer momento e de deixar de participar do estudo, sem que isto traga prejuízo à continuidade da assistência.

Poderá retirar seu consentimento a qualquer momento, deixando de participar da pesquisa sem prejuízo à continuidade da sua assistência.

\section{3. salvaguarda da confidencialidade, sigilo e privacidade.}

Terá garantia de sigilo e privacidade

4. disponibilidade de assistência no HCFMUSP, por eventuais danos à saúde, decorrentes da pesquisa.

Será garantida assistência médica, no Hospital Regional Universitário de Maringá, por eventuais danos à saúde decorrentes da pesquisa.

\section{5. viabilidade de indenização por eventuais danos à saúde decorrentes da pesquisa.}

Não haverá indenização por eventuais danos a saúde decorrentes da pesquisa 
V. INFORMAÇÕES DE NOMES, ENDEREÇOS E TELEFONES DOS RESPONSÁVEIS PELO ACOMPANHAMENTO DA PESQUISA, PARA CONTATO EM CASO DE INTERCORRÊNCIAS CLÍNICAS E REAÇÕES ADVERSAS.

Pesquisador responsável: Nome: Marcos Borges Machado

Endereço: Avenida Independência, número 258, Sala 2, térreo.

Telefone: (44) 225-3555 ou (44) 9972-4683

Maringá - PR.

VI. OBSERVAÇÕES COMPLEMENTARES:

\section{VII - CONSENTIMENTO PÓS-ESCLARECIDO}

Declaro que, após convenientemente esclarecido pelo pesquisador e ter entendido o que me foi explicado, consinto em participar do presente Protocolo de Pesquisa

Maringá,

de

de 


\section{APÊNDICE 2}

FACULDADE DE MEDICINA DA UNIVERSIDADE DE SÃO PAULO $\mathrm{E}$ UNIVERSIDADE ESTADUAL DE MARINGÁ

\section{TERMO DE CONSENTIMENTO LIVRE E ESCLARECIDO}

\section{I - DADOS DE IDENTIFICAÇÃO DO SUJEITO DA PESQUISA OU RESPONSÁVEL LEGAL}

1- NOME DO PACIENTE:

DOCUMENTO DE IDENTIDADE NÚMERO:

SEXO: MASCULINO $\square$ FEMININO

DATA DE NASCIMENTO:

ENDEREÇO:

$$
\text { APTO: BAIRRO: }
$$

CEP:

NÚMERO: CIDADE: TELEFONE: ( )

2- RESPONSÁVEL LEGAL:

NATUREZA (grau de parentesco ou relação):

DOCUMENTO DE IDENTIDADE:

SEXO: MASCULINO FEMININO

DATA DE NASCIMENTO:

ENDEREÇO: NÚMERO:

CIDADE:

APTO:

BAIRRO:

TELEFONE: ( )

\section{II - PESQUISA CIENTÍFICA}

1- TÍTULO: PADRÃO AUTONÔMICO CARDIOVASCULAR E TRATAMENTO CIRÚRGICO DA OBESIDADE: INFLUÊNCIA DA GASTROPLASTIA. 
2- PESQUISADOR: Marcos Borges Machado, médico, CRM-PR 13837, professor do Curso de Medicina da Universidade Estadual de Maringá.

3- AVALIAÇÃO DO RISCO DA PESQUISA: Sem risco.

4- DURAÇÃO DA PESQUISA: dois anos - de julho de 2004 a junho de 2006.

\section{III - EXPLICAÇÕES DO PESQUISADOR SOBRE A PESQUISA}

O tratamento da obesidade através de cirurgia tem se tornado comum em vários países. É um tratamento efetivo, levando a redução e manutenção do peso. Estudos tem sido realizados para a documentação dos benefícios da cirurgia no que se refere a melhora da saúde geral do paciente. Na área cardiológica os estudos ainda são poucos, porém sugerem benefício, com melhora da hipertensão arterial e melhor controle de outros fatores de risco para infarto do miocárdio, como diabete melito e dislipidemia.

O objetivo da pesquisa é avaliar o efeito da cirurgia sobre a parte do sistema nervoso que regula os batimentos do coração nas diversas situações a que o organismo é submetido durante o dia e a noite.

Para esta avaliação, o senhor (ou senhora), que já está com a cirurgia para a redução do estômago marcada, fará alguns exames antes da operação e após 6 meses. São exames de sangue, urina e mais três exames que analisam a frequência dos batimentos do coração e a pressão arterial.

Os exames de sangue servirão para medir colesterol, triglicérides, glicemia (diabete) e outras alterações que podem aumentar o risco para problemas no coração. O exame de urina será feito com a coleta de urina de 24 horas, ou seja, de um dia inteiro, e servirá para medir substâncias que aumentam a pressão arterial e o número de batidas do coração.

Será feito um exame chamado eletrocardiografia ambulatorial de 24 horas, que é um eletrocardiograma com 24 horas de duração. Serão colocados, no peito, 4 adesivos pequenos chamados eletrodos, os quais são ligados por fios a um pequeno gravador de eletrocardiograma, que fica preso a um cinto, na cintura. O senhor (ou senhora), será liberado, para manter suas atividades normais, em casa, no trabalho e a noite, retornando no outro dia para retirar o gravador. Este aparelho grava o eletrocardiograma das 24 horas. A gravação será analisada pelo médico que está fazendo a pesquisa.

Outro exame, chamado monitorização ambulatorial da pressão arterial de 24 horas, medirá a pressão arterial automaticamente a cada 20 minutos durante o dia e a cada 30 minutos durante a noite. É feito com a colocação de uma braçadeira no braço esquerdo, semelhante aquelas dos aparelhos comuns de pressão arterial, que é conectada a um aparelho, preso na cintura por um cinto, que realizará e registrará as medidas da pressão arterial. O senhor (ou senhora), será liberado para manter suas atividades normais, retornando no outro dia para retirar o aparelho. As medidas da pressão arterial de todo o dia e noite serão analisadas pelo médico.

Um outro exame que será realizado é o teste da mesa inclinada. É um exame simples, em que o senhor (ou senhora), deitará em uma mesa, com apoio para os pés e cintos de segurança. São realizadas medidas de pressão arterial, dos batimentos 
cardíacos e eletrocardiograma. A mesa será inclinada para frente até 60 graus, ficando quase em pé. Serão estudas a frequência dos batimentos do coração, o eletrocardiograma e a pressão arterial, que será medida a cada dois minutos. A mesa ficará nesta posição por 40 minutos, ou até surgimento algum sintoma. Alguns pacientes podem apresentar queda da pressão arterial e ou redução dos batimentos cardíacos quando colocados nesta posição, podendo levar a sensação de mal estar, escurecimento da visão e perda dos sentidos. Estas alterações são causadas pela falta de capacidade do organismo de se adaptar à posição e sempre melhoram rapidamente com a volta da mesa à posição normal, não apresentando riscos para a saúde. São as mesmas alterações daquelas das pessoas que passam mal quando vêem sangue ou quando estão em lugares fechados.

Será também feito uma entrevista com uma psicóloga, para avaliar a qualidade da sua vida antes e depois de 6 meses da cirurgia. As perguntas serão feitas de acordo com um questionário padronizado, mundialmente conhecido.

Os exames a serem realizados são bem conhecidos na área de cardiologia e não oferecem perigo á sua saúde. Podem trazer informações muito importantes sobre as condições da sua pressão arterial e do seu coração. O fato deles serem feitos antes e após 6 meses da cirurgia, vai oferecer condições de medir o efeito da cirurgia sobre a pressão arterial, frequência dos batimentos cardíacos e sobre os resultados dos exames de sangue e urina.

\section{IV - GARANTIAS AO PACIENTE}

O senhor, ou senhora, terá acesso, a qualquer tempo, às informações sobre os exames a que será submetido, riscos e benefícios relacionados à pesquisa, inclusive para tirar eventuais dúvidas.

Poderá retirar seu consentimento a qualquer momento, deixando de participar da pesquisa sem prejuízo à continuidade da sua assistência.

Terá garantia de sigilo e privacidade.

Será garantida assistência médica, no Hospital Regional Universitário de Maringá, por eventuais danos à saúde decorrentes da pesquisa.

\section{V - CONTATO EM CASO DE INTERCORRÊNCIAS CLÍNICAS E REAÇÕES ADVERSAS DECORRENTES DA PESQUISA}

Pesquisador responsável: Nome: Marcos Borges Machado

Endereço: Avenida Independência, número 258, Sala 2, térreo.

Telefone: (44) 225-3555 ou (44) 9972-4683

Maringá - PR.

Comitê Permanente de Ética em Pesquisa Envolvendo Seres Humanos (COPEP):

Universidade Estadual de Maringá

Av. Colombo, 5790, Bloco 10, sala 01

CEP: 87020-900 , Maringá - PR 
Fones (44) 261-4444 Fax (44) 263-5116

\section{VI - CONSENTIMENTO PÓS-ESCLARECIDO}

$\mathrm{Eu}$, declaro que, após convenientemente esclarecido pelo pesquisador e ter entendido o que me foi explicado, consinto em participar do presente protocolo de pesquisa.

Maringá, de de

Assinatura do sujeito da pesquisa ou responsável legal

$\mathrm{Eu}$, Marcos Borges Machado, declaro que forneci todas as informações referentes ao protocolo de pesquisa ao paciente.

Assinatura do pesquisa 